- NUREG/CR-1688

BNL-NUREG-51205

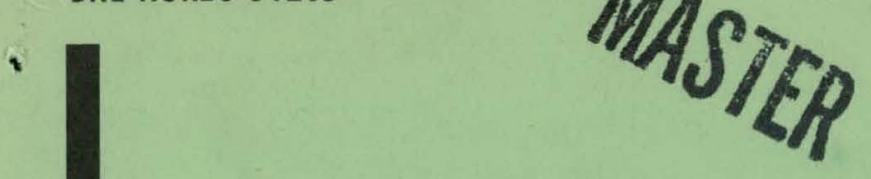

\title{
A COMPARISON OF REGIONAL SCREENING METHODS
}

\author{
BENJAMIN F. HOBBS \\ Michael D. ROWE
}

\section{DO NOT MICROFILM COVER}

\author{
September 1979
}

\section{DIVISION OF REGIONAL STUDIES NATIONAL CENTER FOR ANALYSIS OF ENERGY SYSTEMS BROOKHAVEN NATIONAL LABORATORY UPTON, NEW YORK 11973}
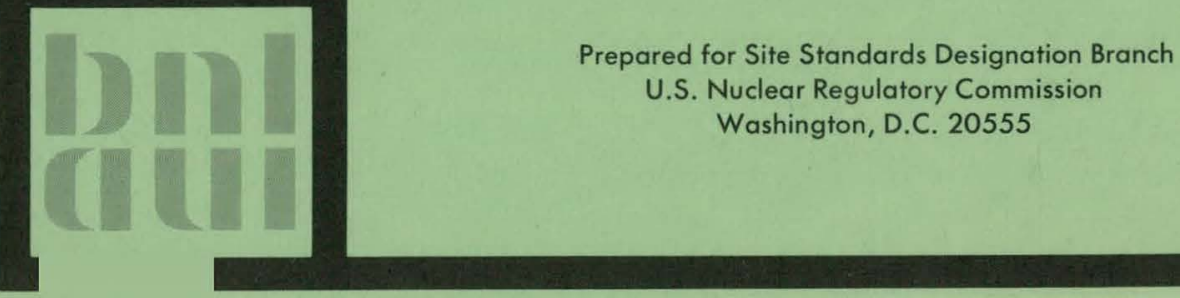


\section{DISCLAIMER}

This report was prepared as an account of work sponsored by an agency of the United States Government. Neither the United States Government nor any agency Thereof, nor any of their employees, makes any warranty, express or implied, or assumes any legal liability or responsibility for the accuracy, completeness, or usefulness of any information, apparatus, product, or process disclosed, or represents that its use would not infringe privately owned rights. Reference herein to any specific commercial product, process, or service by trade name, trademark, manufacturer, or otherwise does not necessarily constitute or imply its endorsement, recommendation, or favoring by the United States Government or any agency thereof. The views and opinions of authors expressed herein do not necessarily state or reflect those of the United States Government or any agency thereof. 


\section{DISCLAIMER}

Portions of this document may be illegible in electronic image products. Images are produced from the best available original document. 


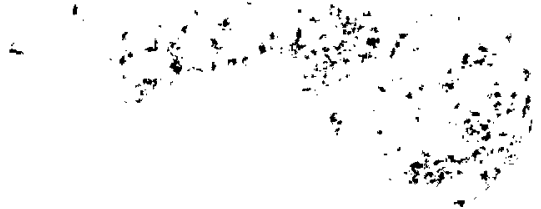 \\ A COMPARISON OF REGIONAL SCREENING METHODS
}

\author{
BENJAMIN F. HOBBS \\ Michael D. ROWE
}

DISCLAIMER

\begin{abstract}
This report was prepared as an account of work sponsored by an agency of the United States Government.- Neither the United States Government nor any agency thereof, nor any of their employees, makes any warranty, express or implied, or assumes any legal liability or responsibility for the accuracy, completeness, or usefulness of any information, apparatus, product, or process disclosed, or represents that its use would not infringe privately owned rights. Reference herein to any specific commercial product, process, or service by trade name, trademark, manufacturer, or otherwise does not necessarily constitute or imply its endorsement, recommendation, or favoring by the United States Government or any agency thereof. The views and opinions of authors expressed herein do not necessarily state or reflect those of the United States Government or any agency thereof.
\end{abstract}

September 1979

\author{
DIVISION OF REGIONAL STUDIES \\ NATIONAL CENTEER FOR ANALYSIS OF ENERGY SYSTEMS \\ BROOKHAVEN NATIONAL LABORATORY \\ UPTON, NEW YORK 11973
}

Prepared for

SITE STANDARDS DESIGNATION BRANCH

U.S. NUCLEAR REGULATORY COMMISSION

WASHINGTON, D.C. 20555

CONTRACT DE=AC02-76CH0O016

NRC FIN N0. A-3076

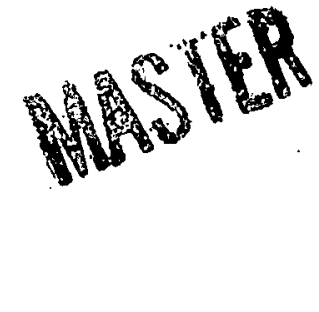




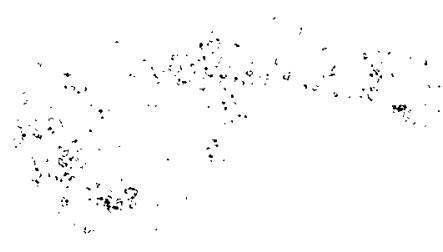

、

\section{NOTICE}

This report was prepared as an account of work sponsored by an agency of the United States Government. Neither the United States Government nor any agency thereof, or any of their employees, makes any warranty, expressed or implied, or assumes any legal liability or responsibility for any third party's use, or the results of such use, of any information, apparatus, product or process disclosed in this report, or represents that its use by such third party would not infringe privately owned rights.

The views expressed in this report are not necessarily those of the U.S. Nuclear Regulatory Commission.

\section{Available from}

GPO Sales Program

Division of Technical Information and Document Control

U.S. Nuclear Regulatory Commission

Washington, D.C. 20555

$$
\text { and }
$$

National Technical Information Service

Springfield, Virginia 22161 


\section{THIS PAGE}

\section{WAS INTENTIONALLY \\ LEFT BLANK}


Many persons assisted in the analyses contained herein and, without their help, this report would not have been possible. The Maryland Power Plant Siting Program sponsored the research in Chapter 2. Dr. Paul Massicot and Howard Mueller of that agency provided a great deal of guidance and many weights. Susan Alderman and Dale Johnson of the Maryland Department of State Planning performed the computer analyses of Chapters 2 and 3 . John Antenucci, now with the Kentucky Department of State Planning, also assisted. Dr. Hugh Canham, the primary author's advisor at the State University of New York, Syracuse, advised and directed the research in Chapter 2. John H. Robinson and Dennis B. Smith of Dames and Moore, Los Angeles, did the computer analyses in Chapter 4. Eighteen persons, named in the text, contributed weights and other value judgments that were used in this report's screening models. They sustained their good cheer through many tedious exercises. Finally, we are indebted to $B$. Burke for her excellent typing.

None of the above, however, are in any way responsible for any inaccuracies and shortcomings, which, as usual, rest exclusively with the authors. 
This report is one of a series on quantitative methods for nuclear power plant siting prepared by the BNL Division of Regional Studies for the Site Standards Designation Branch of the U.S. Nuclear Regulatory Commission. The other reports in this series are:

- Hobbs, Benjamin F., Analytical Multiobjective Decision Methods for Power Plant Siting: A Review of Theory and Applications, BNL-NUREG-51204, Division of RegionaT, Studies, Brookhaven National Laboratory, Upton, N.Y., September 1979.

- Pierce, Barbara L., and Michael D. Rowe, Quantitative Nuclear Power Plant Siting Methods: A Review of Current Practice, BNL-NUREG-28115, Division of Regional Studies, Brookhaven National Laboratory, Upton, N.Y., February 1979.

- Rowe, Michael D., and Barbara L. Pierce, A Comparison of Site Evaluation Methods, BNL-NUREG-51203, Division of Regional Studies, Brookhaven National Laboratory, Upton, N.Y., September 1979.

- Rowe, Michael D., Benjamin F. Hobbs, Barbara L. Pierce, and Peter M. Meier, An Assessment of Nuclear Power Plant Siting Methods, BNL-NUREG-51206, Division of Regional Studies, Brookhaven National Laboratory, Upton, N.Y., November 1979. 
Ack nowl edgments. .................................

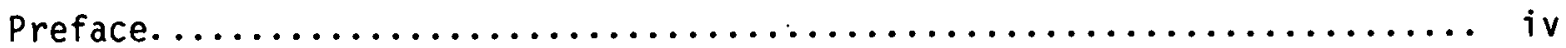

Abstract. ..........................................

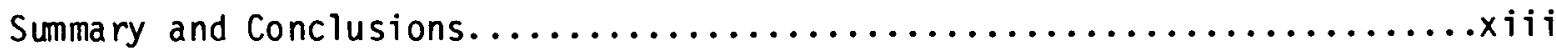

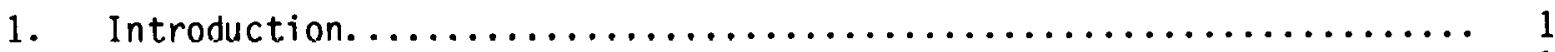

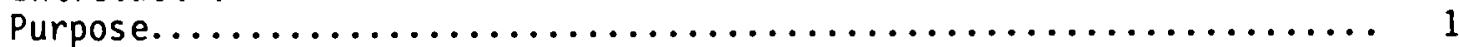

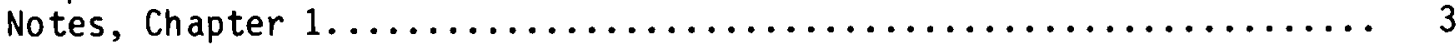

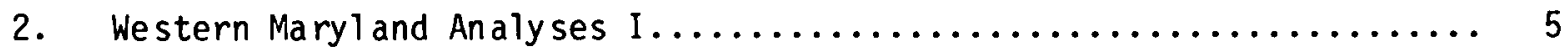

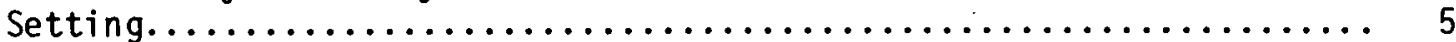

The Study Area...................................... 5

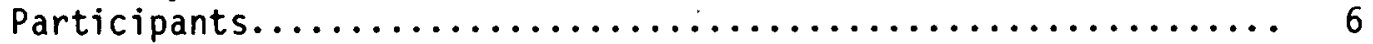

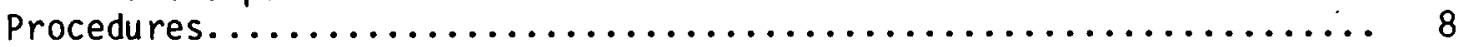

Creation of Attribute Value Functions................. 8

Weighting Procedures........................... 9

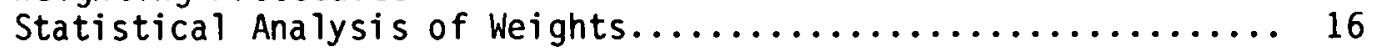

Comparison of Variation of Rating and Indifference Tradeoff

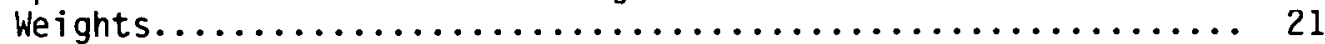

Comparison of Indifference Tradeoff and Decision Analysis

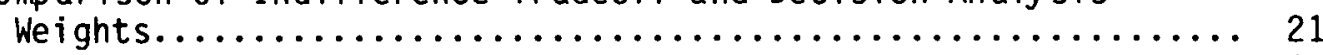

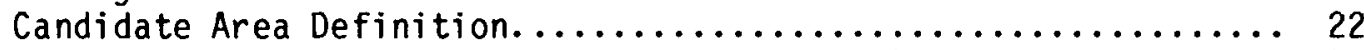

Results

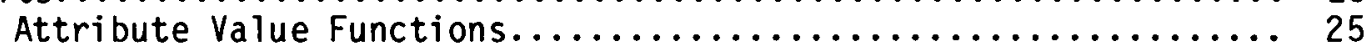

Exclusionary Screening Criteria....................... 31

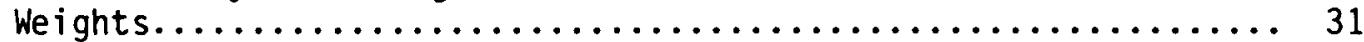

Summary of Participant Comments..................... 31

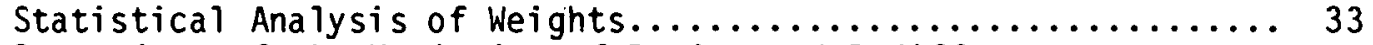

Comparison of the Variation of Rating and Indifference

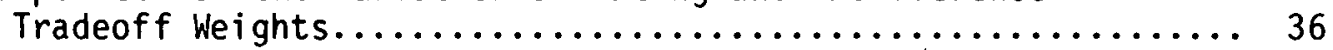

Comparison of Indifference Tradeoff and Decision Analysis

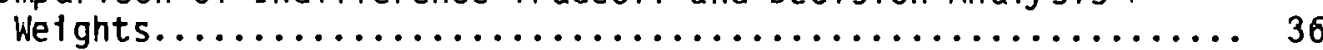

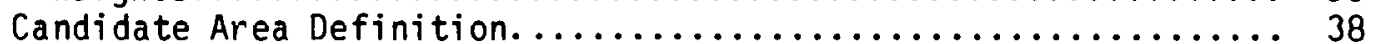

Analysis of Cell Suitability Scores and Candidate Areas....... 38

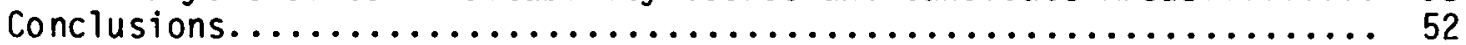

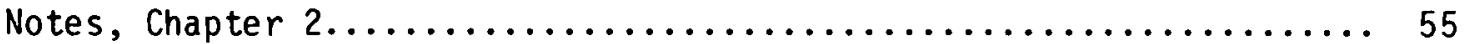

3. Western Maryland Analysis I I........................ 57

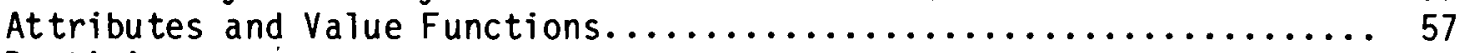

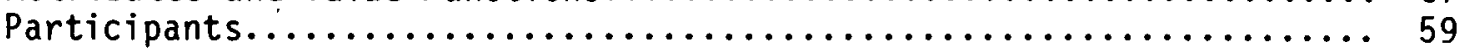

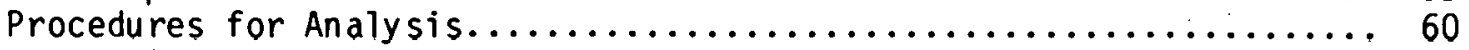

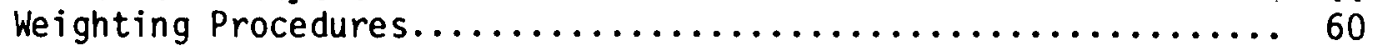

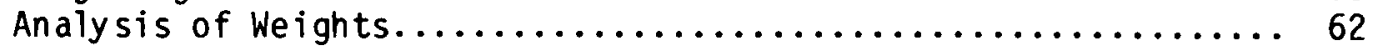

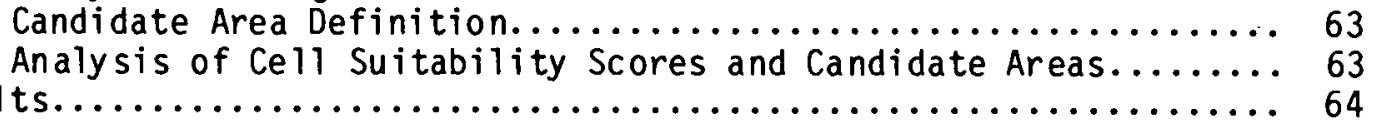

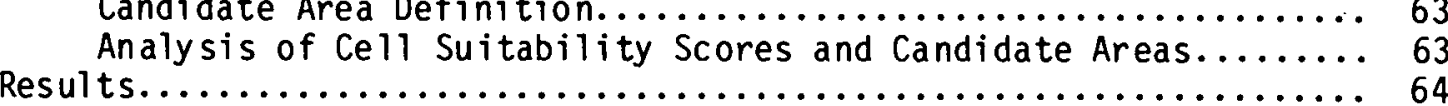

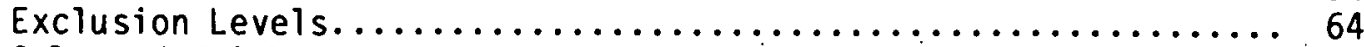

Selected Weights..................................... 64 
Analysis of weights.................................. 67

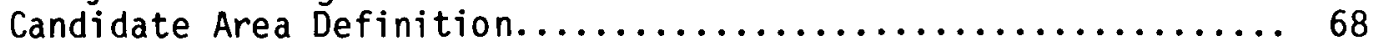

Analysis of Cell Suitability Scores and Candidate Areas........ 73

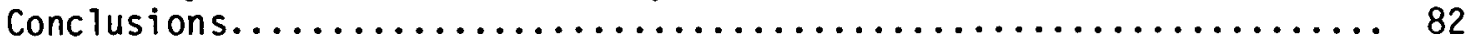

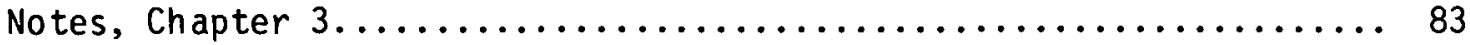

4. Western United States Analysis........................ 85

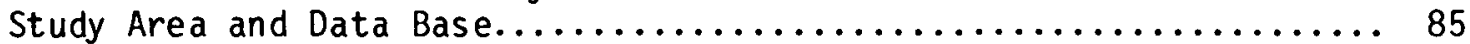

Attributes and Value Functions....................... 85

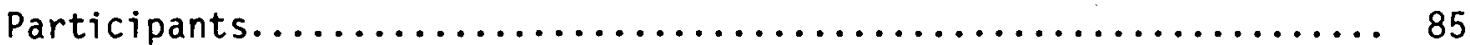

Procedures for Analysis.............................. 85

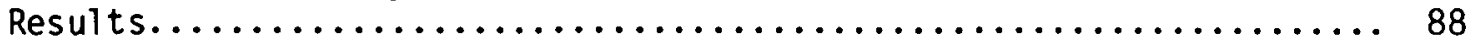

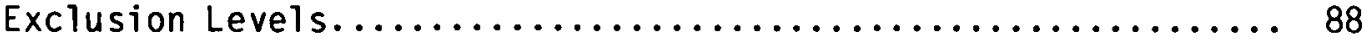

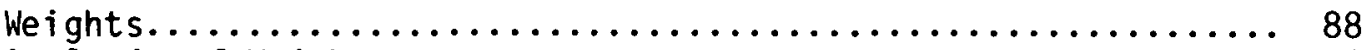

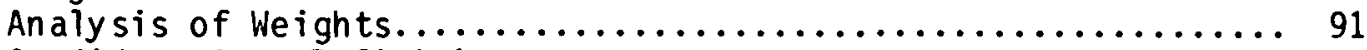

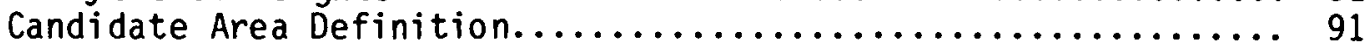

Analysis of Cell Suitability Scores and Candidate Areas......... 103

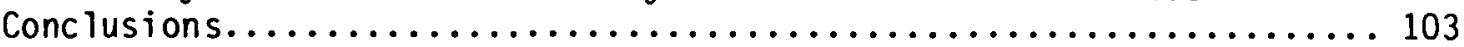

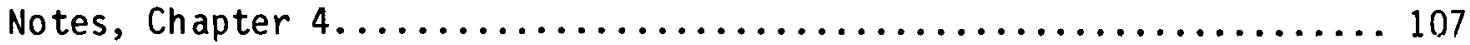

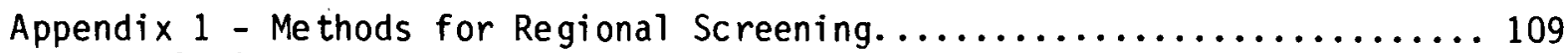

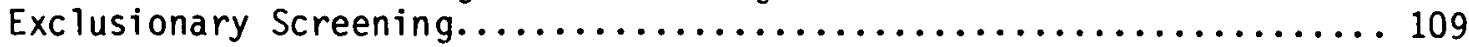

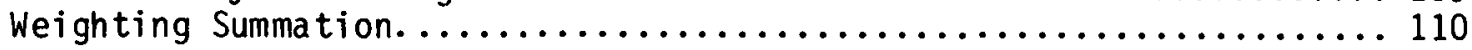

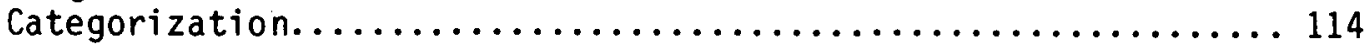

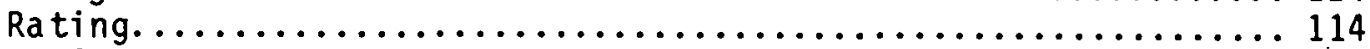

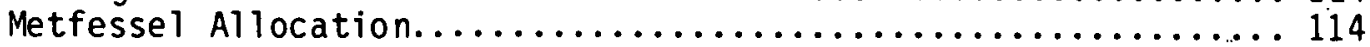

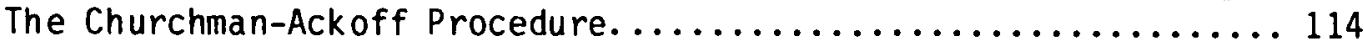

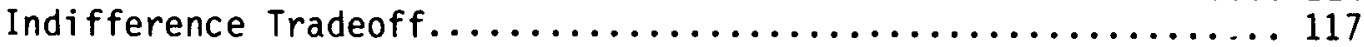

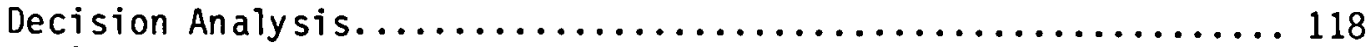

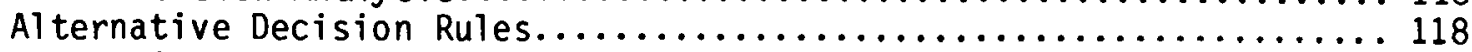

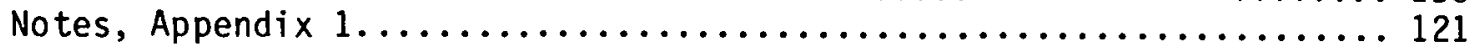




\section{LIST OF TABLES}

TABLE NO.

PAGE NO.

1

2

3

4

6

7

8

9

10

11

12

14

15

16

17

MAGI Variables Included in Weighting Summation, Power Law, and Decision Analysis Screenings, Maryland Screening I

Attribute Value Functions, Maryland Screening I

Exclusionary Categories, Maryland Screening I

Rating, Indifference Tradeoff, and Churchman-Ack off Weights, Maryland Screening I

Decision Analysis Weights, Maryland Screening I

Between-Persons Correlations of Weights, Maryland Screening I

Be tween-Methods Correlations of Weights, Maryland Screening I

Descriptive Statistics of Groups of Correlations of Weights, Maryl and Screening I

Ratios of Weights for Decision Analysis Attributes, Maryland Screening I

Ratios of Weights for Decision Analysis Attributes, Maryl and Screening I

Between-Persons Correlations of Cell Suitability Scores, Maryland Screening I

Between-Methods Correlations of Cell Suitability Scores, Maryl and Screening I

Descriptive Statistics of Groups of Correlations Between Summation Suitability Scores, Maryland Screening I

Between-Persons Proportions of Overlap of Candidate Areas, Maryl and Screening I

Between-Rating and Indifference Tradeoff Proportions of Overlap of Candidate Areas, Maryland Screening I

Deseriptive Slatistics of Groups of Proportions of Overlap of Candidate Areas, Maryland Screening I

Power Law and Weighting Summations, Correlations and Proportions of Overlap of Candidate Areas, Maryland Screening I 
TABLE NO.

PAGE NO.

58

60

Siting Me thodology Project Advisory Panel

Instructions for Weighting Methods, Maryland Screening II

61

65

Categorization Weights, Maryland Screening II 65

Rating Weights, Maryland Screening II 66

Metfessel Allocation Weights, Maryland Screening II 66

Between-Methods Correlations, Maryland Screening II

69

Correlations Between Rating Weight Sets, Maryland Screening II

69

Number of Cells Passing All Exclusionary Criteria, Maryland Screening II

70

Exclusionary Screening and Weighting Summation

Proportions of Overlap of Candidate Areas, Advisory

Pane 1, Maryland Screening II

Between-Methods Correlations of Suitabiity Scores, Maryland Screening II

Between-Persons Correlations of Metfessel Allocation Suitability Scores, Maryland Screening II

Between-Weighting Methods Proportions of Overlap of Candidate Areas, Maryland Screening II

Between-Persons Proportions of Overlap of Metfessel Allocation Candidate Areas, Advisory Pane 1, Maryland Screening II

Variables and Value Functions, Western U.S.

87

Exclusion Levels, Western U.S. Screening

89

Categorization Weights, Western U.S. Screening

89

Rating Weights, Western U.S. Screening

90

Metfessel Allocation Weights, Western U.S. Screening 


\section{LIST OF TABLES (Continued)}

TABLE NO.

PAGE NO.

Be tween-Me thods Correlations, Western U.S. Screening

Between-Persons Correlations of Rating Weight Sets, Western U.S. Screening

Number of Cells Passing Exclusionary Screening

Criteria, Western U.S. Screening

Exclusionary Screening and Weighting Summation

Proportions of Overlap of Candidate Areas, Western U.S. Sc reening

Between-Weighting Methods Proportions of Overlap of Candidate Areas, Western U.S. Screening 


\section{LIST OF FIGURES}

FIGURE NO.

PAGE NO.

1

2

3

4

5

6

7

8

11

12

13

14

15

16

17
Western Maryland Study Area Showing Counties, Rivers, and Major Cities

Relationships of Pairs of Weight Sets

Exclusionary Screening Candidate Areas, Maryland Screening I

40

Maryland Screening I

Maryl and Screening I

Power Law Candidate Areas, Mr. Mueller, Maryland Screening I

Screening I

r. Canham, Maryland

Top $8 \%$ of Cells Shared by All. Five Rating-Weighting

Summation Candidate Areas, Maryland Screening I

Cells Selected by Power Law and Weighting Summation

Exclusionary Screening Candidate Areas, Advisory

Panel (MH), Maryland Screening II

Exclusionary Screening Candidate Areas, Advisury

Panel (SL), Maryland Screening II

Exclusionary Screening Candidate Areas, Advisory
Panel Group Median Criteria, Maryland Screening II

Cells Passing Exclusionary Criteria of 11 Persons Maryl and Screening II

Categorization Candidate Areas, Advisory Panel (HM), Maryland Screening II

Screening II

Metfessel Allocation Candidate Areas, Advisory Panel (HM), Maryland Screening II

Metfessel Allocation Candidate Areas, Advisory Panel (MH), Maryl and Screening II 
Metfessel Allocation Candidate Areas, Advisory Panel Group Mean, Maryland Screening II

Categorization Candidate Areas, Advisory Panel (JH), Maryland Screening II

Rating Candidate Areas, Advisory Panel (JH), Maryland Screening I I

Metfesse 1 Allocation Candidate Areas, Advisory Panel

(JH), Maryl and Screening II

24 Exclusionary Screening Candidate Areas, Advisory Panel

$(\mathrm{JH})$, Western U.S. Screening

Number of Persons for Which Each Cell Passed All

Exclusionary Criteria, Advisory Pane 1, Western U.S. Screening.

26 Categorization Candidate Areas, Advịsory Panel (KN), Western U.S. Screening

27 Rating Candidate Areas, Advisory Panel (KN), Western U.S. Screening

Metfesse 1 Allocation Candidate Areas, Advisory Panel $\left(\mathrm{RK}^{\prime}\right)$, Western U.S. Screening

Metfessel Allocation Candidate Areas, Advisory Panel $(\mathrm{JH})$, Western U.S. Screening 


\section{ABSTRACT}

This report describes results of tests of different regional screening methods applied to data from western Maryland and the western United States. The purpose of these tests was to determine whether or not different regional screening methods produce different results, and to obtain some understanding of the nature of any differences found. Methods tested include Exclusionary Screening, Weighting Summation, Power Law, and Decision Analysis; weighting methods used include Categorization, Rating, Metfessel Allocation, Indifference Tradeoff, Churchman-Ackoff, and Decision Analysis.

Results show that different methods do, indeed, produce different results, and that choice of decision rule is most important to results. Exclusionary Screening, in particular, can force decision tradeoffs that decision makers would not make were they to evaluate them directly. Nevertheless, differences in regional screening results do not necessarily mean differences in quality of the final site decision. The final result can depend on the skill with which the stages of the siting process following screening are conducted. The function of screening is to ease the task in those following stages by selecting candidate areas having high probability of containing suitable candidate sites. 
INTRODUCTION

Regional screening is a method used to search a region for candidate areas which have high probability of containing suitable power plant sites. Candidate site selection and final site selection follow. This report examines how choice of multiobjective decision rule and weighting method affects results of regional screening in western Maryland and the western United States. Rules and methods are defined in Appendix 1.

WESTERN MARYLAND ANALYSIS I

Five counties in western Maryland comprise the study area for a hypothetical regional screening for sites suitable for a pair of 1000-MW(e) nuclear plants with evaporative cooling towers. The study area includes forested mountains, wide agricultural valleys, a number of small cities, and the upper Potomac River. The data base used is the Maryland Automated Geographic Information Systems (MAGI) which is gridded into 91.2-acre cells. Seventeen cell attributes from MAGI were chosen for the screening, among them land use, soils, water, transportation, and population density. Personnel of the Maryland Power Plant Siting Program defined each attribute's value function. That agency is charged with monitoring environmental impacts of electric utilities and creating a site "bank" for the State of Maryland.

Five persons from the Maryland agency, State University of New York, and Oak Ridge National Laboratory chose weights for the attributes by the Rating and Indifference Tradeoff Methods. The two Maryland participants selected weights in the presence of the researcher. The others used questionnaires. Consistency checks were applied in the Indifference Tradeoff Method. Weighting Summation "suitability scores" were calculated for each of the 18,500 cells in the study area for each of ten resulting weight sets. Candidate areas were then defined for each weight set as four or more contiguous cells, each of which scored in the top $8 \%$. Four cells (about 360 acres) are the minimum size needed for a nuclear plant with evaporative cooling towers.

The resulting welghts vary greatly among the participants, and between the two methods for each person. The sets of Weighting summation candidate areas are strikingly different. Few cells are chosen by all weight sets. Differences between areas chosen by the two methods are, on average, as large as differences between areas chosen by two persons using the same method. The 
mean overlap of participants' Rating and Indifference Tradeoff areas is $52 \%$, while the mean overlap of every possible pair of persons' Rating areas is $62 \%$. The means are not significantly different. Because site specific investigations would subsequently eliminate most candidate areas in an actual study, Rating and Indifference Tradeoff can lead to different site choices. These choices are not necessarily different in quality.

Weighting Summation suitability scores were also analyzed using correlations (Pearson's $r$ ) between pairs of sets of suitability scores. A "betweenmethods" correlation was calculated for each person between his Indifference Tradeoff and Rating suitability score sets. "Between-persons" correlations were calculated between each possible pair ( 5 persons and 10 pairs) of Rating suitability score sets. The mean between-methods correlation (0.774) is not significantly different from the mean between-persons correlation (0.776). This confirms the above conclusion that variability due to choice of weighting method is as important as variability due to choice of person. Use of correlations between weights instead of between suitability score sets leads to the same conclusion; the mean between-methods correlation (0.306) is not significantly different from the mean between-persons correlation (0.176).

Indifference Tradeoff was considered more difficult than Rating. This led three of the five participants to prefer Rating for regional screening studies. At that time, however, they did not know whether or not choice of method makes a difference in candidate areas. Two participants thought the more difficult method to be better because it forces explicit consideration of the tradeoffs implied by weights. They thought that the "magic numbers" one chooses in a Rating exercise may bear little relationship to tradeoffs he is willing to make.

Each set of Rating weights, on average, has less variation among themselves than Indifference Tradeoff weight sets. This is consistent with a hypothesis that logarithmic perception of values distorts Rating weights more than Indifference Tradeoff weights.

The second stage of the Churchman-Ackoff weighting method was also applied by the Maryland participants to their Indifference Tradeoff weights. The modified weights are almost identical to the original Indifference Tradeoff weights.

Each participants applied the Decision Analysis lottery weighting method to four attributes. The resulting Decision Analysis weights and Indifference 
Tradeoff weights are not proportional. This is in contradiction to theory, which says that both methods should choose valid weights. One reason for this discrepancy is the difficulty of dealing with hypothetical probabilities. Indifference Tradeoff weights were used to infer four sets of Decision Analysis weights for each participant, each set being based on one of the Decision Analysis weights. Because of inconsistencies, the implied risk attitudes of the two decision makers varied considerably. Nonetheless, when each set was used in the Decision Analysis multiplicative decision rule, candidate areas were almost identical. Hence, risk attitudes make little difference in candidate area selection in this case. One can therefore use Weighting Summation (with the same value functions and weights) which would choose the same areas.

Candidate areas for each Rating and Indifference Tradeoff weight set were also generated using the Power Law. Those areas differed less among themselves than did corresponding Weighting Summation candidate areas. This is because the Power Law favors cells with moderately good values in all attributes over cells with both very good and very bad levels.

Choice of decision rule between Weighting Summation and Power Law makes more of a difference in candidate areas than does choice of weighting method or choice of person. On the average, less than half the cells picked by one decision rule are chosen by the other. Therefore, users of either method should check to see which method's assumptions are more appropriate.

One of the Maryland participants also chose cutoff criteria for Exclusionary screening. The criteria closely resemble those used in an actual screening of eastern Maryland. About $9 \%$ of the study area passed all screens. Differences between Exclusionary Screening and Weighting Summation areas are striking. Only a third of the cells passing all screens also score in the top 9\% of that person's Rating or Indifference Tradeoff Weighting Summation cells. Hence, the exclusionary criteria imply tradeoffs that the decision maker in this case would not approve were they presented to him directly. WESTERN MARYLAND ANALYSES II

The same study area and many of the same attributes used in the first Maryland study were also used in a second study. Again, candidate areas were sought for a pair of nuclear plants. A panel of fourteen siting experts from academia, consulting firms, government agencies, utilities, and a public interest group helped choose the attributes to be weighted. Attribute value 
functions, where possible, were based on those used in the analyses described in the previous section. A key difference between this study and the preceding one is that only nine instead of seventeen attributes were selected. The three population attributes in this study compounded the difference, lowering the effective number of attributes to seven.

Each of the fourteen panel members chose exclusion criteria for the seven attributes. They also applied three weighting methods: Categorization, Rating, and Metfessel Allocation. None of the three assesses the correct type of attribute importance, and only Metfessel Allocation assures a ratio level of measurement. Because the methods ask directly for weights (encouraging panel members to try to remember them and be consistent among methods) and because the techniques were applied on the same afternoon, each person's three weight sets are more similar than they would be if the assessments were truly independent. This carryover effect biases results, making choice of method appear to be less important than it really is.

Between-methods correlations of weights are high; few are less than 0.8 , much higher than those found in the first Maryland study, above. If one of the methods had assured theoretically valid weights, correlations might have been lower. Between-methods correlations are significantly higher than between-persons correlations (correlations between pairs of Rating weights), the mean of which was 0.4 .

These conclusions regarding importance of choice of weighting method versus choice of person are confirmed by analysis of Weighting Summation suitability scores and candidate areas. Between-methods correlations of suitability scores are much higher than correlations between Metfessel Allocation suitability scores for different persons. Candidate areas from different weighting methods generally overlap almost completely, although important differences exist for some participants. This is in contrast to the analyses summarized in the previous section, where Rating chose candidate areas strikingly different from Indifference Tradeoff. In general, little practical difference exists between the Categorization, Rating, and Metfessel Allocation weighting methods for the conditions of this study.

Almost everyone's Categorization weights did, however, vary much less among themselves than did Rating or Metfessel Allocation weights. Categorization tends to compress ratios among weights. 
Almost everyone's Exclusionary Screening areas contain the same $6 \%$ of the cells as acceptable. Between-persons differences in Exclusionary Screening are insignificant.

Exclusionary Screening and Weighting Summation (with any of the three weighting methods) picked the same areas for only two participants. Group median exclusionary criteria and group mean weights select areas which, on the average, overlap less than 50\%. In that case, however, Categorization disagrees less with Exclusionary Screening than do the other two weighting methods. As in the first Maryland study, Exclusionary Screening makes tradeoffs among attributes of which the group would not approve if presented with them directly. It appears that Weighting Summation and Exclusionary Screening may be more likely to choose similar areas if there are few attributes than if there are many.

WESTERN UNITED STATES ANALYSES

This hypothetical study sought candidate areas in the western continental U.S. for two nuclear power plants with a mix of dry and wet cooling towers, optimized for each of 11924 10-mile square cells in the study area. Seven siting attributes and value functions were adapted from a previous Nuclear Energy Center study of the region. The 14-member Advisory Panel who chose weights and exclusionary criteria in the second Maryland study did the same for this one, choosing exclusionary criteria and weights using Categorization, Rating, and Metfessel Allocation all on the same day. As in the second Maryland study, the results of the three methods are more similar than would be the case if the application of each method could have been truly independent. This makes choice of method appear less important than it would be if applications were indejuendent.

Correlations were calculated between each person and each method. As in the second Maryland study, these between-methods correlations are high; only two persons had correlations less than 0.8. Between-persons correlations are generally higher than the between-persons correlations from the second Mary1 and study. The small number of attributes (7 as opposed to 9 ) might account for that. Nevertheless, hetween-persons correlations are significantly less than between-methods correlations of weights. Therefore, choice of person in this case affects weights more than choice of weighting method (from among Categorization, Rating, and Metfessel Allocation). This agrees with conclusions of the second Maryland study. 
Analysis of overlaps of different sets of Weighting Summation candidate areas confirms this conclusion. Nevertheless, on the average, candidate areas. from different individual's Metfessel Allocation weights differ more than do Categorization and Rating areas.

As in the second Maryland study, Categorization weights vary less among themselves than do either Rating or Metfessel Allocation weights. This again supports the hypothesis that Categorization compresses ratios of importance.

Exclusionary Screening areas of six persons are compared with corresponding weighting summation areas (for all three weighting methods). For three of the six persons, the disagreement in decision rules is greater than the agreement. Candidate areas from the different methods overlap more than 50\% for the other three persons and for the group as a whole (represented by mean weights and exclusionary criteria). Nevertheless, the differences are still larger than most of the between - weightings method and between-persons differences discussed above.

CONCLUSIONS

Choice of method clearly can influence results of screening exercises and, among methods, choice of decision rule is most important. Decision makers choosing between Exclusionary Screening and other decision rules must, therefore, give careful consideration to the nature of their screening problem. Exclusion screening is useful for selecting candidate areas which meet mandatory legal and engineering requirements. It tends to perform poorly if discretionary criteria are added because it does not allow for marginally unacceptable conditions of one kind to be overridden by unusually good conditions of another kind. As a result, Exclusionary Screening using discretionary criteria forces tradeoffs which decision makers might not consider acceptable were they presented with them directly. If a screening problem requires tradeoffs among discretionary criteria, then some form of Weighting Summation decision rule should be applied.

Among different methods for generating weights for a Weighting Summation screening, importance of method depends on the nature of the problem. Weighting Summation using a small number of attributes appears to be more sensitive to persons generating weights than to weight generation method. For a larger number of attributes, weighting method may be more important. Theoretically invalid methods that ask similar questions (Categorization, Rating, Metfessel) choose similar weights and candidate areas. Theoretically valid methods (In- 
difference Tradeoff, Churchman-Ack off, and Decision Analysis) can choose areas

- that differ strikingly from those selected by simpler invalid methods.

The results reported herein compare candidate areas selected by different methods. No evaluation is made of the quality of the sites that might be found in these areas. It is not necessarily the case that different candidate areas will yield different qualities of candidate sites. To a certain extent, quality of candidate sites depends on the skill and experience of the persons involved in the candidate site selection stage which follows screening, but more important, the probability that "good" candidate areas can yield "good" candidate sites is a function of correlations among variables used in screening, candidate site selection, and final site selection. The greater the correlations among these variables in the region, the more likely that a screening and candidate site selection process will be successful in identifying sites that are among the "best" available with respect to the variables and values used. Also, the greater the correlations among variables, the more important is the success of each stage in providing areas to the next stage which have high probability of yielding "good" sites and, therefore, the more important are the methods to that success. 
PURPOSE

This report investigates the influence of choice of multiobjective decision procedure on results of regional screening for power plant sites. In general, power plant site selection is conducted in three stages : $^{\circ}$

1. Regional screening for candidate areas,

2. Selection of candidate sites from candidate areas,

3. Final site selection.

This report focuses on the first of these stages.

Siting is a multiobjective problem; one tries simultaneously to minimize cost and community disruption, prevent environmental damage, and maximize system reliability and engineering feasibility. New regulations and increasing public concern, together with increasing size of facilities, complicate siting even more. Regional screening often involves searching large regions, using computerized data banks, under the watchful eye of state and federal agencies and perhaps citizen task forces. Screening must be more explicit and systematic than ever before. Thus, we see greater use of analytical multiobjective decision methods. Only with rigorous methods can bases for decisions be thoroughly documented and reviewed.

A wide range of multiobjective decision rules has been applied or proposed for use in siting. 2 They are compared and critiqued in a companion volume to this report. 3 The ones applied in this report are summarized in Appendix 1. Only two of them have been used in regional screening: Exclusionary screening and Weighting Summation. The former eliminates areas unsatisfactory in one or more attributes. The latter chooses areas that maximize:

$$
\text { Suitability }=\sum_{i=1}^{n} w_{j} v_{j}\left(x_{i}\right)
$$

where:

$$
\begin{aligned}
v_{i}()= & \text { Value or suitability function for physical attribute } x_{i} ; \\
& \text { and } \\
W_{i} & =\text { Weight or importance of } x_{i} .
\end{aligned}
$$


The assumptions about decision makers' values underlying these two decision rules differ sharply. Exclusionary Screening, for instance, does not allow good values of some attributes to compensate for bad values in others; Weighting Summation does. This does not necessarily mean that the two methods pick different candidate areas. If the areas chosen usually differ, then decision makers must give more attention to which method they select than if the method has no effect. Previous to this research, only Sandia Laboratories had investigated whether choice of decision rule makes a difference in regional screening 4 ; for their data, Exclusionary Screening and Weighting Summation do indeed produce different candidate areas.

Furthermore, the assumptions underlying Weighting Summation are stringent. Two of them are that weights are on a ratio level of measurement and that they represent the relative values of unit changes in their attribute value functions. 5 The latter implies values of specific tradeoffs decision makers are willing to make among attribute levels. Some methods for choosing weights are specifically designed to assess weights having the correct characteristics, and others are not. Most siting studies use invalid methods. Since the resulting weights probably do not reflect tradeoffs that decision makers are willing to make, the resulting candidate areas may differ from those chosen by valid weights. There is little empirical evidence, however, as to what difference choice of weighting method makes. 6

Decision rules other than Exclusionary Screening and Weighting Summation can be used in regional screening. Again, however, there is little research that shows whether different decision rules choose different candidate areas. SCOPE

This report presents three studies of two different geographical areas, western Maryland and the western United States. In each study a panel of decision makers was given a hypothetical screening problem based on data from one of the two areas. These exercises were repeated several times using different decision rules and weight estimation methods. Results from different weighting methods and decision rules were then compared for similarities and differences among individuals and methods. The three studies are reported separately in following chapters and conclusions appropriate to all of the studies are collected in the report summary.

Brief descriptions of the weight estimation and screening methods used are presented in Appendix 1. More detailed descriptions are given in a companion volume to this report. 7 


\section{NOTES}

\section{CHAPTER 1}

1. J. Calvert, W. Heilman, and H. Smith, Nuclear Power Plant Siting: A Generalized Process, Commonwealth Associates, Jackson, Michigan, prepared for Atomic Industrial Forum, New York, 1974.

2a. G. B. Baecher, J. Gros, and K. McCusker, Balancing Apples and Oranges: Methodologies for Facility Siting Decisions, RR-75-33, International Institute for Applied Systems Analysis, Schloss Laxenburg, Austria, 1975.

b. J. Calvert, W. Heilman, and H. Smith, op. cit.

c. E. Graf-Webster et al., Resource and Land Investigations Program: Methodologies for Environmental Assessment, Vol. III, Power Plant Siting, MTR-6740, MITRE Corporations, McLean Virginia, prepared for U.S. Geological Survey, 1974.

d. B. F. Hobbs, Analytical Multiobjective Decision Methods for Power Plant Siting: A Review of Theory and Applications, BNL-NUREG 51204, Brookhaven National Laboratory, Division of Regional.Studies, 1979.

e. B. F. Hobbs and A. H. Voelker, Analytical Multiobjective Decision-Siting: A Survey and Critique, ORNL-5288, Feb. 1978.

f. D. R. MacFarlane, B. M. Hoglund, P. A. Roberts, and J. J. Yates, Power Facility Siting in the State of Illinois Part II - Enviromental Impacts of Large Energy Conversion Facilities, IIEQ Doc. No. 15-03, Environmenta Technology Assessment, Oakbrook Illinois, prepared for State of Illinois, Institute for Environmental Quality, 1975.

g. U.S. Nuclear Regulatory Commission, Nuclear Energy Center Site Survey1975, Part V: Resource Availability and Site Screening, NECSS-75,NUREG0001, Washington, D.C., Jan. 1976.

3. B. F. Hobbs, ibid.

4. B. F. Hobbs, ibid. Hobbs exhaustively surveys studies comparing results of different methods. The Sandia research is presented in $R$. L. Keeney, C. W. Kirkwood, C. Ford, J. H. Robinson, and P. Gottlieb, An Evaluation and Comparison of Nuclear Power Plant Siting Methodologies, NUREG/CR0407, SAND 78-1284, Sandia Laboratories, prepared for U.S. Nuclear Regulatory Commission, March 1979.

5. B. F. Hobbs, ibid.; B. F. Hobbs and A. H. Voelker, op. cit.; and G. W. Fischer, Convergent validation of decomposed multi-attribute utility assessment procedures for risky and riskless decisions, Organizational Behavior and Human Performance 18, 295-315 (1977).

6. See Note 4 .

7. B. F. Hobbs, op. cit. 
THIS PAGE

\section{WAS INTENTIONALLY LEFT BLANK}




\section{Chapter 2}

\section{WESTERN MARYLAND ANALYSES I}

This chapter describes work undertaken during 1977-1978, most of which is described in greater detail elsewhere.1 Five persons familiar with siting chose weights by up to four different methods apiece. Candidate areas for a pair of 1000-MW(e) nuclear plants with evaporative cooling towers were generated using Weighting Summation, the Power Law, and the Decision Analysis Multiplicative form: One person also defined criteria for Exclusionary Screening.

\section{SETTING}

\section{The Study Area}

The five counties of the western Maryland study area are shown in Figure 1. The east-west length of the region is 144 miles, and its width varies from 2 to 35 miles. The area contains a variety of physical, natural, and cultural environments. Garrett and Allegany Counties contain steep topography characteristic of the Appalachian Mountains; forests cover most of these counties. In contrast, the predominant land use in Frederick and Carroll Counties is agriculture. Many areas of historical importance are located in the eastern counties, and parks are scattered throughout the study area. Hagerstown, Cumberland, and Frederick are the major cities.

The Maryland Automated Geographic Information System (MAGI) is a computerized data base, which covers the entire state on a grid scale of 2000 by 2000 feet per cell (91.2 acres).3 The study area contains 18533 cells. Approximately 50 variables were encoded by the Maryland Department of State Planning. Complete documentation of the sources and encoding methods for the variables is available. 4 Oak Ridge National Laboratory (ORNL) added 21 more siting variables to the data base for Maryland's eight northern counties. 5

Attributes used in the regional screening of this chapter are presented in Table 1. Reasons for omitting other attributes are given elsewhere ${ }^{6}$; many are irrelevant to siting, while others suffered from serious errors or inadequacies.

Some of the attributes are "raw" data, as they contain information that has undergone relatively little interpretation or manipulation (e.g., slope). Others result from substantial reworking of information (e.g., Site Population Factors). A large number of proximity attributes were also computed by ORNL. Each consists of the distance to the nearest cell in Maryland that contains 


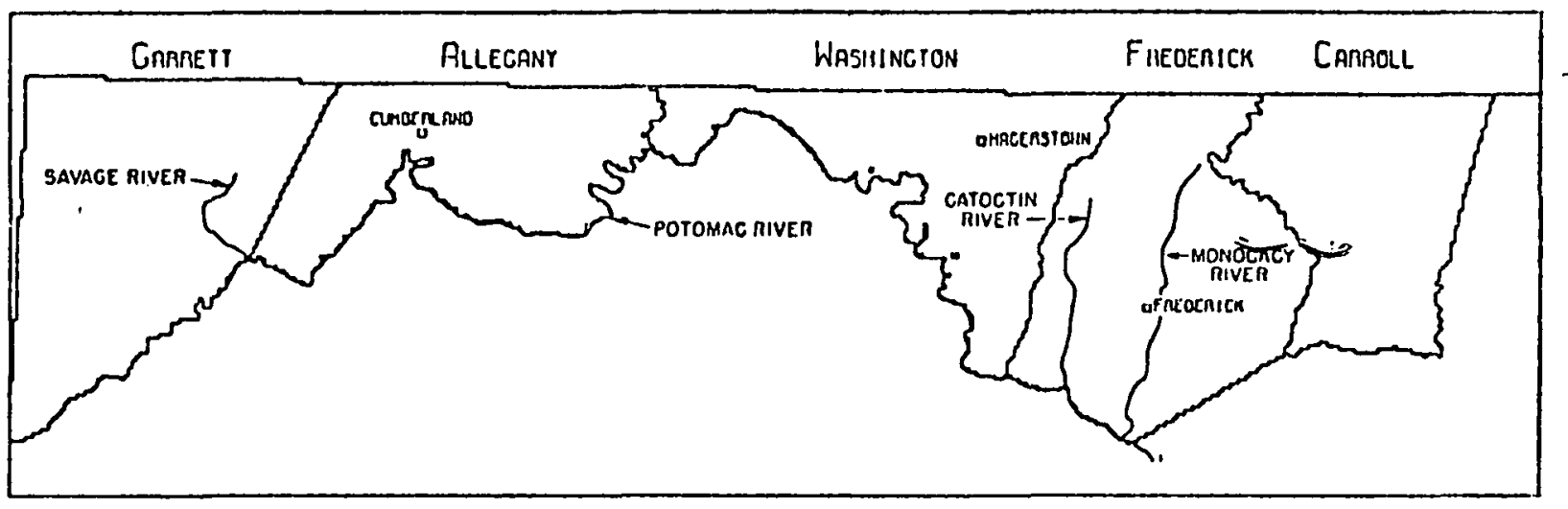

Source: Dobson, Note 2 .

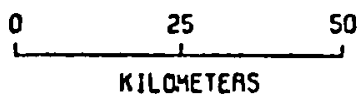

Figure 1. Western Maryland Study Area Showing Counties, Rivers, and Major Cities.

a phenomenon of interest. An example is Proximity to Stream Flow.

The designations "primary" and "secondary" refer to whether the attribute in question is the largest or second largest of that kind of phenomenon in a given cell. Soil Group (Secondary), for instance, gives the soil type that covers the second greatest area within each cell.

Each cell is assigned one value or category for each attribute. A complete listing of the categories within the variables included in the case study that occur in the study area is given in Table 2 in a following section.

MAGI by itself does not contain sufficient information for a regional siting study. Other important considerations, including flooding potential, air quality, and the possibility of severe socio-economic impacts are not part of the data base. For this reason alone, the candidate areas presented in Chapters 2 and 3 are hypothetical; they may bear little resemblence to areas that would be most suitable in a more thorough siting study. Furthermore, no agency or utility is currently considering these areas for sites.

\section{Participants}

At least two weighting methods were applied by each of five persons (in alphabetical order):

1. Dr. Hugh Canham, Resource Economist, Associate Professor, State University of New York, Syracuse, NY; 
Table 1

MAGI VARIABLES INCLUDED IN WEIGHTING SUMMATION, POWER LAW, AND DECISION ANALYSIS SCREENINGS, MARYLAND SCREENING I

\begin{tabular}{|c|c|c|}
\hline $\begin{array}{c}\text { MAGIa } \\
\text { Variable \# }\end{array}$ & Variable Name & Source \\
\hline 4 & Surface Water Quality/Fish and Shellfish & $\begin{array}{l}\text { Maryland Department } \\
\text { of State Planning (DSP) }\end{array}$ \\
\hline 7 & Tranportation and Transmission (Primary) & DSP \\
\hline 8 & Transportation and Transmission (Secondary) & DSP \\
\hline 9 & State and Federal Lands (Primary) & DSP \\
\hline 10 & State and Federal Lands (Secondary) & DSP \\
\hline 11 & Mineral Resources & DSP \\
\hline 14 & Soil Group (Primary) & DSP \\
\hline 17 & Natural Features (Primary) & DSP \\
\hline 18 & Natural Features (Secondary) & DSP \\
\hline 19 & Land Surface Slope (Primary) & DSP \\
\hline 23 & Historic Sites (First) & DSP \\
\hline 26 & Land Use and Land Cover (Primary) & DSP \\
\hline 35 & 30 Mile Site Population Factor & Oak Ridge National \\
\hline 36 & Endangered Species & ORNL \\
\hline 37 & Excavation Requirements & ORNL \\
\hline 38 & Overburden Thickness & ORNL \\
\hline 39 & Aquifer Recharge Zones & ORNL \\
\hline 40 & 5 Mile Site Population Factor & ORNL \\
\hline 42 & Population Density & ORNL \\
\hline 43 & Proximity to Highways & ORNL \\
\hline 45 & Proximity to Stream Flow & ORNL \\
\hline \\
\hline
\end{tabular}

2. Dr. John Felleman, Civil Engineer, Associate Professor, State University of New York, Syracuse, NY, and Land Use Consultant;

3. Dr. Paul Massicot, Physicist, Head, Maryland Power Plant Siting Program, Annapol is, MD;

4. Mr. Howard Mueller, Economist, Site Acquisition, Maryland Power Plant Siting Program; and

5. Mr. Al Voelker, Electrical Engineer, Researcher, Regional and Urban Studies, ORNL.

Each individual had worked with or was familiar with the Weighting Summation model. Some, however, were more aware than others of the assumptions and relative advantages of different weighting methods.

No claim can be made that these five individuals are a statistically valid or even representative sample of the people involved or interested in 
power plant siting decisions. No representatives of environmental or consumer groups, utilities, regulatory agencies, or legislative bodies were included. Nevertheless, results from this group provide a rough indication of the differences in weight sets and cell evaluations attributable to persons who select the weights. Readers should not lose sight of the significance of the small and probably biased sample.

PROCEDURES

Creation of Attribute Value Functions

Before weights can be assigned, an interval-scaled value function must be created for each attribute (see Appendix 1). It is this value estimate that is weighted and summed and/or multiplied with other weighted value functions to obtain a suitability score for each cell. Attribute scaling should ideally be done by all persons choosing weights. Time limits made this impossible, therefore, Dr. Massicot and Mr. Mueller jointly created a function for each selected MAGI variable as follows:

1. First, those categories that were to be "exclusionary" in Weighting Summation, Power Law, and Decision Analysis Screening were chosen. Cells with any of those categories were considered unsuitable and were dropped from the analysis before application of decision rules.

2. From the remaining categories, the most and least suitable were selected. The former category was assigned a rating of "10," and the latter "0."

3. Other categories were then given ratings between 0 and $10, a c-$ cording to their relative suitability. If the physically measured variable was approximately continuous (such as Population Density), ratings were sketched on a graph as a function of that variable.

4. To ensure that the resulting value function was on an interval level of measurement, special checking questions were asked. These took several forms, including:

a. Is the difference in value between categories $A$ and $B$ actually $X$ times as much as that between $B$ and $C$ ?

b. Is category $B$ actually halfway (or three quarters of the way, or whatever was the case) between $A$ and $C$ in value? 
This process resulted in a number of value functions, each usually corresponding to one attribute, on an interval scale of 0 to 10.

Mr. Mueller also chose more stringent criteria for an Exclusionary Screening. These criteria were to resemble as closely as possible those used to define nuclear candidate areas in a regional screening of the eastern shore of the Chesapeake Bay performed for the Maryland Power Plant Siting Program. 7 Many of these criteria are only "potential restrictions," meaning that plants could be sited there, but it is desirable to avoid such areas as one way of minimizing adverse affects. This is in contrast to the exclusionary criteria used in Weighting Summation, Power Law, and Decision Analysis screening of this chapter for which a cell is dropped only if its characteristics make licensing of a nuclear plant impossible.

Weighting Procedures

Four weight selection techniques were used in this study. They were applied in the following order:

1. Rating $(R)$.

2. The Indifference Tradeoff Method (IT).

3. The Churchman-Ack off Method (CA).

4. Decision Analysis (DA).

(Refer to Appendix 1 for overviews of these techniques, and of their theoretical validity and siting applications.)

Each person who selected weights received the following background materials prior to the weighting exercises:

1. Detailed documentation of the source, categories, value function, and, where possible, geographical distribution of each attribute.

2. A list of attributes to be weighted, along with a list of the lowest and highest rated categories within each attribute.

3. A list of the ratings of each category (the value function) within each attribute.

4. Background information on the study area, the MAGI system, the Weighting Summation Method, and how candidate areas would be defined.

The Rating (R) and Indifference Tradeoff (IT) methods were used by all five participants. Two participants, Dr. Massicot and Mr. Mueller, applied them in the presence of the researcher, while the other three individuals used a mailed questionnaire. As the complexity of the Churchman-Ackoff (CA) and 
Decision Analysis (DA) techniques precluded application via questionnaire, only the Power Plant Siting Program personnel used them.

Three variables presented a special problem. Population Density 5 Mile Site Population Factor (SPF) and 30 Mile SPF are all indicators of the number of persons in the vicinity of each cell. Were each of their weights assigned separately, their sum might be much greater than the weight that would be given the single concept "Population." This violates an assumption of most decision rules that each attribute is conceptually unique. To handle this problem, the IT and DA exercises required participants to set an overall weight for Population and then apportion it among the three component attributes. This correction procedure is similar to the Metfessel Allocation weighting technique (Appendix 1). The CA method originally was applied without use of the general Population factor. The intent was to see if the second stage of that technique could resolve interactions of the three attributes.

The following subsections present the procedures used for the four techniques, and the questions asked of the participants. Each person did the exercises by himself, producing five sets of weights each for the $R$ and IT methods, and two sets each for the CA and DA methods.

Rating. In this case, attribute "importance" was intentionally defined ambiguously, and the weight assessors were not told to ensure that a ratio level of measurement for the weights resulted. This duplicates the conditions under which most weight selections for siting are made.

Each person rated the importance of each attribute on a 0 to 1 scale for 0 to 10 , if he preferred). Each was also asked for a definition of "importance."

Indifference Tradeoff. To supplement other background information, each individual was sent a description of the assumptions of Weighting Summation. The purpose was to inform them of what characteristics the underlying theory requires of weights.

Thirty questions, trading off two attributes at a time, were asked of each person. They took the form:

"Given two cells:

a. One cell with:

- the best category attribute $X_{j}$; and

- the worst category of $x_{j}$; and

b. a second cell with:

- category (or value function level) $A$ of $x_{i}$; and

- the best (or another specified) category of $X_{j}$;

What category (or value function level) $A$ of $x_{j}$ would make the suitability of the two cells equal?". 
In some cases, the answers exceeded the range of the attribute in question. For instance, 40,000 feet is the limit of the data for proximity to streamflow and highways, but the importance of a particular attribute can be so high that the ' $A$ ' for its question is greater than 40,000 feet. Participants were told to record that answer and to assume that "value" or "suitability" of proximity attributes is linearly related to distance.

There were more questions than attributes; the extra ones act as checks. Step two of the IT exercise asked the weight setter to check his choices for consistency, and to alter his answers if they were not consistent. The instructions were:

"For the first 30 questions, each attribute was paired once with Proximity to Stream Flow and once with Proximity to Highways (MAGI variables 43 and 45). Thus each attribute [or, in the case of the population attributes (numbers 35,40 , and 42 ), the group of attributes] was involved in two questions. The two responses can be compared to ensure consistency. This is done in the following manner:

$$
\begin{aligned}
\text { Definition: Indifference Ratio }= & \frac{v_{j}\left(x_{j}\right)}{v_{j}\left(x_{j}\right)} \\
= & \text { the ratio of the amount } \\
& \text { of change in } v_{j}\left(x_{j}\right) \text { that } \\
& \text { is as important or desir- } \\
& \text { able as the given amount } \\
& \text { of change in } v_{j}\left(x_{j}\right) .
\end{aligned}
$$

Assumption: $\frac{v_{j}\left(x_{j}\right)}{v_{j}\left(x_{j}\right)}=\frac{v_{j}\left(x_{j}\right)}{v_{k}\left(x_{k}\right)} \cdot \frac{v_{k}\left(x_{k}\right)}{v_{j}\left(x_{j}\right)}$

(From one (From a 2nd (From a 3rd question) question) question)

"If $v_{j}\left(x_{j}\right)$ from question 1 is equal to the third question's $v_{j}\left(x_{j}\right)$, then the following simplification can be made:

$$
\begin{aligned}
& v_{i}\left(x_{j}\right) \equiv \frac{v_{j}\left(x_{j}\right)}{v_{k}\left(x_{k}\right)} \cdot v_{k}\left(x_{k}\right) \\
& \text { (From one (From a 2nd (From a 3rd } \\
& \text { question) question) question) }
\end{aligned}
$$

"This should be true for every combination of three attributes, if the answers (to the questions) are consistent. If the equality does not hold, the answers (the $\left.v_{j}\left(X_{j}\right)^{\prime} s\right)$ should be changed. Otherwise, there is no 
unique set of weights. Below is an example of three hypothetical questions and answers, involving attributesthat will not be weighted:

\begin{tabular}{|c|c|c|c|c|}
\hline Q\# & MAGI\# & Variable Name & Cel1 1 & Cell 2 \\
\hline \multirow[t]{3}{*}{1} & 44 & Proximity to Railroad & 1000 Feet & A Feet \\
\hline & 33 & Seismicity & High Risk & Low Risk \\
\hline & $A=$ & 101,000 Feet & & \\
\hline \multirow[t]{3}{*}{2} & 44 & Proximity to Railroad & 1000 Feet & A Feet \\
\hline & 48 & Prox. to Transmission & 30,000 Feet & 0 Feet \\
\hline & $A=$ & $=20,000$ Feet & & \\
\hline \multirow[t]{3}{*}{3} & 48 & Prox. to Transmission & 0 Feet & A Feet \\
\hline & 33 & Seismicity & High Risk & Low Risk \\
\hline & $A=$ & 120,000 Feet & & \\
\hline
\end{tabular}

So: $\frac{v_{44}\left(x_{44}\right)}{v_{33}\left(x_{33}\right)} \cdot=\frac{v_{44}\left(x_{44}\right)}{v_{48}\left(x_{48}\right)} \cdot \frac{v_{48}\left(x_{48}\right)}{v_{33}\left(x_{33}\right)}$

(Q\# 1)

(Q\# 2)

(Q\# 3)

Drop, since equal

or (cancelling the units):

$$
\begin{aligned}
(101,000-1000) \stackrel{\text { should }}{=} & \\
& \frac{(20,000-1000)}{(30,000-0)} \cdot(120,000-0)
\end{aligned}
$$

Or: $100,000 \stackrel{\text { should }}{=} \frac{19,000}{30,000} \cdot 120,000$; however

$$
100,000 \neq 76,000 \text {. }
$$

"(We assume above that attributes 44 and 48 are linear in respect to site suitability. This is actually the case with Variables 42 and 45, which are used in a similar manner below.)

"Since the above equality does not hold, at least one answer must be adjusted. Say it is decided that the answer to Question 1 should be dropped to 91,000 feet, and the answer the Question 3 raised to 142,000 feet. No adjustment is made to Question $2^{\prime} \mathrm{s}$ answer. The equality now (approximately) holds: 


$$
(91,000-1000) \stackrel{\text { should }}{=} \frac{(20,000-1000)}{(30,000-0)} \cdot(142,000-0)
$$

(Q\# 1)

(Q\# 2)

$$
90,000 \doteq 89,993
$$

"Checks for each of the variables are given below. The following shorthand will be used:

$A_{n}=$ Answer for question number $n$; and

$R_{j}^{i}=$ Indifference ratio of Variable $i$ to Variable $j$.

"Thus, in the above hypothetical example, the shorthand formulation would be:

$$
\begin{gathered}
A_{1}-1000 \stackrel{\text { should }}{=} \frac{\left(A_{2}-1000\right)}{30,000} \cdot A_{3} . \\
\text { Or: } A_{1}-1000 \stackrel{\text { should }}{=} R_{48}^{44} \cdot A_{3} .
\end{gathered}
$$

"In each of the checks below, fill in the appropriate $X_{i}$ 's and $R_{45}^{43}$, check to see if the equality holds, and alter the $X_{i}$ 's or $R_{45}^{43}$ as necessary. If you alter $R_{45}^{43}$ in a consistency check, you must redo all the previous checks that involve $R_{45}^{43}$. Thus be careful when you decide on a value for $R_{45}^{43}$."

Fifteen consistency checks followed. The first one calcu1 ated $R_{45}^{43}$. Check number 2 shows the form of the other fourteen

"2. Does $A_{1} \cdot R_{45}^{43}=\left(A_{16}-1000\right)$ ?

"This checks for consistency of your answers dealing with Surface Water Quality. If $R_{45}^{43}$ is not quite right, adjust

it here, and in your answers in Check number 1."

The last portion of the exercise calculated the weights. The following procedure was used. The weight of proximity to water was set at 10 . In effect, this says that proximity to water is a common value, i.e., a monetary system. All other weights were then calculated relative to the weight or "price" of proximity to water being 10 for a decrease of 40,000 feet. Participants could then adjust the weights. If they did so, they had to redo the 
other indifference questions involving attributes whose weights were changed. At this point, participants also allocated the weight assigned to "Population" among its three constituent attributes.

Finally participants were asked, once again, to define attribute "importance." They were also asked whether Indifference Tradeoff or Rating is better for regional siting studies.

The Churchman-Ackoff Method. Since either Rating or IT weights could be used as inputs to the second stage of this method, the first stage, preliminary weight setting, was not performed in this exercise. The IT weights were selected. The reason for that choice was that the Churchman-Ack off (CA) and IT methods are both theoretically valid techniques for choosing weights (Appendix 1). It was therefore of interest to see if the application of the second stage of the CA approach would substantially change the IT weights.

Because of the large number of attributes, the second variation of the second stage of the CA method was applied (Appendix 1). Attributes were randomly broken down into four groups, subject to the requirement that the three population attributes be assigned to the same group. The systematic comparison questions of Stage 2 were then asked. If there was a logical inconsistency between one of the participant's answers and the IT weights, it was immediately pointed out. Then either the response to the question was altered or the weights were changed.

In the third stage, each person examined the entire list of weights, and adjusted any he felt were "not quite right". For each attribute that had its weight changed, the person was asked to review the answers to the second-stage questions which involved that attribute. Participants were then asked to specify the method they preferred for use in regional siting studies.

Decision Analysis. The Decision Analysis weighting method (DA) was applied to determine weights of four attributes:

11. Mineral Resources.

36. Endangered Species.

45. Proximity to Stream Flow.

35, 40, and 42. "Population."

Technically, to yield a complete set of DA weights, only one attribute must be weighted by the DA lottery technique, and the rest can be inferred by the IT method. Because of the difficulty of the lotteries, however, more than one 
attribute was weighted this way, providing a check on the consistency of the - results of the lottery approach with those of the IT procedure. The weights derived using DA should be directly proportional to those selected by the IT technique. That is, the following equality should hold:

$$
\frac{k_{i}}{w_{i}}=c \quad i=1,2, \ldots, n .
$$

where

$$
\begin{aligned}
k_{i}= & \text { The weight for attribute } x_{i} \\
& \text { selected by the DA lottery } \\
& \text { technique (below). } \\
W_{i}= & \text { The weight for } X_{i} \text { chosen by } \\
& \text { the IT procedure alone as } \\
& \text { just outlined. } \\
\mathrm{n}= & \text { The number of attributes. } \\
\mathrm{C}= & \text { Constant which the ratio of } \\
& \text { the DA and IT weights of each } \\
& \text { attribute should equal. } \mathrm{C} \\
& \text { can vary from person to } \\
& \text { person. }
\end{aligned}
$$

Each person individually completed the following exercise for each attribute weighted (Attribute 45 is the example given below):

"1. Select weight for Attribute 45, Proximity to Stream

Flow.

The two alternatives are:

a. A cell with all attributes at their worse value, except for Proximity to Stream Flow, which is at its best ( 0 feet); and

b. A cell whose attribute levels will be determined by the following lottery:

i. A chance $p$ that all attributes (including Proximity to Stream Flow) will be at their best values; and

ii. A chance $(1-p)$ that all attributes (including Proximity to Stream Flow) will be at their worst values.

"At what probability $p(0 \leq p \leq 1)$ are you indifferent to the two alternatives?

$$
p=
$$


"The selection of $p$ might be made easier if you arbitrarily select a very low (or high) value for $p$, and then ask yourself 'Is that about right?' If it is not, adjust $p$, and ask yourself that question again. Continue until you are satisfied."

Again, each participant was then asked which weight selection method he preferred for regional siting studies.

Statistical Analysis of Weights

The question of whether or not there are important differences between results of alternative weighting methods is best determined by evaluation of differences in cell suitability scores. Unfortunately, conclusions could not be generalized beyond the study area and decision rule involved. Comparison of the weight sets themselves may sometimes give a better indication of differences among results of the techniques independent of the peculiarities of the distribution of attribute levels within the study area. If there are cells in the study area that are superior in every attribute, for example, then any set of positive weights will choose those cells as best and there would be no differences among methods in spite of differences in weights.

Significance of differences in weights due to choice of method is evaluated here by comparing magnitudes of those differences with those due to other influences. Other influences include ${ }^{8}$ : .

1. Values, background, and quantification ability of participants.

2. Purpose and context of the siting study.

3. Random error due to influences of participants' mood and uncertainty which are functions of knowledge and the appropriateness of attributes and specificity of their definitions.

The purpose and context of the study is the same for everyone. other influences vary. The task here is to determine whether or not variation in the weight sets due to choice of method is large compared to choice of person and "error."

If one of these influences is held constant and two sets of weights are chosen, differences between the sets should be due to the remaining influences. This research was designed with that in mind. Each person selected weights by at least two different methods. Differences in the resulting weights can thus be attributed to the methods and error (since the study and context were constant). Similarly, differences among weights of the five 
individuals using the same method is due to influences of choice of person and error.

In this study, the observed differences may be larger than what is really due to choice of person and error alone. This is because some individuals did the exercises by mail and the others did them in the presence of the researcher. The importance of choice of method relative to choice of person and individual mood or uncertainty will be understated; therefore, the conclusions resulting from the analyses are conservative.

10 isolate variation due to error alone, two sets of weights should be chosen by the same person and the same method; however, after having determined one set of weights, there is a strong tendency to rely on memory in choosing the second set. The estimate of "error" would therefore be less than if somenow the individual could completely forget the weights he assigned the first time. A rough approximation of the influence of error can be obtained by comparing sets of weights chosen with one method under identical circumstances by two persons who have similar knowledge and perspective on siting. The two persons who are most similar in this regard are Dr. Massicot and Mr. Mueller of the Power Plant Siting Program. The resulting estimate overstates the influence of error. Since we are trying to compare the influence of error with that of method, use of that estimate is conservative. If, however, the uncertainty of other participants is very much greater, it may be that this estimate will understate the effect of error. In the analyses below it is assumed that the error term is the same for each person.

Correlation analysis (Pearson's $r$ ) is used to show the strength or closeness of the relationship between two sets of weights. This is an unusual use of the currelation statistic. Normally, it is applied to bivariate distributions, with the points representing randomly selected individual observations. In contrast, here there are many variables, one per point, which are in no sense randomly chosen (Figure 2). The two axes are two different ways (persons or methods) of choosing weights, rather than two variables. Pearson's $r$ is, however, a concise way of describing how similar two sets of weights are one to another and we take advantage of this useful property. If two weight sets are precisely proportional, the relative importance of each attribute in both cases is the same, and the correlation is 1.0 . Figure $2(a)$ shows such a pair. Each point represents one variable. These two weight sets will necessarily pick the same cells as best because one set can he converted 


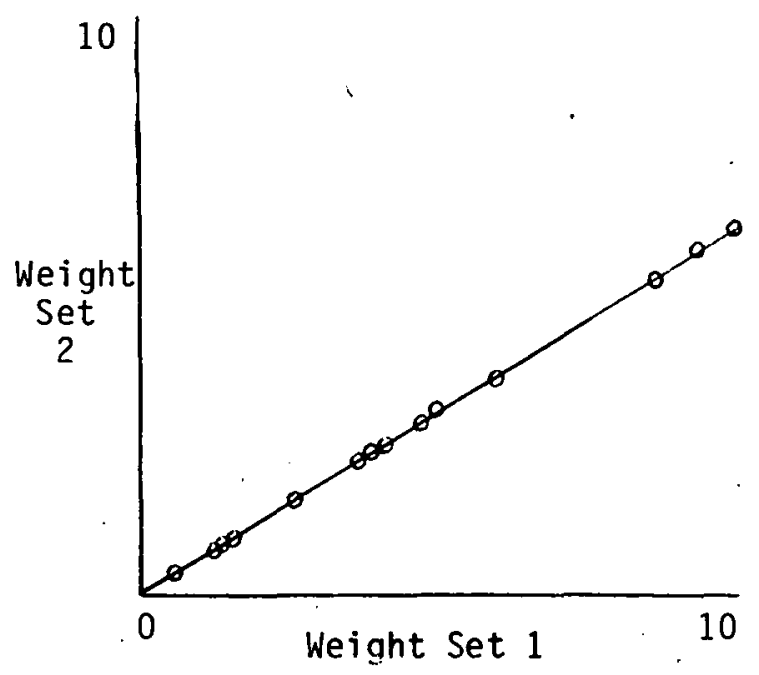

(a) Two Perfectly Correlated Weight Sets With $Y$ Intercept at the Origin

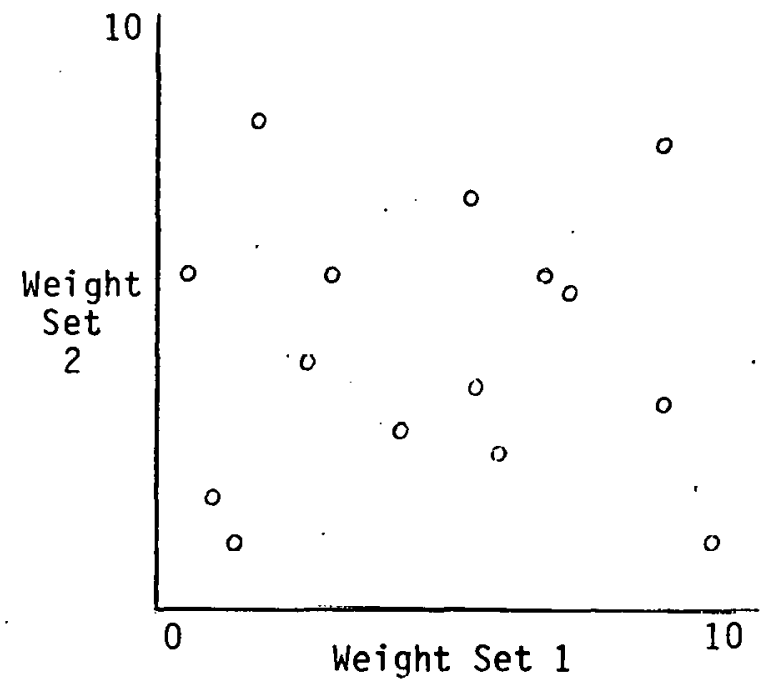

(b) Two Uncorrelated Weight Sets

Figure 2. Relationships of Pairs of Weight Sets 
directly to the other by multiplying by a constant (the slope), and because such a multiplication does not affect the resulting rank ordering of cells.

In contrast, the two sets of weights shown in Figure 2(b) have no obvious relationship, and their correlation is near zero. One cannot say a priori that these two sets of weights would or would not select the same cells as best. The magnitude of differences in results depends on the data base and decision rule used. Certainly, the lower the correlation, the less likely that results will be identical. It is this "likelihood" on which the analysis below is based. Given two pairs of weight sets (four sets total), the pair having a lower correlation will probably have a greater difference in final ranking of cells. To test this proposition, a correlation analysis of the cell suitability scores themselves is performed later in this Chapter.

The following correlations are calculated:

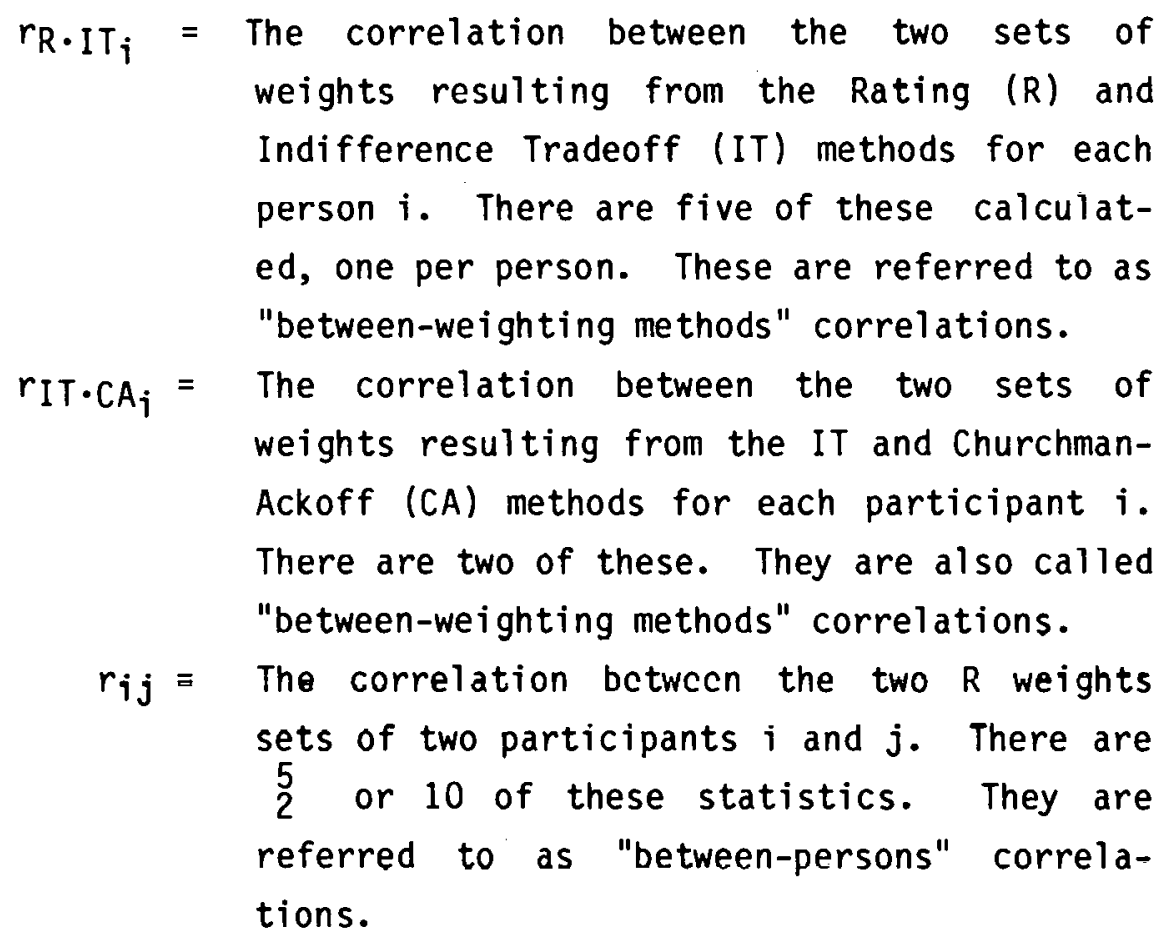

To gauge relative influence of choice of person versus choice of weighting method, we compare the mean $r_{1 j}$ with the mean $r_{R} \cdot I_{1}$ land the mean $\left.r_{I T \cdot C A_{j}}\right)$. If $\bar{r}_{i j}$ is significantly greater than $\bar{r}_{R} \cdot I T$ (or $\bar{r}_{I T \cdot C A}$ ), we can conclude that choice of method has more influence on weights than choice of person. If there is no significant difference, then the influences 
are roughly equal. "Significance" will be measured here with both the Student's $t$ test and a nonparametric test developed by white. 9 The latter test will be applied only to $r_{i j}$ versus $r_{R} \cdot I_{i}$, as this is the only comparison having enough degrees of freedom. Adjustments are made in both tests to account for 4 degrees of freedom, rather than 9, among the $r_{i j}$ 's. This is because only five Rating weight sets are used to calculate $10 r_{i j}$ 's. The null and alternative hypotheses for the tests are detailed elsewhere. 10

White's nonparametric test works as follows:

1. Produce one rank-order for all observations (both samples together).

2. For each sample, add the ranks (e.g., $1+4+6$, etc.). Then subtract the rank sum of sample 1 from $n_{1}\left(n_{1}+n_{2}+1\right)$, where $n_{1}$ is the number of observations in the $i$ th sample. Also subtract the rank sum of sample 2 from $n_{2}\left(n_{1}+n_{2}+1\right)$.

3. Check the smallest of the absolute values of the four numbers calculated in step 2 against the critical value for the chosen level of significance and sample sizes. If the critical value is greater than the calculated number, the samples are significantly different. We modify the test to allow for samples whose degrees of freedom differ from ( $n$ - 1). Ranks are usually listed as $1,2,3, \ldots$ If a sample of 10 has, say, only 4 degrees of freedom, however, we would increment that sample's ranks only by $(4+1) / 10$ instead of 1 . This might yield a "rank" order of $1,1-1 / 2,2-1 / 2,3, \ldots$, where the second and fourth observations are from that sample and the first and third are from a sample with the nomal degrees of freedom [ $n$ 1]. In general, we define the "rank" of an observation to be (df + 1)/n more than the "rank" of the preceding observation, where df and $n$ are the degrees of freedom and size, respectively, of the former observation's sample. We treat the resulting "rank"-order the same as a normal rank-order in White's procedure, except that each "rank" sum would be subtracted from $\left(d f_{j}\right)\left(d f_{1}+d f_{2}+1\right)$, not $n_{j}\left(n_{1}+n_{2}+\right.$ 1), in step 2.

Influence of choice of weighting method can be similarly compared to that of mood and uncertainty by testing $\bar{r}_{R \cdot I T}$ (and $\bar{r}_{I T \cdot C A}$ ) against $\bar{r}_{\text {Mass-Muel }}$ (correlation between Dr. Massicot's and Mr. Mueller's weight sets). Only Student's $t$ test can be used, as the sample sizes are too small to use White's test. 
Comparison of Variation of Rating and Indifference Tradeoff Weights

Researchers in psychophysics assert that people perceive magnitudes in a logarithmic manner. 11 Distances of 2,4 , and 8 miles, for example, might be perceived as being only 1,2, and 3 units long. Some contend that people view "value" the same way. 12 Weights of 1,2 , or 3 might really indicate relative importances of $\mathrm{e}^{1}, \mathrm{e}^{2}$, and $\mathrm{e}^{3}$. This problem can affect methods that ask ratio questions or request numerical estimates of importance (such as Rating). Methods that derive weights from tradeoff questions are more immune. 13

If logarithic perception holds for the five participants, Rating weights should have less "spread" than IT weights. The coefficient of variation (standard deviation/mean) is a valid indicator of relative variation of ratio scales ${ }^{14}$; we adopt it here. A nonparametric paired observations test is used to compare the 5 Rating coefficients of variation ( $C V^{\prime} s$ ) with the 5 IT CV's. Only if everyone's Rating coefficient of variation is less than his IT coefficient can we conclude that the IT weights have significantly larger spread. If so, the hypothesis of logarithmic perception cannot be rejected.

The nonparametric test is based on the binomial distribution. If CV's for the Rating and IT methods came from the same "population" of CV's, then there would be a $50 \%$ chance of a person's Rating CV being greater than his IT $\mathrm{CV}$, and an equal probability of his Rating $\mathrm{CV}$ being less than his IT. Assuming independent observations, the chance that all 5 Rating CV's are less than IT CV's is $(1 / 2)^{5}$, or about 0.03 . If this occurs and if $\alpha=0.05$ is the chosen level of significance, we will conclude that the relative variation among IT weights is significantly greater than the variation among Rating weights.

Comparison of Indifference Tradeoff and Decision Analysis Weights

Decision Analysis (DA) weights are not included in the correlation analyses, because only four of the 18 attributes were weighted this way. If the other weights are inferred by the IT method from one of the DA weights, the results will correlate perfectly with those of the Indifference Tradeoff (IT) method when used alone. Nevertheless, since theoretically the ratio of a person's DA and IT weights for any attribute should be constant, it is of interest to see if those ratios are equal in practice. This gives a measure of how consistent the two methods actually are.

Disparities among individual's ratios are noted. Great dissimilarities indicate that reliance on one DA lottery weight to infer others via the IT 
technique is hazardous. If ratios for the DA and IT methods are not identical, then the choice of attribute from which to infer the rest of the weights will affect the sum of the weights and the Decision Analysis multiplicative form (which must be used when the sum of the weights is not equal to 1.0, indicating either risk-averse or risk-seeking attitudes). If there is enough inconsistency, it is possible that selection of one attribute for the DA lottery exercise will lead to a risk averse model $\left(\Sigma W_{j}>1.0\right)$, while selection of another would yield a risk seeking model $\left(\Sigma W_{i}<1.0\right)$. This may or may not make a difference in which cells are found to be "best"; another section in this chapter investigates this point. For each of the four attributes for each respondent, the sum of the weights inferred by the IT method from its DA weights is given. Each person's sums are then checked for consistency.

\section{Candidate Area Definition}

Exclusionary Screening. Using Mr. Mueller's criteria, candidate areas are defined as groups of four or more adjacent cells (364.8 or more acres, the minumum for two large nuclear plants) which are acceptable in all variables.

Weighting Summation. Suitability scores for each weight set for each cell are calculated using:

$$
\text { Suitability }=\sum_{i=1}^{n} w_{j} v_{i}\left(x_{i}\right) \text {, }
$$

where $W_{i}$ is the weight for variable $X_{j}$ and the $V_{j}()$ 's are the attribute value functions defined by $\mathrm{Dr}$. Massicot and Mr. Mueller. Candidate areas consist of four or more adjacent cells that score in the top $8 \%$. The $8 \%$ cutoff is consistent with the fraction of the study area in candidate areas in the Maryland Eastern Shore.16 Furthemore, cells scoring in the top $2 \%$ are indicated. Candidate areas are defined for each set of weights.

Power Law. Each cells's suitability is calculated as follows:

$$
\text { Suitability }=\prod_{i=1}^{n} v_{i}{ }^{*}\left(X_{i}\right) W_{i}{ }^{*}
$$

where

$$
\begin{aligned}
W_{i} *= & W_{j} / \sum_{i} W_{i} . \\
& \text { equal This causes the sum of the modified weights } W_{i} \text { to } \\
V_{i}= & V_{j}()+3 . \text { The range of the original attribute value functions } \\
& \text { is shifted from }[0,10] \text { to }[3,13] . \text { This is because suitability } \\
& \text { falls to zero when any } V_{i}\left(x_{j}\right) \text { equals zero. Unfortunately, most }
\end{aligned}
$$


cells have at least one $V_{j}\left(X_{j}\right)=0$. Although ratio scaled value functions are preferable, we arbitrarily choose to add 3 to each.

The assumptions of the Power Law are examined in Appendix 1. It presumes that people perceive value in a logarithic rather than linear manner, as discussed above.

Candidate areas are defined with the Power Law in the same manner as for Weighting Summation for every Rating and IT weight set.

Decision Analysis. Each cell's utility is calculated as

Utility $=\left\{\left[\prod_{i=1}^{n}\left(1+C k_{i} v_{i} *\left(x_{i}\right)\right)\right]-1\right\} / C$

where

$k_{\mathbf{j}}=$ Decision Analysis weights.

$V_{i}^{*}=V_{j}() / 10$, ensuring $a[0,1]$ range for each value function. Ideally, utility functions incorporating risk attitudes should be used instead. Nevertheless, we can still obtain an indication of how important choice of decision rule is.

$C=$, Constant, chosen so that utility ranges from 0 to 1 .

See Appendix 1 for a discussion of the theory underlying this decision rule. Candidate areas are delineated in the same fashion as for Weighting Summation for every feasible set of Decision Analysis weights. "Feasible" means that no weight is greater than or equal to 1.0. If any are, the decision rule is invalid.

Analysis of Cell Suitability Scores and Candidate Areas.

Exclusionary Screening versus Weighting Summation. The proportion of cells in Exclusionary screening candidate areas shared by each of two sets of Weighting Summation results is calculated. The two sets are those defined by Mr. Mueller's Rating and IT weights, as it was he who chose the exclusionary criteria.

Weighting Summation Using Differcnt Weighting Melhuds. Variation among weight sets matters little except by the differences it makes in cell suitability scores and candidate areas. Different sets of weights may or may not produce different cell orderings. Variations in cell suitability scores and candidate areas are tested for relative importance of three influences: 
1. Choice of persons selecting weights.

2. Choice of weighting method.

3. Mood and uncertainty of participants.

The importance of these influences on the weights themselves is examined elsewhere in this chapter. Weighting summation suitability scores $\left(w_{i} v_{i}\left(X_{j}\right)\right)$ are calculated for each of the cells in the study area that were not excluded by the stringent exclusionary criteria. The scores are then analyzed statistically by the method described above applied to the weights. Again, we are trying to gauge the influence of "choice of weighting method" versus those of "choice of person" and "weight setter mood and uncertainty." The latter influence, as with weights, is estimated by rMass-Muel.

These tests are also performed using proportions of overlap of the top $2 \%$ and $8 \%$ of the cells instead of correlations. Proportions of overlap is a better indicator of similarity then correlation of results, as we are most interested in which cells are chosen as best, not in the rank order of all cells.

Power Law Versus Weighting Summation. Correlation and fraction of overlap of candidate areas between Weighting Summation and Power Law suitability scores are calculated for each set of Rating and IT weights. The following comparisons are made using Student's t tests:

1. Mean proportion of overlap between the Power Law and Weighting Summation versus mean proportion of overlap among Rating Weighting Summation candidate areas. This compares the importance of choice of decision rule versus choice of person.

2. Mean proportion of overlap between Power Law and Weighting Summation areas versus overlap between Dr. Massicot's and Mr. Mueller's Rating Weighting Summation areas. This indicates how important choice of decision rule is compared to weight setter's mood and uncertainty.

3. Mean proportion of overlap between the Power Law and Weighting Summation versus mean overlap between Rating and IT Weighting Summation candidate areas. This constrasts the importance of choice of decision rule versus choice of weighting method.

Decision Analysis Multiplicative Form Versus Weighting Summation. Decision Analysis areas are compared with each other for each person. Each set reflects a different attitude towards risk (as indicated by the sum of the weights). Results of Weighting Summation (representing risk neutrality) with 
Indifference Tradeoff weights are also contrasted with Decision Analysis areas.

RESULTS

Attribute Value Functions

This step converts physical attributes into measures of value. Nondiscretionary Exclusionary categories for the Weighting Summation, Power Law, and Decision Analysis runs were also selected at this stage. Table 2 displays the final attribute ratings assigned by Dr. Massicot and Mr. Mueller.

Some problems encountered in this step anticipate those of weighting exercises. Expecially exasperating was a lack of specific definitions for many categories which often made value assigment both difficult and arbitrary. Even for categories that were precisely defined, there remained uncertainty as to their "importance." This was the case, for instance, with the three population variables. The cause of the uncertainty in this case was that the U.S. Nuclear Regulatory Commission was re-evaluating the population criteria used for evaluating nuclear power plant sites, and Maryland Power plant siting Program personnel could not predict the outcome of that re-evaluation.

Table 2

ATTRIBUTE VALUE FUNCTIONS, MARYLAND SCREENING I.

Key: EXCLUDE $=$ Severe restriction, cell is dropped

$10=$ The best or most desirable category within the variable for power plant siting

0 = The worst or least desirable rated category within the variable for power plant siting

Values Between

0 and $10=$ Categories intermediate in desirability

\begin{tabular}{ccr}
\hline MAGI & Variable Name/Category Name or Description & Value \\
\hline 4 & SURFACE WATER QUALITY & \\
Class I Waters (General Use and Recreatioal & 8 \\
& Class II Waters (Natural Trout Stream) & 0 \\
Class II Waters (Rccrcational Trout Streail) & 3 \\
& No Stream in Cell & 10 \\
7,8 & TRANSPORTATION AND TRANSMISSION & 7 \\
& None & 0 \\
& Highway Intersections, Railroads & 3 \\
& Gas/Petroleun Pipeline & 10 \\
& Transmission Line & 3 \\
& Airport and Airport Property & 5
\end{tabular}


Table 2 (Continued)

MAGI

Variable

Variable Name/Category Name or Description

Value

9,10

STATE AND FEDERAL LANDS

None

10

Maryland Depts. of Forests and Parks, and

Fish and Wildlife

Other State of Maryland

All Federal Government Categories

Municipal Ownership

MINERAL RESOURCES

None

Deep Coal Mine or Gas Field

Strip Coal Mine (Active)

Strip Coal Mine (inactive)

NERAL RESOURCES Continued

Sand and/or Gravel Pit

Stone Quarry or Copper Deposit

Peat or Clay and Shale Pit

14 SOIL GROUP (PRIMARY)a

Al Deep, sandy, excessively drained, rapidly permeable, highly acidic

5

EXCLUDE

0

A2 Loose sands, depth of 1 to 10 feet or more, rapidly permeable, pH highly variable

0

8

10

B1 Deep, permeable, silt or loam at surface, clay in subsoil, pH highly variable. Prime Agricultural Land.

B2 Well drained, strongly acidic, slowly permeable layers of gravel and clay below 2 to $3 \mathrm{ft}$. Prime Agricultural Land.

B3 Deep, well drained, unstable structure, subsurface clays, gently sloping to rolling surface, plastic, sticky, slowly permeable, strongly acidic.

C1 20 to 40 inches in depth, shaly surface with localized stony spots, strongly acidic.

C2 Well drained, nonacidic, clayey, tough, intractable, usually surface slope over $15 \%$, plastic, dense, very slowly permeable, contains natural lime.

D1 Less than 20 inches in depth, high content of rocky fragments, well to excessively drained, low natural fertility.

E1 Moderately well drained, substrata of loose sand, strongly acidic, rapidly permeable. Prime Agricultrual Land.

E2 Perched water table to a depth of about 2 feet over fragipan or clayey subsoil, moderately well drained, saturated and mushy in late winter and early spring, surface is silt or loam, strongly acidic, slow permeability.

asoils defined as "Prime Agricultural Land" were so designated by consultants to the Maryland Power Plant Siting Program (Rogers and Golden, Note 16). 
Table 2 (Continued)

MAGI

Variable \# Variable Name/Category Name or Description Value

14

SOIL GROUP (PRIMARY), Continued

E3 Deep, moderately well drained, silty, moderately slow permeability, water table to within 1.5 to 2.5 feet of the surface in late winter and early spring, strongly acidic. Prime Agricultural Land

F1 Wet, sandy, poorly drained, strongly acidic, rapidly permeable when water table is low.

F2 Wet, sandy, poorly drained, strongly acidic, rapidly permeable when water table is low, generally unstable structure, fluctuating water table from surface in winter to depth of 4 to 6 feet in summer, loamy sand or sand substrata.

F3 Poorly drained, dense subsoils of silt, clay, or fragipan, surface is clayey, sticky, plastic when dry, slowly permeable, strongly acidic.

G1 Deep, well drained floodplains, loamy alluvium, strongly acidic to neutral, moderately permeable. Prime Agricultural Land.

G2 Deep, poorly drained floodplains, silty sediments, pH variable, slowly permeable.

H1 Very to extremely stony soils which otherwise would be in groups B1, B2, C1, C2, $\mathrm{D1}$, E2, or F3; 1 arge loose stones.

H2 Very to extremely rocky soils which otherwise would be in groups $\mathrm{B} 1, \mathrm{C} 2$, or $\mathrm{D} 1$; hard bedrock exposed.

Soils covered by urban development or

17,18 al tered by mining or cut-and-fill.

NATURAL FEATURES

None in Cell

One in Cell

Two or More in Cell

LAND SURFACE SLOPE (PRIMARY)

0 to $3 \%$ slope

3 to $10 \%$ slope

10 to $20 \%$ slope

Greater than $20 \%$ slope

23 HISTORIC SITES (FIRST)

None in Cell

One in Cell

26 LAND USE AND LAND COVER (PRIMARY)

Residential, Commercial

Industrial, Urban Open and Other

Extractive, Transporation, Communication, Utilities

Institutional

Strip and Clustered Settlement 
Table 2 (Continued)

MAG I

Variable

Variable Name/Category Name or Description

Value

26

LAND USE AND LAND COVER (PRIMARY), Continued

Mixed

Orchards, Groves, Vineyards, Bushfruits, or Horticultural Areas

Cropland and Pasture, other Agricultural, or Forest, Shrub

Water Areas or Wetlands

Other Barren Land

30 MILE SITE POPULATION FACTOR

0.0 TO 0.2

0.2 T0 0.5

0.5 TO 1.0

Greater than 1.0

ENDANGERED SPECIES

Observed Location of Indiana Bat 0

37

other

EXCAVATION REQUIREMENTS

No Data Available

Blasting Required

Power Gradings and Some Blasting Required

Power Grading Required

OVERBURDEN THICKNESS

No Data Available

Thin Overburden

Medium or Variable Overburden

Thick Overburden

39

AQUIFER RECHARGE ZONES

Not an Aquifer Recharge Zone

Hydrologic Unit I of Piedmont and Appa-

lachian Provinces (PAP)

Hydrologic Unit II of PAP

Hydrologic Unit III of PAP

40

5 MILE SITE POPULATION FACTOR

0.0 to 0.2

0.2 to 0.5

0.5 to 1.0

Greater than 1.0

42

POPULATION DENSITY

Greater than 1000 Persons/sq.mi.

Other Levels

2

8

0

10

10

7

3

0

10

5

10

5

0

5

10

5

0

10

0

3

6

10

7

3

0

EXCLUDE

Graph, below 
Table 2 (Continued)

MAG I

Variable \#

POPULATION DENSITY

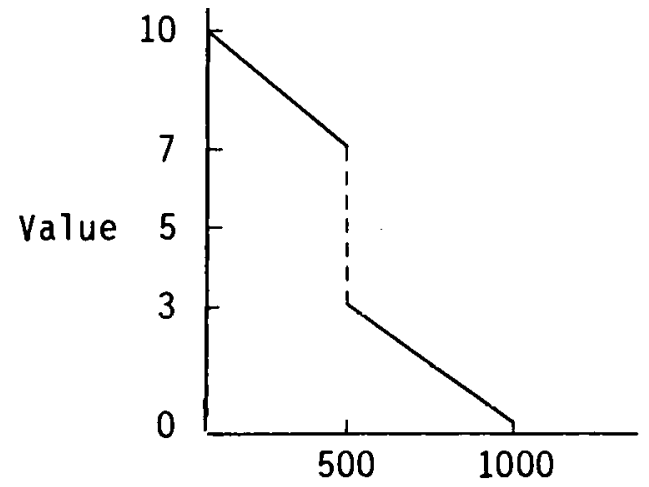

43

PROXIMITY TO HIGHWAYS

0 to 1000 Feet, or Greater Than 40,000 Feet

0

1000 Feet

10

Between 1000 Feet and 40,000 Feet

Graph, below

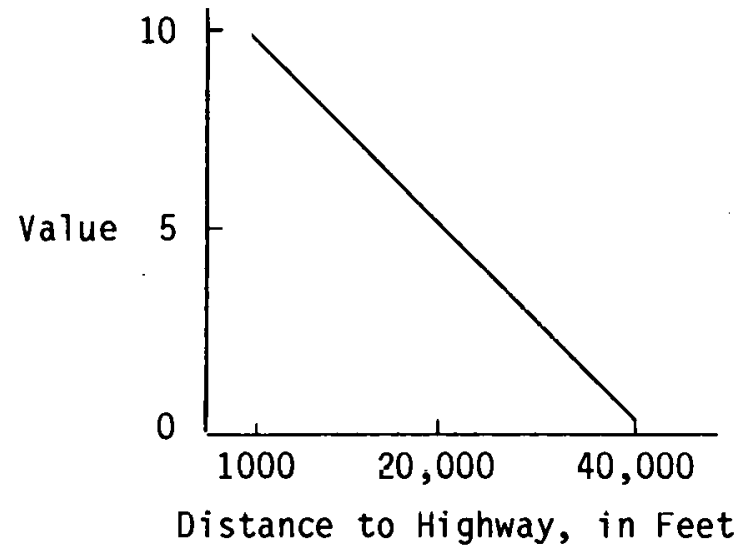

45

PROXIMITY TO STREAM FLOW

All Levels

Graph, below

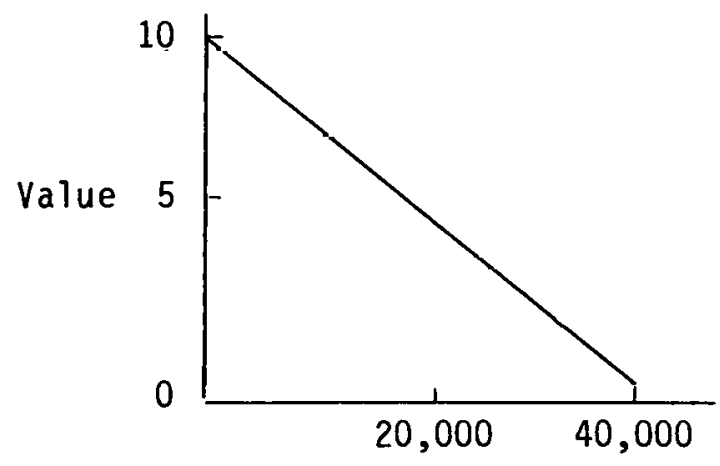

Distance to Stream Flow, in Feet 
Table 3

EXCLUSIONARY CATEGORIES, MARYLAND SCREENING I

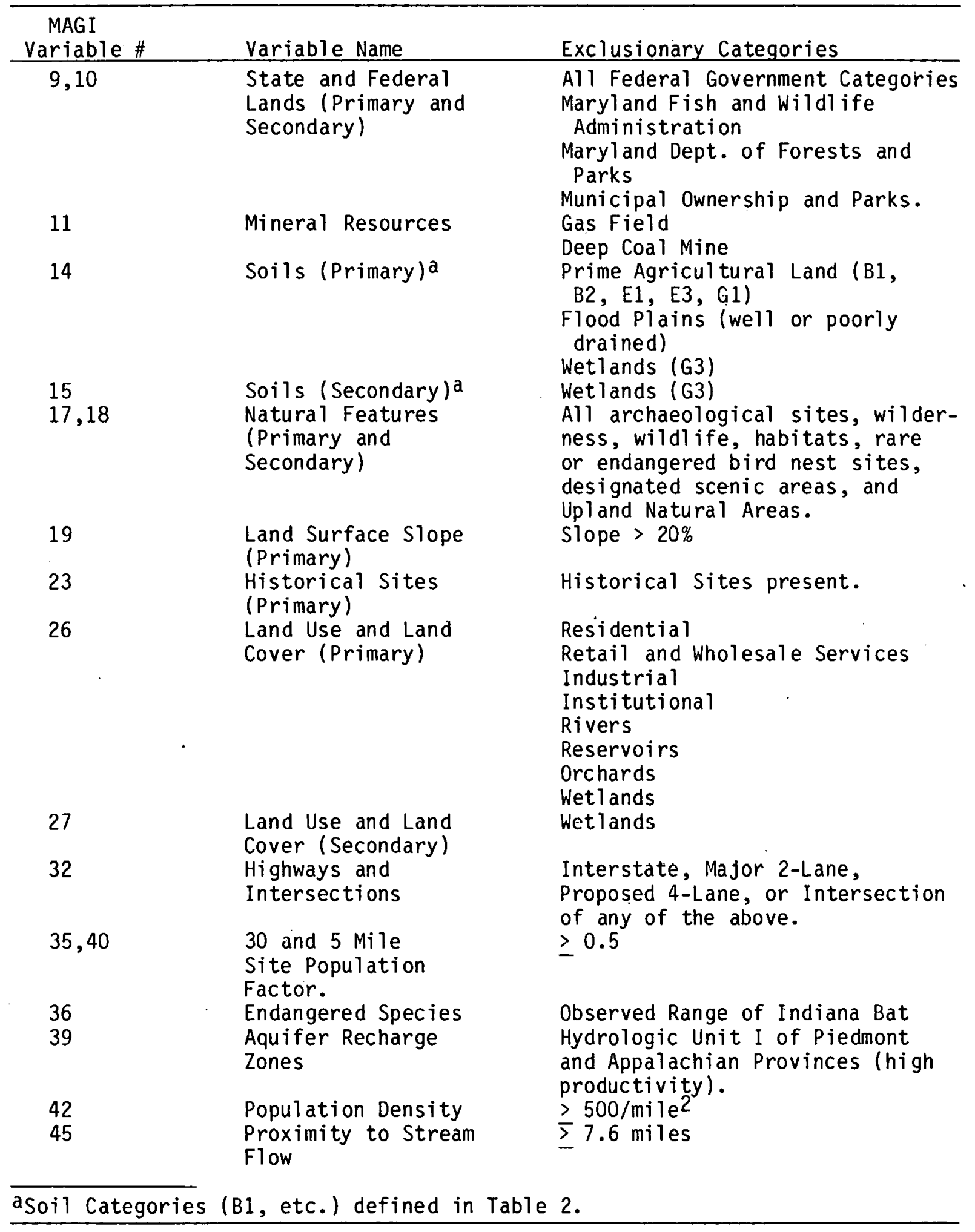




\section{Exclusionary Screening Criteria}

Table 3 shows the categories for Exclusionary Screening chosen by Mr. Mueller. Cells with any of these categories were dropped. Weights

Table 4 presents weights set by the five participants using the Rating (R), Indifference Tradeoff (IT), and Churchman-Ackoff (CA) methods. If the original scale was 0.0 to 1.0 , weights were multiplied by 10 to create a $0-10$ scale. Decision Analysis (DA) weights are presented in Table 5.

Summary of Participant Comments

Participants answered several questions concerning ease of use and applicability of the four weighting methods. In addition, they made other comments.

The points they agreed upon include:

1. Rating is the easiest to use of the four techniques. Indifference Tradeoff is much more difficult. The Churchman-Ackoff method is intermediate in difficulty. In general, the more precise a decision maker must be and the more checks on his answers he is forced to make, the more difficult is the technique.

2. A weight is the relative importance of one attribute compared to other attributes.

3. A major cause of uncertainty or arbitrariness in assigning weights is the nature of the attributes themselves. Much of the information in the data base is only indirectly related to siting decisions, poorly defined, and/or of the wrong resolution for regional siting studies.

4. Neither the Churchman-Ackoff nor Decision Analysis approach is preferred to Indifference Tradeoff for regional siting studies.

The most important difference in opinion was lack of agreement as to whether Rating or Indifference Tradeoff is a better way to set weights for regional siting studies. A partial explanation for this was that those who disliked the more complex approach did the weighting exercises by mail. Because no experienced persons were present when they estimated weights, confusing or incomplete portions of the background material and instructions could not be cleared up easily. This produced a more difficult exercise. That does not, however, completely explain the differences of opinion. Those who preferred Rating felt that it was more appropriate to the quality of the data 


\section{Table 4}

RATING, INDIFFERENCE TRADEOFF, AND CHURCHMAN-ACKOFF WEIGHTS, MARYLAND SCREENING Ia

\begin{tabular}{|c|c|c|c|c|c|c|c|c|c|c|c|c|}
\hline \multirow{2}{*}{$\begin{array}{c}\text { MAGI } \\
\text { Variable \# }\end{array}$} & \multicolumn{2}{|c|}{ Dr. Canham } & \multicolumn{2}{|c|}{ Dr. Felleman } & \multicolumn{3}{|c|}{ Dr. Massicot } & \multicolumn{3}{|c|}{ Mr. Mueller } & \multicolumn{2}{|c|}{ Mr. Voelker } \\
\hline & $\mathrm{R}$ & IT & $\bar{R}$ & IT & $R$ & IT & $\overline{C A}$ & $\mathrm{R}$ & IT & $\overline{C A}$ & $R$ & IT \\
\hline 4 & 6 & 2.5 & 6 & 1.25 & 1 & 3 & 2 & 4 & 7.5 & 7.5 & 2 & 2.5 \\
\hline 7,8 & 4 & 1.25 & 5 & 0.5 & 4 & 2.5 & 2.5 & 5 & 1.25 & 1.31 & 0 & 1 \\
\hline 9,10 & 5 & 1.5 & 2 & 1.25 & 4 & 0.5 & 0.5 & 2 & 5 & 5 & 2 & 3.75 \\
\hline 11 & 7 & 1.75 & 2 & 1.25 & 3 & 12.5 & 12.5 & 5 & 6.25 & 6.25 & 1 & 5 \\
\hline 14 & 1 & 1.25 & 2 & 0.75 & 5 & 2.5 & 2.5 & 5 & 5 & 5 & 9 & 5 \\
\hline 17,18 & 6 & 0.5 & 5 & 1.25 & 7 & 2 & 2 & 6 & 7.5 & 7.5 & 4 & 2 \\
\hline 19 & 4 & 1.25 & 3 & 0.25 & 6 & 7.5 & 7.5 & 6 & 10 & 10 & 6 & 2 \\
\hline 23 & 7 & 0.25 & 2 & 0.25 & 5 & 1.5 & 1.5 & 6 & 1.25 & 2 & 7 & 3.75 \\
\hline 26 & 7 & 1.25 & 10 & 1.25 & 4 & 0.5 & 0.5 & 6 & 1.25 & 1.25 & 6 & 25 \\
\hline 35 & 6 & 0.55 & 5 & 1 & 3.5 & 10 & 10 & 2 & 8.75 & 8.75 & 0 & 2.5 \\
\hline 36 & 3 & 0.1 & 3 & 0.75 & 9 & 12.4 & 15 & 10 & 9.375 & 7.5 & 1 & 1 \\
\hline 37 & 2 & 0.625 & 2 & 0.25 & 4 & 1.5 & 1.5 & 4 & 9.3725 & 9.375 & 2 & 2.5 \\
\hline 38 & 2 & 0.25 & 3 & 0.25 & 4 & 2 & 2.6 & 4 & 6.5 & 5.74 & 2 & 0.25 \\
\hline 39 & 8 & 5.5 & 10 & 2.5 & 3 & 1.5 & 1.5 & 6 & 2.5 & 2.56 & 3 & 2.5 \\
\hline 40 & 9 & 2.2 & 10 & 2.5 & 3.5 & 10 & 10 & 3 & 8.75 & 8.75 & 9 & 8.75 \\
\hline 42 & 7 & 2.2 & 10 & 1.5 & 2.5 & 5 & 9 & 4 & 7.5 & 7.5 & 0 & 1.25 \\
\hline 43 & 1 & 2.25 & 3 & 5.25 & 2 & 1.625 & 1 & 4 & 1.8 & 1.86 & 8 & 4.5 \\
\hline 45 & 6 & 10 & 7 & 10 & 9 & 10 & 10 & 10 & 10 & 10 & 10 & 10 \\
\hline
\end{tabular}

$\overline{a_{R}}=$ Rating, $I T=$ Indifference Tradeoff, and $C A=$ Churchman-Ackoff.

Table 5

DECISION ANALYSIS WEIGHTS, MARYLAND SCREENING I

\begin{tabular}{clcc}
\hline $\begin{array}{c}\text { MAGI } \\
\text { Variable \# }\end{array}$ & Variable Name & $\begin{array}{c}\text { Weights } \\
\text { Dr. Massicot }\end{array}$ & Mr. Mueller \\
\hline 11 & Mineral Resource & 0.1 & 0.1 \\
36 & Endangered Species & 0.8 & 0.1 \\
45 & Proximity to Stream Flow & 0.1 & 0.1 \\
35,40, and 42 & "Population" & 0.8 & 0.25 \\
\hline
\end{tabular}


base. They also stated that many of the tradeoff questions of the Indifference Tradeoff method were impossible to relate to. Furthermore, they preferred to select weights directly rather than implicitly via tradeoffs.

The Power Plant Siting Program individuals preferred the Indifference Tradeoff method because they believed that it was important to face tradeoffs explicitly, despite the added difficulty.

Only one person hinted that his opinion as to which method was better would partially depend on whether choice of method makes a difference in cell evaluations. If the others had known before the exercises whether or not it could make a difference, their opinions might have been different.

\section{Statistical Analysis of Weights}

As explained above, a series of Student's $t$ and nonparametric tests were applied to groupings of correlations between sets of weights. Table 6 shows the ten correlations between the five sets of Rating ( $R$ ) weights, and the ten between the five sets of Indifference Tradeoff (IT) weights. The Rating correlations are referred to as "between-persons" correlations. Table 7 displays for each individual correlations between sets of weights chosen by different methods. These are called "between-methods" correlations. Table 8 presents statistics describing the distribution of each group of correlations.

Only 4 of the 20 correlations in Table 6 and none of the between $R$ and IT correlations are significantly different from zero (assuming that the test found in Scheflerl7 is valid for this use of correlations). Two pairs of individuals (Drs. Canham and Felleman, and Dr. Massicot and Mr. Mueller) have correlations larger than would be expected by chance alone. The differences between the value judgments, as expressed in weights of the various participants, is important. Similarly, the correlations between the $R$ and IT methods for each person are statistically indistinguishable from what would have resulted if they had used a random numbers table to select the weights. Nevertheless, most of the correlations are weakly positive, indicating that there is not a complete absence of relationship between the weight sets.

The between-persons correlations are similar to those found in a number of other studies that had different individuals choose weights. 18 This indicates that the diversity of the group is as high as in most other studies of this type. 
Table 6

BETWEEN-PERSONS CORRELATIONS OF WEIGHTS, MARYLAND SCREENING I a

\begin{tabular}{lccccc}
\hline Person & Dr. Canham & Dr. Felleman & Dr. Massicot & Mr. Mueller & Mr. Voelker \\
\hline Dr. Canham & - & $0.672^{b}$ & -0.133 & -0.023 & -0.021 \\
Dr. Felleman & $0.869 \mathrm{~b}$ & - & -0.183 & 0.043 & 0.082 \\
Dr. Massicot & 0.182 & 0.227 & - & $0.783^{\mathrm{b}}$ & 0.272 \\
Mr. Mueller & 0.122 & 0.118 & $0.624 \mathrm{~b}$ & - & 0.272 \\
Mr. Voelker & 0.219 & 0.274 & -0.072 & -0.270 & -
\end{tabular}

aCorrelations in the upper-right hand half of the table are those between Rating weight sets. The lower-left hand half contains correlations between Indifference Tradeoff weight sets.

bCorrelation is significantly different from zero at a 0.05 level of confidence using a test described in Schefler (Note 17). That test is properly applicable only to correlations taken from randomly sampled bivariate populations. It is used here for lack of a better test.

In the statistical tests of this chapter, the average correlation between Rating weight sets is used as an indicator of influence of choice of person on weights. There are several reasons for using that statistic instead of the average correlation between IT weight sets:

1. Rating is the most common method.

2. $r_{i j}$ (IT) is not significantly different from $r_{i j(R)}$ using either the Student's $t$ test or a nonparametric test described by Snedecor. 19

3. Use of the mean of the $r_{i j}(R)^{\prime} s$ would be conservative, as it is lower, making it less likely that the null hypothesis of the statistical tests will be rejected.

Because the two means are not significantly different, it can be concluded that choice of person from among the five participants has, on the average, about the same effect on weights when Rating is used as when the IT approach is used.

Table 7

BETWEEN-METHODS CORRELATIONS OF WEIGHTS, MARYLAND SCREENING I

\begin{tabular}{lcc}
\hline & $\begin{array}{c}\text { Between Rating and } \\
\text { Person }\end{array}$ & $\begin{array}{c}\text { Between Indifference Tradeoff } \\
\text { and Churchman-Ackoff Methods }\end{array}$ \\
\hline Dr. Canham & 0.291 & - \\
Dr. Felleman & 0.283 & - \\
Dr. Massicot & 0.363 & $0.969 a$ \\
Mr. Mueller & 0.131 & $0.997 a$ \\
Mr. Voelker & 0.463 & - \\
acorrelation significantly different from zero at a 0.05 level of confidence, \\
usinga test described in Schefler (Note 17). \\
\hline
\end{tabular}


Table 8

DESCRIPTIVE STATISTICS OF GROUPS OF CORRELATIONS OF WEIGHTS, MARYLAND SCREENING I

\begin{tabular}{|c|c|c|c|c|c|}
\hline Group & Correlation & Mean & Number & $\begin{array}{c}\text { Degrees of } \\
\text { Freedom }\end{array}$ & Standard Deviation \\
\hline \multirow{5}{*}{$\begin{array}{l}\text { Between } R \text { and IT } \\
\text { Methods } \\
\text { Between IT and CA } \\
\text { Methods } \\
\text { Between Persons } \\
\text { (R Method) } \\
\text { Between IT Weight } \\
\text { Sets } \\
\text { Error }\end{array}$} & $r_{R} \cdot I T_{i}$ & 0.306 & 5 & 4 & 0.109 \\
\hline & $r_{I T} \cdot C A_{i}$ & 0.983 & 2 & 1 & 0.014 \\
\hline & $r_{i j}(R)$ & 0.176 & 10 & $4^{a}$ & 0.310 \\
\hline & $r_{i j}(I T)$ & $\begin{array}{l}0.230 \\
0.783\end{array}$ & $\begin{array}{r}10 \\
1\end{array}$ & $\begin{array}{l}4^{a} \\
0\end{array}$ & $\begin{array}{c}0.308 \\
0\end{array}$ \\
\hline & rMass-Muel1 & $\operatorname{er}(R)$ & & & \\
\hline
\end{tabular}

The nonparametric paired-observations test (Snedecor, Note 19) used above works as follows:

1. Samples $A$ and $B$ must consist of paired observations.

2. Count for how many pairs $A>B$, and for how many pairs $B>A$. Count ties as half a "win".

3. Calculate the Chi squared statistic with 2 degrees of freedom as follows:

$$
\chi^{2}=\frac{(a-b-1)^{2}}{n},
$$

where

$$
\begin{aligned}
& a=\text { the number of times } A>R, n r B>A, \text { whichever is larger. } \\
& b=\text { the number of times } A>B \text { or } B>A \text {, whichever is smaller. } \\
& n=\text { number of paired observations. }
\end{aligned}
$$

4. If the calculated $\chi^{2}$ is greater than the chosen critical value $\mathbf{3 . 8 4}$ at $\alpha=0.05 ; 6.635$ at $\alpha=0.01)$, then accept the hypothesis that the two samples are significantly different.

The two tailed Student's $t$ tests and nonparametric test show that:

1. $r_{i j}$ is not significantly different from $r_{R} \cdot I T_{j}$;

2. $r_{i j}$ is significantly less than $r_{I T} \cdot C A_{j}(t=3.50, p<0.025$, $d f=5)$, as is $r_{R} \cdot I T(t=8.29, p<0.001$, $d f=5)$; and

3. $r_{R} \cdot I T_{j}$ is significantly less than rMass.Mueller $(t=4.00$, $p<0.025, d f=4)$, while $r I T \cdot C A_{j}$ is slgniflcantly greater, $(t=11.67, p<0.1, d f=1)$. 
Only $t$ tests were used in comparisons 2 and 3 , as there are too few degrees of freedom to use the nonparametric test. These results lead to the following conclusions.

1. There is no significant difference between the average amount of variation in the weights due to choice between Rating and IT and that due to choice of person. The relative influences on final cell evaluations are, therefore, unlikely to be very different. (This is confirmed later in this chapter.)

2. Differences between IT weights and IT weights modified by the CA procedure $\left(r_{I T \cdot C A}\right)$ are significantly less than that due to choice of person, choice of method (between Rating and IT), and influence of mood and uncertainty.

3. Variation in weights due to the choice between the Rating and IT methods is significantly greater than the influence of mood and uncertainty. Therefore, choice of method will likely have more effect on cell evaluations than mood and uncertainty.

4. Choice of person will make more of a difference in weights than mood and uncertainty.

Comparison of the Variation of Rating and Indifference Tradeoff Weights

As explained above, if weight setters perceive importance in a logarithmic rather than linear fashion, then Rating will understate ratios of importance compared to the IT method. This is tested by comparing the coefficients of variation (CV) of each person's Rating weights with that of his IT weights. The variation of the IT weights is significantly greater $(p<0.5)$ than that of the Rating weights, as each person's IT CV is greater than the corresponding Rating CV. (For brevity, we do not display the calculated CVs.) Therefore, the hypothesis that people perceive value logarithically is not rejected. This means that Rating might choose weights that are not on a true ratio scale, and the method may understate ratios of importance of attributes.

Comparison of Indifference Tradeoff and Decision Analysis Weights

Decision Analysis (DA) weights are excluded from the correlation analyses just made. Instead, we compare the ratios of weights of each variable resulting from the Indifference Tradeoff (IT) and DA method for each individual (Table 9). The ratios show that the DA and IT methods are not precisely equivalent (that is, the DA weights will not be exactly proportional to the IT weights). Dr. Massicot's ratios differ strikingly, reflecting his difficulties in estimating probabilities. $\quad-36$ - 


\section{Table 9}

RATIOS OF WEIGHTS FOR DECISION ANALYSIS ATTRIBUTES, MARYLAND SCREENING I

\begin{tabular}{clcc}
\hline MAGI & & & \\
Variable \# & Variable & Dr. Massicot & Mr. Mueller \\
\hline 11 & Mineral Resources & 0.008 & 0.016 \\
36 & Endangered Species & 0.064 & 0.011 \\
45 & Proximity to Stream Flow & 0.010 & 0.010 \\
$35,40,42$ & "Population" (Combined) & 0.032 & 0.010 \\
\hline
\end{tabular}

The DA weights were used one at a time as a base for inferring weights, using the "indifference ratios" determined in the IT exercise. The sum of the weights in each case is given in Table 10. A sum greater than 1.0 indicates risk aversion; a sum less than 1.0 indicates risk seeking behavior; a sum of 1.0 indicates risk neutrality. Table 1.0 also shows these inferred attitudes toward risk.

The results displayed in Table 10 show that, depending on which variable is the base from which the other welghts are inferred, Dr. Massicot could be either risk seeking or highly risk averse. Mr. Mueller was more consistent, varying from slightly risk averse to risk averse. The variability in Dr. Massicot's results can be traced, in part, to his discomfort in working with hypothetical probabilities.

Table 10

RATIOS OF WEIGHTS FOR DECISION ANALYSIS ATTRIBUTES, MARYLAND SCREENING I

\begin{tabular}{|c|c|c|c|c|}
\hline Person & Attributes & $\begin{array}{c}\text { Decision } \\
\text { Analysis } \\
\text { Weight }\end{array}$ & $\begin{array}{l}\text { Inferred Sum } \\
\text { of Weights of } \\
\text { Al1 Attributes }\end{array}$ & $\begin{array}{c}\text { Inferred Attitude } \\
\text { Towards Risk } \\
\end{array}$ \\
\hline \multirow[t]{4}{*}{ Dr. Massicot } & $\begin{array}{l}\text { 11, Mineral } \\
\text { Resources }\end{array}$ & 0.1 & 0.693 & \multirow{4}{*}{$\begin{array}{l}\text { Risk Seeking } \\
\text { Extremely } \\
\text { Risk Averse } \\
\text { Slightly } \\
\text { Risk Seeking } \\
\text { Strongly } \\
\text { Risk Averse }\end{array}$} \\
\hline & $\begin{array}{l}\text { 36. Endangered } \\
\text { Species }\end{array}$ & 0.8 & 5.544 & \\
\hline & $\begin{array}{l}\text { 45. Proximity to } \\
\text { stream FLow }\end{array}$ & 0.1 & 0.866 & \\
\hline & $\begin{array}{l}35,40, \text { and } 42 . \\
\text { "Population" }\end{array}$ & 0.8 & 2.772 & \\
\hline \multirow[t]{4}{*}{ Mr. Mueller } & $\begin{array}{l}\text { 11. Mineral } \\
\text { Resources }\end{array}$ & 0.1 & 1.753 & Risk Averse \\
\hline & $\begin{array}{l}\text { 36. Endangered } \\
\text { Species }\end{array}$ & 0.1 & 1.169 & \multirow{3}{*}{$\begin{array}{l}\text { Slightly } \\
\text { Risk Averse } \\
\text { Slightly } \\
\text { Risk Averse } \\
\text { Slightly } \\
\text { Risk Averse }\end{array}$} \\
\hline & $\begin{array}{l}\text { 45. Proximity to } \\
\text { Stream Flow }\end{array}$ & 0.1 & 1.095 & \\
\hline & $\begin{array}{l}35,40, \text { and } 42 . \\
\text { "Population", }\end{array}$ & 0.25 & 1.095 & \\
\hline
\end{tabular}


The effect of the inconsistencies on cell suitability scores shown in Table 10 is discussed later in this chapter.

Candidate Area Definition

Figure 3 presents the Exclusionary Screening candidate areas derived from the criteria chosen by Mr. Mueller. Figures 4 and 5 display Rating and Indifference Tradeoff (IT) Weighting Summation areas chosen by Messrs. Mueller and Canham. The other six Summation areas are shown elsewhere. 19 The differences between Mr. Mueller's results are the smallest of the five pairs of Rating and IT sets. His Weighting Summation areas can also be compared with his Exclusionary Screening areas: Dr. Canham's results are at the other extreme: the differences between them are the largest from among the five pairs of Rating and IT sets. Figure 8 shows the areas passed by all 5 Rating weight sets.

Messrs. Mueller's and Canham's Power Law areas are shown in Figures 6 and 7. Both Rating and Indifference Tradeoff areas are included. Differences among these areas and between them and the Weighting Summation areas are representative. The other six sets of Power Law areas are not displayed here; they closely resemble those of Figures 6 and 7 .

No Decision Analysis multiplicative form areas are displayed, as the areas are almost identical. Even a change in risk attitude from risk seeking to strongly risk averse scarcely altered Dr. Massicot's areas. Thus, risk preferences are unimportant in this case, and one can use Weighting Summation (with IT weights); results will be the same as the multiplicative form.

\section{Analysis of Cell Suitability Scores and Candidate Areas}

Exclusionary Screening Versus Weighting Summation. A comparison of $\mathrm{Mr}$. Mueller's Exclusionary Screening areas (Figure 3) with his Weighting Summation areas (Figure 4) shows that the two decision rules choose strikingly different candidate areas. The differences are especially apparent in the western portion of the study area. Only 3.1\% (of a possible 9.5\%) of the area's cells pass all screens and are also in the top $9.5 \%$ of the Rating-Weighting Summation cells. The analogous number for Exclusionary Screening vs Indifference Tradeoff is 2.2\%. Furthemore, Exclusionary Screening eliminates most of the top $2 \%$ Weighting Summation areas. This means that the Exclusionary Screening makes tradeoffs among attributes that $\mathrm{Mr}$. Mueller would not make when presented with them directly. Superior areas (based on the tradeoffs he is willing to make) are prematurely screened. This conclusion can also be drawn from 


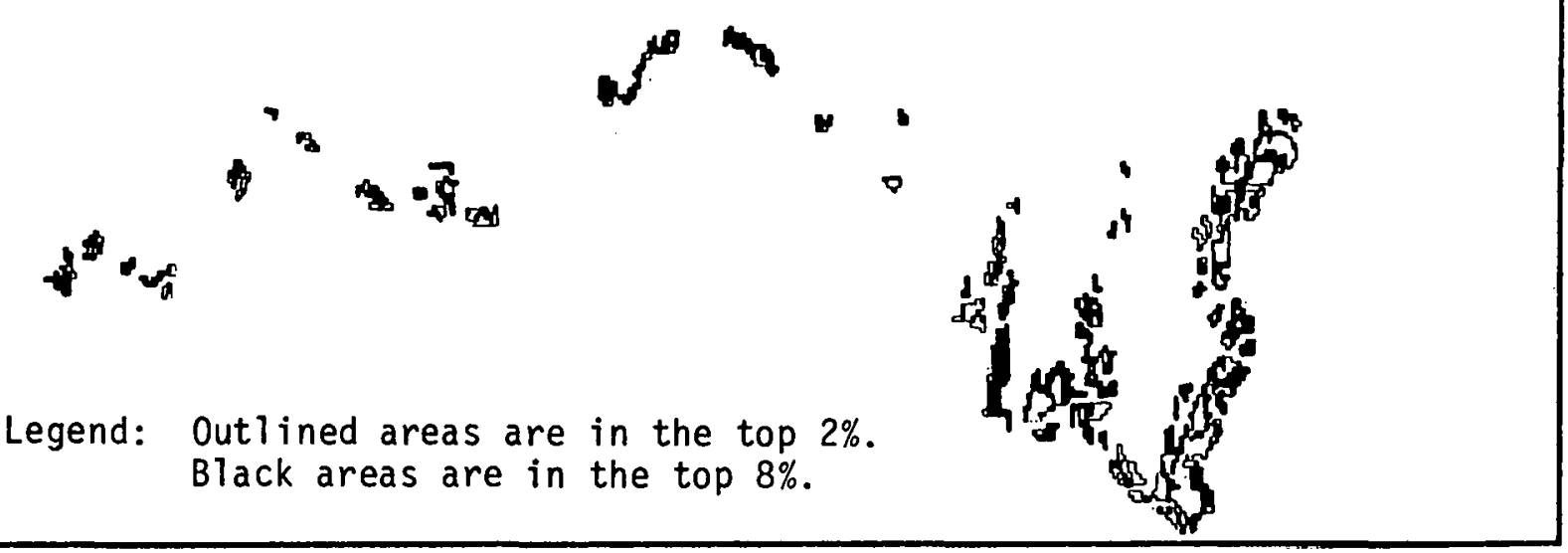

a. Rating Weighting Method

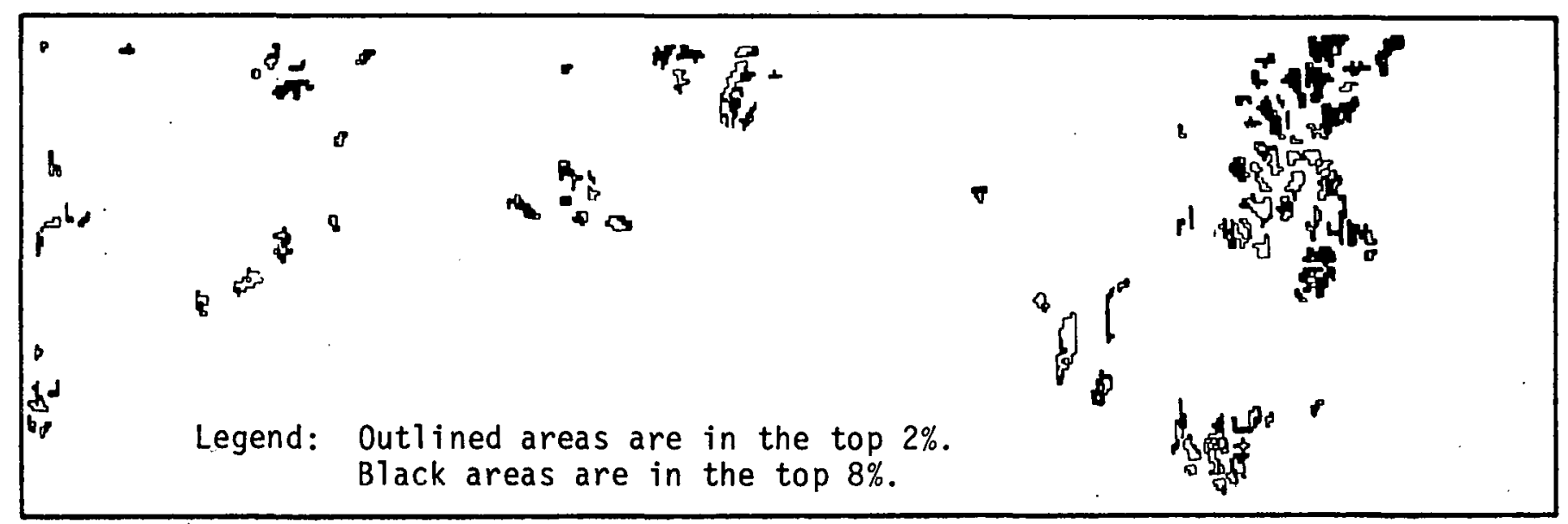

b. Indifference Tradeoff Weighting Methor

Figure 5. Weighting Summation Carididite Areas, Dr. Canham, Maryland Screening I.

Source: Hobbs, Note 20. 


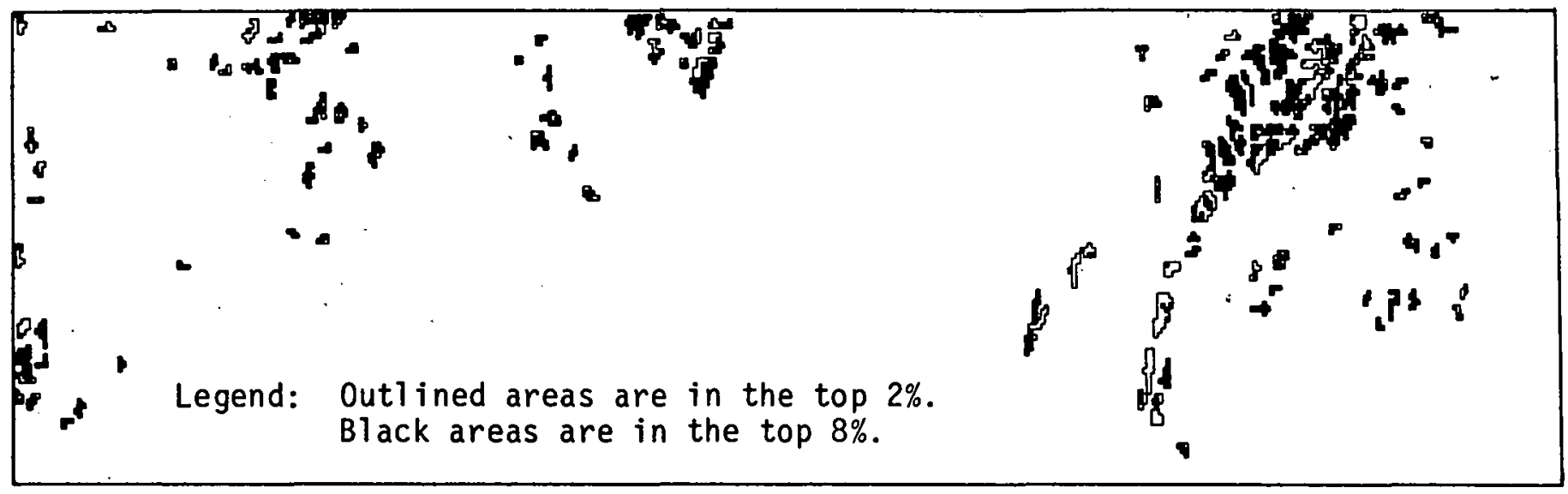

a. Rating Weighting Method

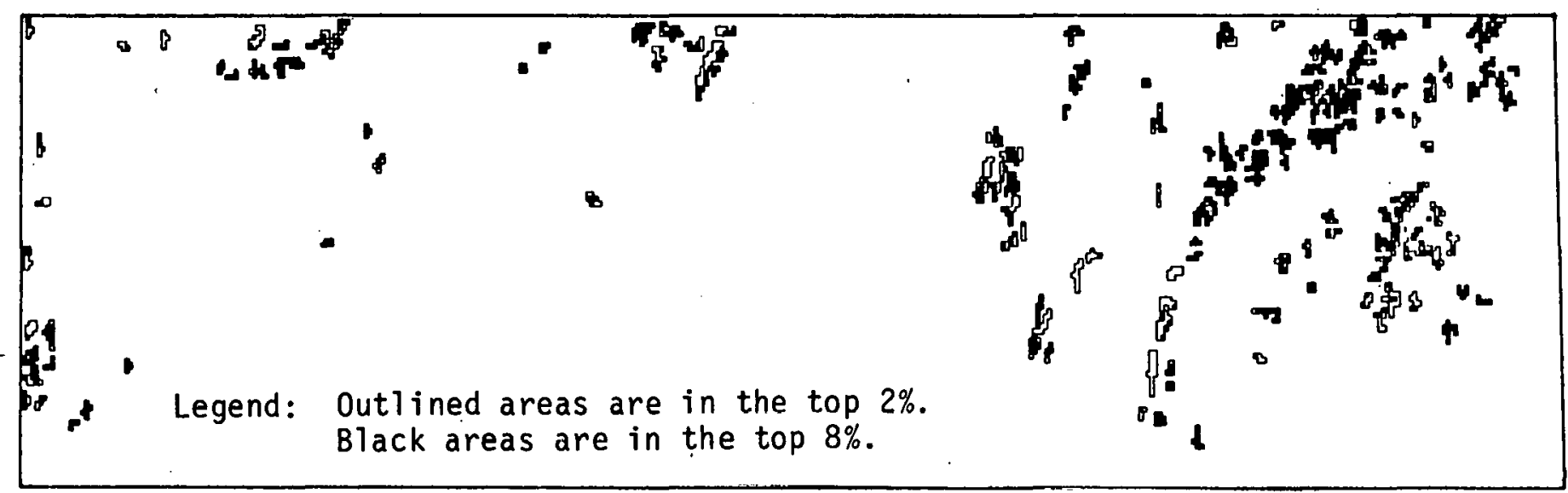

b. Indifference Tradeoff Weighting Method

Figure 6. Power Law Candidate Areas, Mr. Mueller, Maryland. Screening I. 


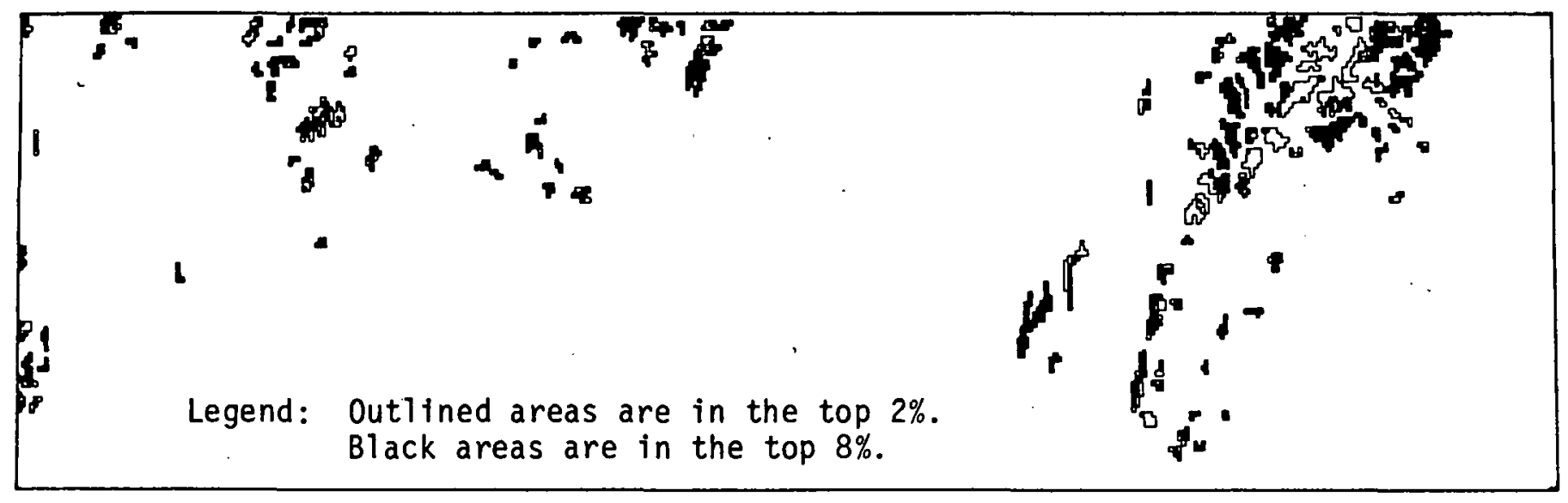

a. Rating Weighting Method

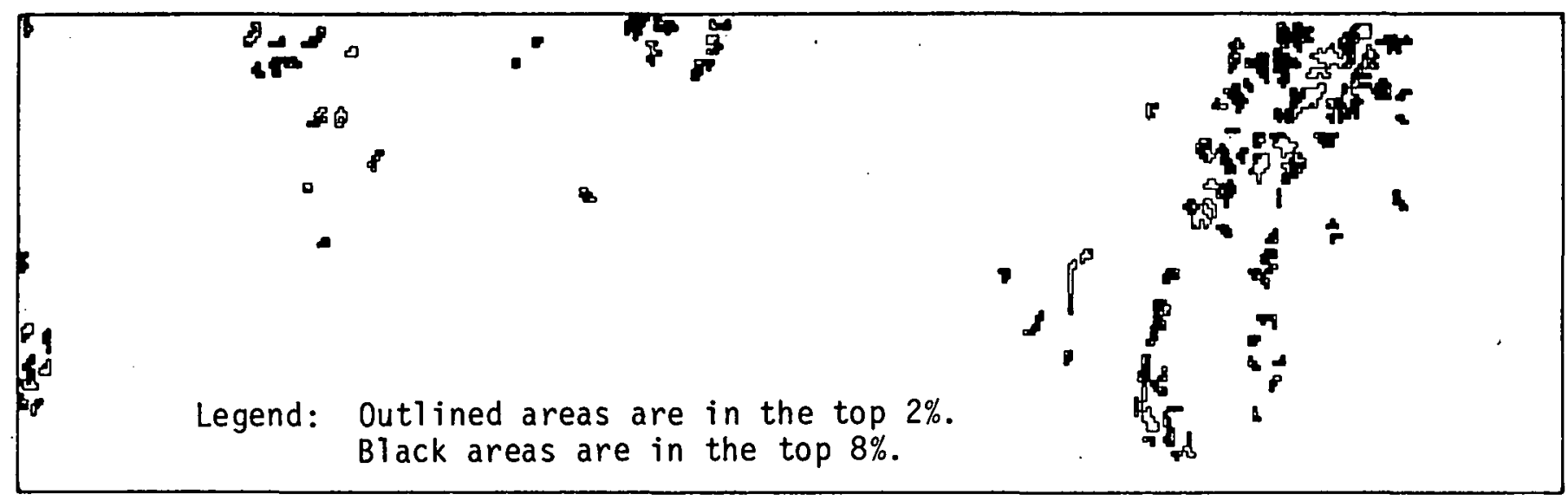

b. Indifference Tradeoff Weighting Method

Figure 7. Power Law Candidate Areas, Dr. Canham, Maryland Screening I. 
Table 11

BETWEEN-PERSONS CORRELATIONS OF CELL SUITABILITY SCORES, MARYLAND SCREENING I

\begin{tabular}{lcccc}
\hline Person & Dr. Felleman & Dr. Massicot & Dr. Mueller & Mr. Voelker \\
\hline Dr. Canaham & 0.900 & 0.757 & 0.790 & 0.785 \\
Dr. Felleman & - & 0.646 & 0.756 & 0.726 \\
Dr. Massicot & - & - & 0.940 & 0.729 \\
Mr. Mueller & - & - & - & 0.734 \\
\hline
\end{tabular}

Table 12

BETWEEN-METHODS CORRELATIONS OF CELL SUITABILITY SCORES, MARYLAND SCREENING I

\begin{tabular}{lcc}
\hline Person & Between R and IT Methods & Between IT and CA Methods \\
\hline Dr. Canham & 0.678 & - \\
Dr. Fell eman & 0.670 & - \\
Dr. Massicot & 0.781 & 0.984 \\
Mr. Mueller & 0.852 & 0.997 \\
Mr. Voelker & 0.891 & - \\
\hline
\end{tabular}

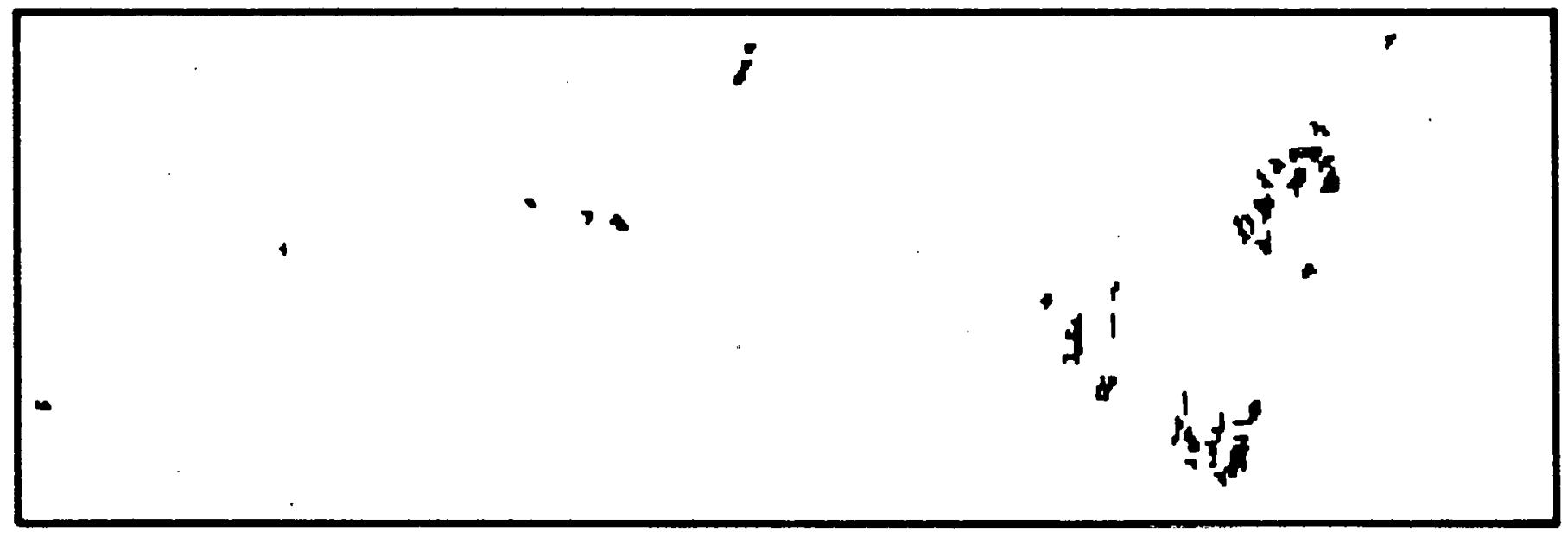

Figure 8 . Top $8 \%$ of Cells Shared by All Five Rating-Weighting Summation Candidate Areas, Maryland Screening I.

Source: Hobbs, Note 19. 
All correlations in Tables 11 and 12 are significantly different from zero at the 0.001 level of confidence (number of cells $=17,431$ ). Comparison of these tables with Tables 6 and 7 shows that relatively highly correlated pairs of weight sets also have the highest correlations between sets of suitability scores. The correlation between the two sets of correlations is 0.803. Thus, the more similar the weights, the closer the correspondence between the orderings of suitability scores. Correlations between suitability scores are much higher than those between weight sets. There are four negative correlations between Rating weight sets, while sets of suitability scores derived from those weights all show high positive correlations. This indicates a partial ordering of cells in the sense that some cells are better in most variables than other cells. This is not surprising. A cell in a mountain forest, far from highways and water, is likely to be less attractive under most weight sets than a cell containing agricultural land in a river valley.

Table 13 presents descriptive statistics for each group of correlations. The results of the statistical tests are similar to those of the tests of correlations between weight sets presented above. The conclusions stated in that subsection are therefore confirmed. To reiterate them:

1. Differences between Rating and IT results are not significantly larger or smaller than the difference in results between persons.

2. Differences between IT results and IT results as modified by the Churchman-Ackoff procedure (CA) are significantly. less than the differences between results from different persons $(t=3.456, p<0.025$, $d f=5$ ) and different weighting methods (Rating versus IT: $t=3.232$, $p<0.025, d f=5)$.

3. Mood and uncertainty make significantly less difference in results than choice between Rating and IT $(t=1.736, p<0.1$ [one tailed test], $\dot{d f}=4)$, but it makes significantly more difference than the choice between IT and IT weights modified by $C A(t=-7.355, p<0.1, d f=1)$.

Two tailed Student's $t$ tests are used in all but one case, as noted above.

The same statistical tests were also made using proportions of overlap of candidate areas. Table 14 displays between-persons proportions of overlap, and Table 15 presents between - weighting methods overlaps. Proportions of overlap between Indifference Tradeoff and Churchman-Ackoff area sets were not calculated, as each person's pair of sets is nearly identical. Descriptive statistics for each group of proportions of overlap are presented in Table 16. 
Table 13

DESCRIPTIVE STATISTICS OF GROUPS OF CORRELATIONS BETWEEN WEIGHTING SUMMATION SUITABILITY SCORES, MARYLAND SCREENING I ${ }^{\mathrm{a}}$

\begin{tabular}{|c|c|c|c|c|c|}
\hline Group & Correlation & Mean & Number & $\begin{array}{c}\text { Degrees of } \\
\text { Freedom }\end{array}$ & $\begin{array}{l}\text { Standard } \\
\text { Deviation }\end{array}$ \\
\hline \multirow{4}{*}{$\begin{array}{l}\text { Between } R \text { and } \\
\text { IT Methods } \\
\text { Between IT and } \\
\text { CA Methods } \\
\text { Between Persons } \\
\text { (R Method) } \\
\text { Mood and } \\
\text { Uncertainty }\end{array}$} & $r^{\star} R \cdot I T_{j}$ & 0.774 & 5 & 4 & 0.089 \\
\hline & $r^{\star} I T \cdot C A_{i}$ & 0.990 & 2 & 1 & 0.007 \\
\hline & $r^{\star} i j$ & 0.776 & 10 & $4^{b}$ & 0.082 \\
\hline & $r^{\star}$ Mass-Muel & 0.940 & 1 & 0 & 0 \\
\hline \multicolumn{6}{|c|}{$\begin{aligned} & \mathrm{a} R=\text { Rating } \\
& \mathrm{IT}=\text { Indifference Tradeoff Method } \\
& \mathrm{CA}=\text { Churchman-Ackoff Method } \\
& \mathrm{b} \text { Correlations are calculated from on }\end{aligned}$} \\
\hline
\end{tabular}

Table 14

BETWEEN-PERSONS PROPORTIONS OF OVERLAP OF CANDIDATE AREAS, MARYLAND SCREENING Ia

\begin{tabular}{lccccc}
\hline \multicolumn{1}{c}{ Person } & Dr. Canham & Dr. Felleman & Dr. Massicot & Mr. Mueller & Mr. Voelker \\
\hline Dr. Canham & - & 0.0674 & 0.0449 & 0.0507 & 0.0394 \\
Dr. Felleman & 0.0138 & - & 0.0360 & 0.0502 & 0.0365 \\
Dr. Massicot & 0.0107 & 0.0107 & - & 0.0629 & 0.0527 \\
Mr. Mueller & 0.0132 & 0.0127 & 0.0138 & - & 0.0505 \\
Mr. Voelker & 0.0090 & 0.0106 & 0.0099 & 0.0096 & -
\end{tabular}

aThe upper right half of the table shows proportion of cells in the study area contained in both person's top $8 \%$ Rating Weighting Summation cells. Maximum possible proportion is 0.08 . The lower left half shows the proportion of cells containing both person's top $2 \%$ cells. Maximum possible proportion is 0.02 . 


\section{Table 15}

BETWEEN-RATING AND INDIFFERENCE TRADEOFF PROPORTIONS OF OVERLAP OF CANDIDATE AREAS, MARYLAND SCREENING I

\begin{tabular}{lcc}
\hline & $\begin{array}{c}\text { Proportion of Cells } \\
\text { Scoring in top } \\
\text { 2\% by both } \\
\text { Methodsa }\end{array}$ & $\begin{array}{c}\text { Proportion of Cells } \\
\text { Scoring in top } \\
8 \% \text { by both } \\
\text { Methods }\end{array}$ \\
\hline Dr. Canham & 0.0097 & 0.0310 \\
Dr. Felleman & 0.0093 & 0.0264 \\
Dr. Massicot & 0.0021 & 0.0420 \\
Mr. Mueller & 0.0095 & 0.0551 \\
Mr. Voelker & 0.0124 & 0.0531 \\
Mean & 0.0086 & 0.0415 \\
aMaximum possible is 0.02. & & \\
bMaximum possible is 0.08. & & \\
\hline
\end{tabular}

Table 16

DESCRIPTIVE STATISTICS OF GROUPS OF PROPORTIONS OF OVERLAP OF CANDIDATE AREAS, MARYLAND SCREENING Ia

\begin{tabular}{|c|c|c|c|c|c|c|}
\hline Group & $\begin{array}{c}\text { Mean Proportion } \\
2 \% \text { cutoff }\end{array}$ & $\begin{array}{l}\text { of Cells } \\
8 \% \text { cutoff }\end{array}$ & $\begin{array}{l}\text { Standa } \\
2 \% \text { cut }\end{array}$ & $\begin{array}{l}\text { Deviation } \\
8 \% \text { cutoff }\end{array}$ & Number & $\begin{array}{l}\text { Degrees } \\
\text { of } \\
\text { Freedom }\end{array}$ \\
\hline \multirow{3}{*}{$\begin{array}{l}\text { Between } R \text { and } \\
\text { IT Methods } \\
\text { Between Persons } \\
\text { (R Methods) } \\
\text { Mood and } \\
\text { Uncertainty }\end{array}$} & 0.0086 & 0.0415 & 0.0034 & 0.0115 & 5 & 4 \\
\hline & 0.0114 & 0.0492 & 0.0017 & 0.0099 & 10 & $4^{c}$ \\
\hline & 0.0138 & 0.0629 & 0 & 0 & 1 & 0 \\
\hline \multicolumn{7}{|c|}{$\begin{array}{l}a_{R}=\text { Rating } \\
I T=\text { Indifference Tradeoff Method } \\
\text { Suitability scores are calculated using Weighting Summation } \\
\text { bAverage proportion of cells in study area scoring in the top } 2 \% \text { or } 8 \% \text { of } \\
\text { both suitability score sets. } \\
\text { conly } 5 \text { sets of scores were used to calculate proportions of overlap. }\end{array}$} \\
\hline
\end{tabular}


Neither two-tailed Student's $t$ test nor the nonparametric test reveals a significant $(\alpha=0.1)$ difference between the between-persons and the betweenmethods (Rating and IT) proportions of overlap (for either the $8 \%$ or $2 \%$ cutoffs). Hence, choice of weighting method (Rating versus IT) makes about as much difference in candidate areas as choice of person. Note, however, that both (2\% and $8 \%$ ) between methods mean proportions of overlap are still less than the between-persons means.

The proportions of overlap between Dr. Massicot's and Mr. Mueller's $2 \%$ and $8 \%$ areas are indicators of influence of mood and uncertainty on candidate areas. By a one-tailed Student's $t$ test $(t=1.7, p<0.1)$, mood and uncertainty have significantly less influence on the $8 \%$ candidate areas than choice of weighting summation (Rating versus IT). Hence, comparisons of proportions of overlap confirm the conclusion that mood and uncertainty are less important than choice of method between Rating and IT. This difference is insignificant for the $2 \%$ cutoff.

Power Law Versus Weighting Summation. Even with the same set of weights, the Power Law can pick different candidate areas from Weighting Summation (Figures 4 through 7 ). These figures also show that Power Law areas from different weights differ less among themselves than do Weighting Summation areas. Figure 9 offers one possible explanation. Figure 9a shows Power Law indifference curves resulting from each of two different sets of weights; Figure 9b displays Weighting Summation "curves" (actually straight lines) from the same weight sets. Each curve is an $8 \%$ cutoff for candidate areas -- only cells above and to the right are in candidate areas. The figure is drawn so that the same area is selected by each of the four curves. Only cells below and to the left of the noninferior curve are feasible. Note that there is more overlap of the two areas selected by the Power Law than of the areas selected by Weighting Summation. This is due to the shape of the Power Law indifference curves, which favor cells with fair values in both attributes over cells with one good value and one bad value. Thus, Power Law models having different weights are more likely to select the same locations than Weighting Summation models having different weights.

Table 17 presents correlation and proportions of overlap for each pair of Power Law and Weighting Summation suitability score sets. The modified White's nonparametric test shows no significant difference between correlations between suitability scores (or proportions of overlap) and those between 
Table 17

POWER LAW AND WEIGHTING SUMMATION CORRELATIONS AND PROPORTIONS OF OVERLAP OF CANDIDATE AREAS, MARYLAND SCREENING I

\begin{tabular}{|c|c|c|c|c|}
\hline Participant & $\begin{array}{l}\text { Weighting } \\
\text { Me thod }\end{array}$ & $\begin{array}{l}\text { Correlation } \\
\text { Between } \\
\text { Suitability } \\
\text { Scores }\end{array}$ & $\begin{array}{l}\text { Proportion of } \\
\text { Cells Scoring in } \\
\text { Top } 2 \% \text { by Both } \\
\text { Decision Rules }\end{array}$ & $\begin{array}{l}\text { Proportion of } \\
\text { Cells Scoring in } \\
\text { Top } 8 \% \text { by Both } \\
\text { Decision Rules }\end{array}$ \\
\hline $\begin{array}{l}\text { Dr. Canham } \\
\text { Dr. Canham } \\
\text { Dr. Felleman } \\
\text { Dr. Felleman } \\
\text { Dr. Massicot } \\
\text { Dr. Massicot } \\
\text { Mr. Mueller } \\
\text { Mr. Mueller } \\
\text { Mr. Voelker } \\
\text { Mr. Voelker }\end{array}$ & $\begin{array}{l}\text { Rating } \\
\text { ITa } \\
\text { Rating } \\
\text { IT } \\
\text { Rating } \\
\text { IT } \\
\text { Rating } \\
\text { IT } \\
\text { Rating } \\
\text { IT }\end{array}$ & $\begin{array}{l}0.817 \\
0.393 \\
0.640 \\
0.446 \\
0.855 \\
0.830 \\
0.863 \\
0.864 \\
0.226 \\
0.616 \\
\end{array}$ & $\begin{array}{l}0.0071 \\
0.0038 \\
0.0034 \\
0.0054 \\
0.0043 \\
0.0093 \\
0.0053 \\
0.0047 \\
0.0049 \\
0.0062 \\
\end{array}$ & $\begin{array}{l}0.0478 \\
0.0147 \\
0.0146 \\
0.0433 \\
0.0292 \\
0.0339 \\
0.0301 \\
0.0353 \\
0.0219 \\
0.0251 \\
\end{array}$ \\
\hline Mean & & 0.655 & 0.0054 & 0.0296 \\
\hline \multicolumn{5}{|c|}{$\begin{array}{l}\text { alndifference Tradeoff. } \\
\text { bMaximum possible is } 0.02 \text {. } \\
\text { cMaximum possible is } 0.08 \text {. }\end{array}$} \\
\hline
\end{tabular}

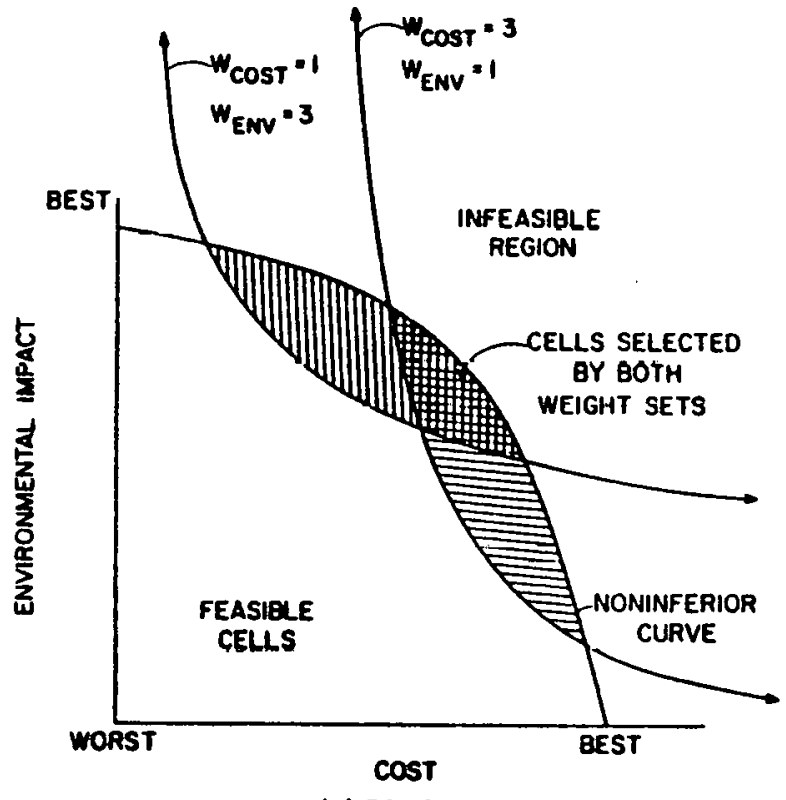

(a) POWEA LAW

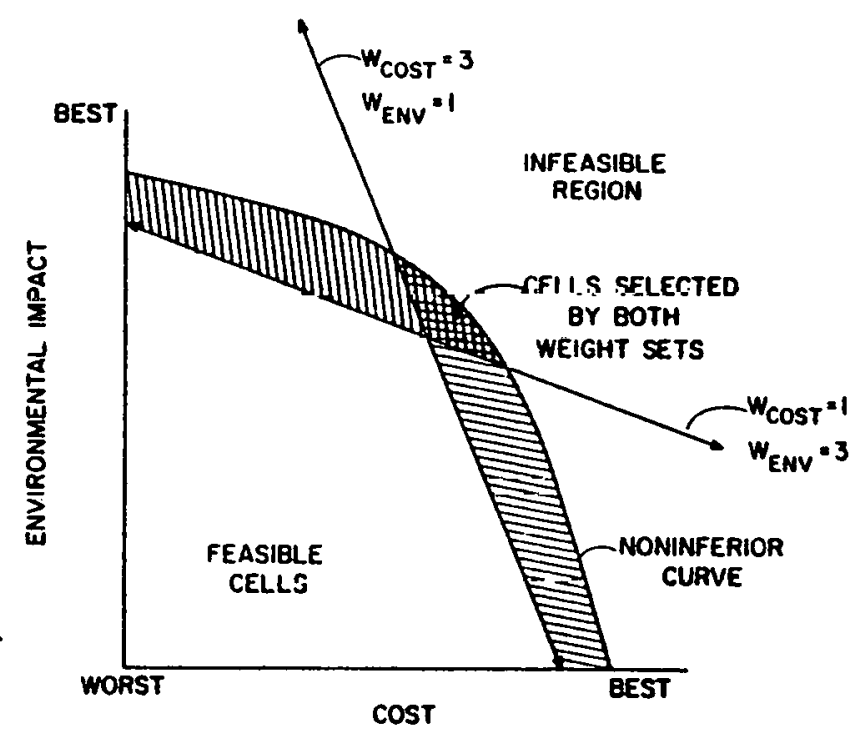

(b) WEIGHTING SUMMation

Figure 9. Cells Selected by Power Law and Weighting Sumation. 
persons (using Weighting Summation with Rating Weights); however, a two-tailed Student's $t$ test shows that choice of decision rule makes significantly more of a difference in candidate areas than choice of person. For the $8 \%$ cells $t$ $=3.459(p<0.005, d f=13)$ and for the $2 \%$ cutoff, $t=6.517(p<0.001)$. The $t$ test is unable to distinguish between the between - decision rules and between-persons (Table 11) correlations.

Furthermore, one-tailed Student's $t$ tests show that choice of decision rule has a greater influence on candidate areas than mood and uncertainty (as measured by the overlap of Dr. Massicot's and Mr. Mueller's areas). The $t$ statistic for the top $8 \%$ cells is $3.03(p<0.01$, df $=9)$ and for the $2 \%$ cutoff, it is $4.89(p<0.0005)$. The mood and uncertainty correlation $(0.94)$ could not be distinguished by a $t$ test from the between-decision rules correlations.

We also compared between - weighting methods (Tables 14 through 16) and the between - decision rules (Table 17) results using two-tailed Student's $t$ tests. Choice of decision rule influences candidate areas more than does choice between Rating and the Indifference Tradeoff weighting method (using Weighting Summation). For the $8 \%$ cutoff, the $t$ statistic is $2.02(p<0.1$, df $=$ $13)$, and it is $2.45 \quad(p<0.05)$ for the $2 \%$ cells. This conclusion would also hold if the between - weighting methods fractions are calculated with Power Law rather than Weighting Summation areas, because Power Law areas agree more among themselves than do Weighting Summation areas (with the same weights), as explained above.

Decision Analysis Multiplicative Form Versus Weighting Summation. None of the Decision Analysis candidate area sets are shown, as they are nearly identical to weighting summation areas with the same weights. Correlations are near 1.0; overlaps are almost complete.

Significance of Differences in Candidate Areas. Although different decision rules and different weighting methods can select different candidate areas, this does not mean that the quality of the final siting decision must necessarily be different. It may not even mean that the quality of the candidate areas necessarily differs. The primary function of screening is to reduce the magnitude of data gathering, etc. required of the following stage of the process, candidate site selection, by using a relatively small amount of information to remove from consideration a large portion of the total area. One tries also to conduct screening so as to select candidate areas having high probability of containing "good" sites, however "good" is defined. The 
success of, screening in selecting candidate areas having high probability of containing "good" sites depends on the extent to which the attributes used capture characteristics of primary importance to siting in the region. Exclusionary Screening based on legal and engineering restrictions clearly meets this requirement. However good a site may be with respect to other attributes, if it does not meet minimum legal or engineering requirements it will be impossible to license. There is no justification for wasting time and money evaluating such areas. If discretionary attributes are used, however, the success of screening, either Exclusionary or Weighting Summation, depends first on the skill of the site evaluation team in identifying "good" candidate sites within candidate areas, and second on relationships between the attributes selected for screening and the attributes selected for site evaluation. If the attributes selected for screening are of highest importance to final site evaluation, then it is reasonable to expect that there will be few areas containing "good" sites which do not also meet these important screening criteria. If, instead, the attributes selected are discretionary and of medium importance to final site evaluation (compared to other attributes included later in the siting process), or if regional level data on important attributes are of relatively poor quality, then it is much more likely that the distribution of "good" sites will be relatively independent of the distribution of the candidate areas. In this case, the relative success of screening in selecting areas having high probability of containing "good" sites depends on the spatial correlation between the attributes included at each stage. High spatial correlation among attribute values increases the likely success of the screening stage, whatever screening criteria are used.

It is the nature of attributes important to siting that they tend to be correlated, either positively or negatively. Mountains tend to be remote from load centers, low in water supply, and high in potential environmental impacts; large demand centers (high population densities) tend to be located along large supplies of water; etc. Given knowledge of the correlations among siting attributes in a region, it is possible, therefore, to select discretionary screening attributes that are not only. important to final site evaluation, but also highly correlated with other important siting considerations. Such a scheme would maximize the effectiveness of screening.

Note that even under the worst conditions in which all siting attributes are uncorrelated and "good" sites are randomly distributed over the region 
under consideration, the quality of the resulting final siting decision is not necessarily decreased. Under this condition, after exclusion of areas not meeting nondiscretionary criteria, screening based on discretionary criteria fulfills only its function of reducing effort required in following stages by reducing the area under consideration. All discretionary areas are equally likely to contain "good" sites. The quality of the final decision in such a case depends entirely on the skill with which the site evaluation team selects candidate sites. If they are able to find a reasonable number of "good" candidates, then the quality of the resulting site decision is nearly assured. If they select inferior candidate sites, then no amount of skillfully designed methodology can yield a "good" result.

CONCLUSIONS

It must be stressed that the estimates made here of the relative importance of different influences in weight selection are specific to this study. A different sample of people might have produced much greater or less agreement in weights, although the agreement was about the same as in other studies. A better data base and more knowledge on the part of the participants would lessen the effect of mood and uncertainty. If the individual is told little about the attributes being weighted, the "error term" can overwhelm all other influences. The outcome of this analyses is most applicable to regional studies that involve many alternatives and attributes, and in which "experts" determine weights. Where more public input is used, where sites and/or attributes are few, or where the data base (and the participants' knowledge of it) is of much different quality, the conclusions of this research will be less relevant.

1. Exclusionary Screening and Weighting Summation choose different candidate areas. Less than a third of one's areas are included in the other's. Hence, in this case, exclusionary criteria imply tradeoffs that the decision makers would not approve if presented with them directly. These tradeoffs are not considered when setting criteria.

2. Choosing weights by Rating is easier than by the Indifference Tradeoff method; the latter method forces decision makers to make and double check direct tradeoffs among attributes. Two participants believed that such tradeoffs should be considered in selecting weights for regional screening, but the other three participants disagreed, preferring the easier technique. No one preferred either the Churcman-Ackoff or the Decision Analysis weighting method. 
3. Correlations among different persons' Rating weights are statistical- ly indistinguishable from correlations between each person's Rating and Indifference tradeoff weights. Thus choice between these two weighting methods makes about as much difference in weights as choice of person (from among our limited sample). Most correlations are very low (more than half are below 0.25). Both choice of method and choice of person have more impact on weights than the mood and uncertainty of the weight setter alone (as estimated by the correlation between the two Maryland Power Plant Siting Project Personnel Rating weight sets).

This conclusion regarding relative influence of choice of weighting method, choice of person, and mood and uncertainty is confimed by analysis of weighting summation suitability scores resulting from the weight sets. Analyses used both correlations of suitability scores and fractions of overlap of candidate areas. Candidate areas chosen by different techniques or persons usually differ strikingly. On the average, only half of the cells scoring in the top $8 \%$ of a person's Rating evaluations also scored in the top $8 \%$ of his Indifferent Tradeoff evaluations.

The conclusion is that one should make sure that weights have the characteristics necessary for valid use of Weighting Summation. Weighting methods that produce a ratio scale and the correct type of importance can choose drastically different weights and candidate areas from techniqes that do not.

4. The Churcman-Ack off method, when applied to Indifference Tradeoff weights, produces weights that are almost identical to the original ones. Both methods choose theoretically valid weights (see Appendix 1).

5. Rating weights have less variation among themselves than Indifference Tradeoff weights. This is consistent with a hypothesis that logarithic perception of value distorts Rating weights more than Indifference Tradeoff weights.

6. The Indifference Tradeoff and Decision Analysis weighting methods did not choose weights that are proportional one to another, even though both methods, in theory, choose valid weights. A reason for this, is that the weight assessers had difficulty handling Decision Analysis probabilities. This produces Decision Analysis multiplicative decision rules whose degree and even type of risk attitudes depend on which attribute is chosen for the Decision Analysis lottery question. 
7. Power Law and Weighting Summation suitability scores and candidate areas differ more than do Weighting Summation scores and areas chosen by dif- ferent persons or weighting methods. On the average, less than half of the cells picked by one decision rule are chosen by the other. Hence, users of either method should give some thought to their underlying assumptions.

8. Power Law candidate areas from different weight sets overlap more than do Weighting Summation areas from different sets. This is because the former decision rule favors cells with moderately good values in all attributes over cells with both very good and very bad levels.

9. Degree of risk aversion or preference does not significantly affect candidate areas in the Decision Analysis multiplicative form. The simpler Weighting Summation form chooses essentially the same areas (given the same weights and attribute value functions); therefore, there is no reason to use the more complex multiplicative form for regional screening with this many variables. Weighting Summation avoids use of the difficult Decision Analysis lottery method of weighting. The Indifferent Tradeoff or Churchman-Ackoff methods should, however, be used to choose weights to assure a valid Weighting Summation model.

10. Differences in candidate areas selected by different decision rules or weighting methods do not necessarily imply differences in quality of candidate areas or in quality of the candidate sites or the final site decisions which follow. The success with which screening achieves its goal of identifying areas having high probability of containing "good" sites can depend, in part, on conditions that are not included in the screening process. 
1. B. F. Hobbs, Power Plant Siting and the Weighting Summation Method of Decision Making, M.S. Thesis, State University of New York, College of Enviromental Science and Forestry, Syracuse, New York, 1978.

2. J. E. Dobson, The Maryland Power Plant Siting Project: An Application of the ORNL-Land Use Screening Procedure, ORNL/NUREG/TM-79, Oak Ridge National Laboratory, 1976.

3. An overview of the MAGI system is contained in Maryland Department of State Planning, MAGI-Maryland Automated Geographic Information System, Publication \#349, Baltimore, Maryland, Jan. 1979. A detailed summary of the information contained and the relevence to siting of each of MAGI's variables and those encoded by Oak Ridge National Laboratory is in $B$. $F$. Hobbs, Description of Variables within the Maryland Automated Geographic Information System (MAGI), Informal Report, Maryland Power Plant Siting Program, Annapolis, Maryland, Aug. 5, 1977.

4. See Note 3 and Maryland Department of State Planning, Maryland Automated Geographic Information System, Technical Series \#207, Baltimore, MaryTand, 1974.

5. J. S. Jalbert and J. E. Dobson, A Cell Based Load Use Screening Procedure for Regional Siting Analysis, ORNL/NUREG/TM-80, Oak Ridge National Laboratory, 1979.

6. B. F. Hobbs, op. cit.

7. Rogers and Golden and Allan Mallach Associates, Eastern Shore Power Plant Siting Study, Maryland Major Facilities Study, Vol. 2, PPSA-4, prepared for the Maryland Power Plant Siting Program, Annapolis, Maryland, 1977.

8. This list of influences is similar to that of Edwards (W. Edwards, Social utflities, Proc. Symp., U.S. Naval Acad., Annapolis, Maryland, 1971), who says that "utility" is a function of three basic elements:
a. the evaluator;
b. the purpose for which the evaluation is made; and
c. the alternative being evaluated.

9. C. White, The use of ranks in a test of significance for comparing two treatments," Biometric Bul1. 8, 33-41 (1952).

10. B. F. Hobbs, op. cit.

11. S. S. Stevens, on the operation known as judgment, Am. Sci., 54(4), 385-401 (1966).

12. R. L. Gum, R. G. Roefs, and D. B. Kimball, Quantifying social goals: Development of a weighting methodology, Water Resources Res., 12(4), 617$622(1976)$. 
13. B. F. Hobbs, Analytical Multiobjective Decision Methods for Power Plant Siting: A Review of Theory and Applications, BNL-NUREG 51205, Brookhaven National Laboratory, 1979.

14. S. S. Stevens, on the theory of scales of measurement, Science 103(2684), 677-680 (1946).

15. Rogers and Golden and Allan Mallach/Associates, op. cit.

16. Rogers and Golden, The Development and Application of a Methodology for the Identification of Potential Major Facility Sites in Maryland's Coastal Counties, A Proposal to the Maryland Energy and Coastal Zone Administration, Philadelphia, Pennsylvania, 1976.

17. W. C. Schefler, Statistics for the Biological Sciences, Addison-Wesley, Reading, Massachusetts, 1969.

18. See studies summarized in Section 6.11 of B. F. Hobbs, Analytical Multiobjective Decision Methods for Power Plant Siting: A Review of Theory and Applications, op. cit.

19. G. W. Snedecor, Statistical Methods Applied to Experiments in Agriculture and Biology, Section 5.8, Iowa State Univ. Press, Ames, Iowa, 1956.

20. B. F. Hobbs, Power Plant Siting and the Weighting Summation Method of Decision Making, op. cit.

21. R. L. Keeney, C. W. Kirkwood, et a1., An Evaluation and Comparison of Nuclear Power Plant Siting Methodologies, NUREG/CR-0407, SAND-78-1284, Sandia, March 1977. 
Chapter 3

WESTERN MARYLAND ANALYSIS II

This chapter describes work undertaken at Brookhaven National Laboratory in 1979. Fourteen siting experts chose weights by three methods, and also selected exclusionary criteria. One of the three methods produces ratio scaled weights, but none assures weights with the correct type of importance (see Appendix 1). Candidate areas for a pair of 1000-MW(e) nuclear plants with evaporative cooling towers were generated using the Exclusionary Screening andweighting Summation decision rules.

\section{ATTRIBUTES AND VALUE FUNCTIONS}

The study area and MAGI data base described in Chapter 2 are also used here, but a different subset of attributes is included. Participants studied descriptions of MAGI variables 1 and selected those they considered appropriate for regional screening. Variables chosen by a majority of participants are included in this analysis (Table 18). Note that there are about half as many as in Chapter 2. The attributes "1980 County Plans (Primary)" and "Seismicity" are excluded in Chapter 2 because of data quality problems, 2 but are included here because of their general relevance to regional screening. The Oak Ridge seismicity attribute is discarded in favor of a seismicity variable created for this study. The new variable indicates areas close to faults (all nonactive) and observed earthquake epicenters on the basis of information used in a study of Nuclear Energy Center issues. 3 Data on relative difficulty of establishing seismic suitability are also considered. 4

The value functions for attributes other than seismicity and 1980 County Plans (Primary) are those used in Chapter 2 (Table 2), modified by substitution of " 0 " for "EXCLUDE" in most variables. The value function for 1980 County Plans (Primary) resembles that for Land Use and Land Cover (Primary). The seismicity value function is based on judgment of the relative difficulty of establishing that a site is seismically suitable. 
Table 18

VALUE FUNCTIONS, MARYLAND SCREENING II

\begin{tabular}{|c|c|c|}
\hline $\begin{array}{c}\text { MAGI } \\
\text { Variable \#a }\end{array}$ & Variable Name/Category & Value \\
\hline 9,10 & $\begin{array}{l}\text { STATE AND FEDERAL LAND } \\
\text { (PRIMARY AND SECONDARY) } \\
\text { None } \\
\text { Maryl and Dept. of Forests and Parks } \\
\text { Maryl and Dept. of Fish and Wildlife } \\
\text { Other State of Maryland } \\
\text { All Federal Government Categories } \\
\text { Municipal Ownership }\end{array}$ & $\begin{array}{r}10 \\
0 \\
0 \\
5 \\
0 \\
0\end{array}$ \\
\hline 23 & $\begin{array}{l}\text { HISTORIC SITES } \\
\text { None in Cell } \\
\text { One or more in Cell }\end{array}$ & $\begin{array}{r}10 \\
0\end{array}$ \\
\hline 26 & $\begin{array}{l}\text { LAND USE AND LAND COVER (PRIMARY) } \\
\text { Residential } \\
\text { Commercial } \\
\text { Industrial } \\
\text { Extractive } \\
\text { Transportation, Communication, Utilities } \\
\text { Institutional } \\
\text { Strip and Clustered Settlement } \\
\text { Mixed } \\
\text { Urban Open and Other } \\
\text { Cropland and Pasture } \\
\text { Orchards, Groves, Vineyards, Bushfruits, } \\
\quad \text { or Horticultural Areas } \\
\text { Other Agriculture } \\
\text { Forest, Shrub } \\
\text { Water Areas } \\
\text { Wetlands (Vegetated. and Unvegetated) } \\
\text { Other Barren Land }\end{array}$ & $\begin{array}{r}0 \\
10 \\
3 \\
0 \\
0 \\
2 \\
1 \\
5 \\
3 \\
8 \\
\\
2 \\
8 \\
8 \\
0 \\
0 \\
10\end{array}$ \\
\hline 29 & $\begin{array}{l}1980 \text { COUNTY PLANS (PRIMARY) } \\
\text { Residential (MAGI Codes 10,12,13, } \\
\text { 14,15,16,17,18,19,67,68) } \\
\text { Commercial (Codes } 30,31,32,33,34, \\
35,36,37,38,39,85,86,99,00 \text { ) } \\
\text { Industrial (Codes } 20,21,22,23,24,75 \text { ) } \\
\text { Employment Center (Codes } 40,41,42 \text { ) } \\
\text { Agriculture (Codes } 50,51,52,53 \text { ) } \\
\text { Recreation, Conservation, Open Spaces, Parks, } \\
\text { (Codes } 60,61,62,63,64,65,66,83 \text { ) } \\
\text { Public and semi-pubi ic (Codes 70,71,72 } \\
73,74,76,77,78,81,82,84 \text { ) } \\
\text { Institutional (Codes } 26,80,87 \text { ) } \\
\text { Rural-Vacant (Code } 11 \text { ) }\end{array}$ & $\begin{array}{r}0 \\
0 \\
0 \\
3 \\
0 \\
8 \\
\\
0 \\
\\
0 \\
0 \\
10\end{array}$ \\
\hline
\end{tabular}

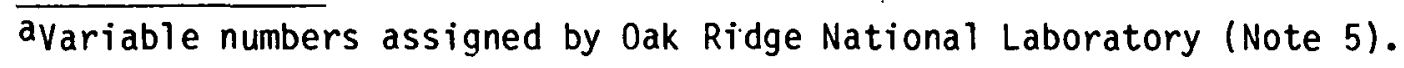


MAGI

Variable

33

Variable Name/Category

Value

SEISMICITY

ZONE 1 - Seismically suitable sites

can be found with little difficulty

ZONE 2 - Detailed site-specific studies would be required to determine seismic suitability

ZONE 3 - Considerable time and money

would be required to determine seismic

suitability of a specific site, or near

known epicenters or inactive faults.

30 MILE POPULATION FACTOR

0.0 to 0.2

0.2 to 0.5

, 0.5 to 1.0

Greater than 1.0

ENDANGERED SPECIES

Observed Location of Indiana Bat

Other

5 MILE SITE POPULATION FACTOR

$0.0 \pm 0 \quad 0.2$

0.2 to 0.5

0.5 to 1.0

Greater than 1.0

40

42

POPULATION DENSITY

Greater than 1000 Persons/Mile 2

Other Levels

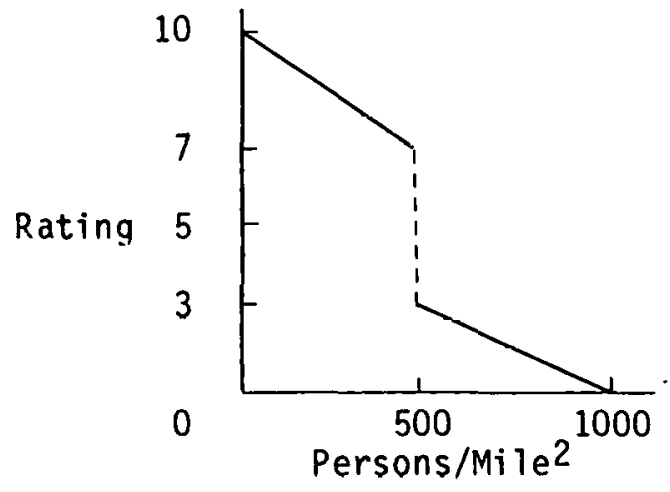

\section{PARTICIPANTS}

The Brookhaven National Laboratory/U.S. Nuclear Regulatory Commission Siting Methodology Project Advisory Panel is composed of 18 siting experts from academia, federal, regional, and state agencies, consultant groups, utilities, and the League of Women Voters. Fourteen panel members (Table 19) met in May, 1979 to choose exclusionary criteria and weights for the analyses of 
Table 19

SITING METHODOLOGY PROJECT ADVISORY PANEL

Dr. Roger Bolton

Department of Economics

Williams College

Williamstown, Massachusetts

Mr. Jack A. Halpern

Dames \& Moore

Park Ridge, Illinois

Mr. R. Michael Hartman

Envi rosphere Company

Atlanta, Georgia

Mr. William Heilman

Gilbert/ Commonwealth Inc.

Jack son, Michigan

Mr. Benjamin Hobbs

School of Civil and

Environmental Engineering

Cornell University

Ithaca, New York

Dr. Thomas J. Horst

Stone and Webster

Engineering Corp.

Boston, Massachusetts

Mr. Robert Kasvinsky

New England River Basins

Commission

Boston, Massachusetts
Dr. Simpson Linke

Department of Electrical Engineering

Cornell University

Ithaca, New York

Mr. Howard Mueller

Maryland Power Plant Siting Program

Annapol is, Maryland

Dr. Keshavan Nair

Woodward-Clyde Consultants

San Francisco, California

Mr. William Ott

Nuclear Regulatory Commission

Washington, DC

Mr. James Schuman

Pacific Gas and Electric

Company

San Francisco, California

Mr. David L. Siefken

Sargent \& Lundy Engineers

Chicago, Illinois

Mrs. Jean Tiedke

League of Women Voters

Southold, New York

this chapter. Although there is only one person from a public interest group, this panel is more representative of people nomally involved in siting than the participants in Chapter 2.

PROCEDURES FOR ANALYSIS

The procedures for analyses discussed in this chapter are similar to those of Chapter 2 which discusses details of use of statistical tests.

Selection of Exclusion Levels

Each participant was asked to choose exclusion levels of the value function for each variable. Cells having values less than or equal to the level specified were excluded from consideration.

Weighting Procedures

The three weighting methods used are Categorization, Rating, and Metfessel Allocation. Only the last of the three assures a ratio scale; none of 
Table 20

INSTRUCTIONS FOR WEIGHTING METHODS, MARYLAND SCREENING II

Categorization. Estimate the relative importance you think each site attribute should have in a-siting decision using the following categories:
0 - No importance
1 - Low importance
2 - Moderate importance
3 - High importance
4 - Very high importance

Rating Rate the relative importance you think each site attribute should have in a siting decision using a scale of 0.0 (least importance) to 10.0 (most important). Scan the list and assign the most important attribute a 10.0 and then estimate the distances the other attributes are in importance from the most important.

\section{0 - Least important \\ 10.0 - Most important}

Metfessel Allocation Estimate the ratios of importances you think each site attribute should have in a siting decision by allocating a total of 100 points to all attributes in proportion to your perception of their relative importance. Watch the ratios among the attributes carefully as they develop and correct them when you find inconsistencies among two or more ratios. Remember that the total number of points must equal 100.

the methods assures weights with the correct type of importance (see Appendix 1). Methods that ensure valid weights might pick different weights and candidate areas, but time constraints precluded their use. The instructions given to the participants are shown in Table 20. Note that the rating method used is slightly different from nomal in that it assigns a zero weight to the least important attribute rather than to zero importance. This yields interval-scaled weights with an arbitrary zero point.

The group applied the three methods in the listed sequence on the same day. Since the types of responses required by the techniques are similar, "carryover" from one method to another was high. That is, Categorization weights ilay resemble Rating weights only because the participants are unable to forget the first method's weights when using the second procedure. Weights from different methods therefore differ less than if the assessments were truly independent, and influences of choice of method in the following analysis are understated. As a result, conclusions about the importance of method are conservative. 


\section{Analysis of Weights}

In Chapter 2 we hypothesize that variations in weights are attributable. to four influences:

1. Values, background, and quantification ability of participants.

2. Purpose and context of the siting study.

3. Weighting method used.

4. Random influences of mood and uncertainty.

The study's purpose and context were the same for each person; hence, differences are due to the other three influences. As in Chapter 2, the influences are measured in the following way.

$r_{i j}=$ Correlation between Rating weight sets of persons $i$ and $j$. This measures variation due to choice of person and mood and uncertainty.

$r_{C} \cdot R_{\mathbf{j}}=$ Correlation between Categorization (C) and Rating ( $R$ ) weight sets of person $i$. This measures variation in weights due to choice of method and mood and uncertainty, as do the following two correlations.

$r_{C} \cdot M_{i}=$ Correlation between Categorization and Metfessel Allocation (MA) weight sets of person $i$.

$r_{R} \cdot M_{i}=$ Correlation between Rating and Metfessel Allocation weight sets of person $i$.

In Chapter 2, the correlation between Dr. Massicot's and Mr. Mueller's Rating weights is used as an indicator of the influence of mood and uncertainty. They work closely together, and are very familiar with the Maryland data base. In this chapter, the correlation between Messrs. Mueller's and Halpern's Rating weights is used in the same manner. Both were intimately involved with the Maryland Eastern Shore Siting Study 6 and are familiar with MAGI. Use of this estimate is conservative, as it overestimates the influence of mood and uncertainty alone.

One can compare a random sample of correlations $r_{i j}$ with each group of correlations between methods by a nonparametric test developed by White. ${ }^{7}$ Because the $\left({ }^{14} 2\right)$ or $91 r_{. j j}$ 's have only 13 degrees of freedom, an adjustment is necessary in the $r_{i j}$ 's sample. A representative 14 -member subsample of the $r_{i j}$ 's is chosen by ranking the $r_{i j}$ 's, and dividing them into 15 groups as equal as possible in size. The "representative" correlations are the 14 that are highest ranked in each group except the first. 
A nonparametric paired observations test described by Snedecor 8 (see Chapter 2) is used to compare the three sets of between-methods correlations, two at a time. This can indicate whether or not choice between a given pair of methods makes a significantly greater difference than choice between another pair.

Categorization weights can understate ratios of importance of different variables. Weight setters might believe for example, that "High Importance" variables (weight $=3$ ) are more than 1.5 times as important as "Moderate Importance" variables (weight $=2$ ). Specific category labels could cause them to assign weights that are not ratio scaled. If this is so, then coefficients of variation of Rating or Metfessel Allocation weight sets should be significantly higher than those of Categorization weights. Coefficient of variation (standard deviation divided by the mean) is a valid measure of relative "spread" of ratio scales. 9 We expect that categorization will produce less relative spread in weights, because it tends to understate importance ratios. The nonparametric statistical procedure for paired observations mentioned in the previous paragraph is applied to test this hypothesis.

Candidate Area Definition

Exclusionary Screening. A set of candidate areas is defined for each participant's Exclusionary Screening criteria. A cell is excluded if it is unsatisfactory in any of the attributes. Candidate areas include all contiguous groups of 4 or more acceptable cells. A "consensus" set of exclusionary criteria is defined as the median (for each attribute) of the group's criteria. That set yields consensus Exclusionary Screening candidate areas.

Weighting Summation. Using the defined attribute value functions and each of the 14 group member's 3 weight sets, 42 sets of candidate areas are specified using the Weighting Summation decision rule (see Appendix 1). In addition, consensus weights for each weighting method (group mean weights) specify three additional sets of candidate areas. Candidate areas consist of all groups of 4 or more contiguous cells each of which scores within the top $8 \%$.

Analysis of Cell Suitability Scores and Candidate Areas

Exclusionary Screening vs Weighting Summation. For each person whose exclusionary screening candidate areas comprise less than $10 \%$ of the study area, a fraction of overlap is calculated with each corresponding set of 
Weighting Summation areas. For this comparison only, Weighting Summation areas are defined to be the top $X$ scoring cells, where $X$ is the number of cells passing all of that person's exclusionary criteria. This overlap analysis is also done for group consensus Exclusionary Screening and Weighting Summation areas.

To estimate the influence of choice of person on Exclusionary Screening areas, a map showing which cells are selected by all persons is shown. This is compared to the effect of choice of person on Weighting Summation areas.

Comparison of Weighting Methods. Correlations of suitability scores are analyzed in the same manner as are correlations of weights. Between-methods correlations are compared with each other and with between-persons correlations. Between-methods correlations are also compared with the correlation between Messrs. Halpern's and Mueller's Metfessel Allocation suitability scores (an indication of influence of mood and uncertainty).

The following proportions of overlap between Weighting Summation candidate areas (the top $8 \%$ scoring cells) are calculated (as in Chapter 2):

1. Between-Methods overlap for each person's Categorization and Rating areas;

2. Between-Methods Overlap for each person's Categorization and Metfessel Allocation areas;

3. Between-Methods overlap for each person's Rating and Metfessel Allocation areas; and

4. Between-Persons overlap for every possible pairing of Metfessel Allocation areas (91 in all).

The three sets of between-methods overlaps are compared informally among themselves and with between-persons overlaps.

RESULTS

Exclusion Levels

Table 21 displays exclusion levels for each variable chosen by each person. Cells with levels equal to or less than any exclusion level are dropped. Selected Weights

Tables 22-24 present the Categorization, Rating, and Metfessel Allocation weights selected by the 14 participants. 
Table 21

EXCLUSION LEVELS, MARYLAND SCREENING II a

\begin{tabular}{cccccccccc}
\hline & \multicolumn{7}{c}{ MAGI } & Variable \#b & \\
Participant & 9,10 & 23 & 26 & 29 & 33 & 35 & 36 & 40 & 42 \\
\hline RB & 5 & 0 & 0 & 0 & 3 & 7 & 0 & 7 & 9 \\
JH & 0 & 0 & 0 & 0 & 0 & 3 & $99 \mathrm{C}$ & 3 & 3 \\
RH & 0 & 0 & 3 & 2 & 0 & 7 & 0 & 7 & 3 \\
WH & 0 & 0 & 2 & 0 & 0 & $99 \mathrm{C}$ & 0 & $99 \mathrm{C}$ & 7 \\
BH & 0 & 0 & 5 & 0 & 0 & 3 & 0 & 3 & 3 \\
TH & 0 & 0 & $99 \mathrm{C}$ & $99 \mathrm{C}$ & 0 & 3 & 0 & 7 & 3 \\
RK & 0 & 0 & 0 & 0 & 0 & 3 & 0 & 0 & 0 \\
SL & 1 & 0 & 2 & 1 & 2 & 7 & 0 & 7 & 8 \\
HM & 0 & $99 \mathrm{C}$ & 3 & 3 & $99 \mathrm{C}$ & 3 & $99 \mathrm{C}$ & 3 & 3 \\
KN & 5 & 0 & 5 & 8 & 3 & 7 & 0 & 7 & 3 \\
WO & $99 \mathrm{C}$ & $99 \mathrm{C}$ & 2 & 2 & $99 \mathrm{C}$ & $99 \mathrm{C}$ & 0 & 6 & 3 \\
JS & 5 & 0 & 4 & 4 & 0 & 3 & 0 & 3 & 3 \\
DS & 0 & 0 & 1 & 0 & 0 & 3 & 0 & 3 & 3 \\
JT & 5 & 0 & 5 & 8 & 8 & 7 & 0 & 7 & 9 \\
Median & 0 & 0 & 2 & 1 & 0 & 3 & 0 & 7 & 3
\end{tabular}

acells having any rating equal to or less than the indicated levels are excluded.

bSee Table 18 for corresponding variables.

c Indicates that no levels are exclusionary.

Table 22

CATEGORIZATION WEIGHTS, MARYLAND SCREENING II

\begin{tabular}{cccccccccr}
\hline & & \multicolumn{7}{c}{ MAGI } & Variable \# \\
Participant & 9,10 & 23 & 26 & 29 & 33 & 35 & 36 & 40 & 42 \\
\hline RB & 0 & 2 & 3 & 3 & 4 & 4 & 1 & 4 & 4 \\
JH & 3 & 1 & 4 & 1 & 0 & 4 & 0 & 4 & 4 \\
RH & 4 & 4 & 4 & 2 & 4 & 4 & 4 & 4 & 4 \\
WH & 3 & 4 & 3 & 1 & 2 & 2 & 4 & 3 & 4 \\
BH & 4 & 1 & 4 & 1 & 3 & 2 & 4 & 1 & 1 \\
TH & 4 & 2 & 0 & 0 & 2 & 1 & 4 & 1 & 3 \\
RK & 3 & 3 & 2 & 2 & 4 & 2 & 4 & 4 & 3 \\
SL & 2 & 4 & 3 & 3 & 4 & 4 & 3 & 4 & 4 \\
HM & 3 & 2 & 2 & 2 & 2 & 3 & 2 & 3 & 3 \\
KN & 3 & 3 & 3 & 3 & 2 & 4 & 4 & 4 & 4 \\
WO & 4 & 2 & 2 & 3 & 2 & 3 & 3 & 4 & 3 \\
JS & 4 & 4 & 2 & 2 & 2 & 4 & 4 & 4 & 4 \\
OS & 3 & 2 & 2 & 1 & 1 & 4 & 3 & 4 & 3 \\
JT & 4 & 2 & 3 & 3 & 4 & 4 & 2 & 4 & 4 \\
\hline MEAN & 3.1 & 2.6 & 2.6 & 1.9 & 2.6 & 3.2 & 3.0 & 3.4 & 3.4 \\
\hline
\end{tabular}


Table 23

RATING WEIGHTS, MARYLAND SCREENING II

\begin{tabular}{ccrrrrrrrr}
\hline & & \multicolumn{7}{c}{ MAGI } & Variable \# \\
Participant & 9,10 & 23 & 26 & 29 & 33 & 35 & 36 & 40 & 42 \\
\hline RB & 0 & 4 & 2 & 2 & 8 & 9 & 2 & 10 & 9 \\
JH & 7 & 2 & 7 & 0 & 0 & 10 & 1 & 10 & 10 \\
RH & 4 & 3 & 5 & 0 & 8 & 7 & 6 & 9 & 10 \\
WH & 8 & 10 & 8 & 0 & 3 & 2 & 10 & 7 & 10 \\
BH & 9 & 0 & 8 & 1 & 7 & 5 & 10 & 4 & 4 \\
TH & 9 & 7 & 0 & 1 & 7 & 2 & 10 & 2 & 8 \\
RK & 9 & 8 & 5 & 6 & 7.5 & 8.5 & 7 & 10 & 9.5 \\
SL & 7 & 9 & 6 & 6 & 10 & 8 & 8 & 8 & 8 \\
HM & 9 & 5 & 7 & 5 & 0 & 10 & 5 & 10 & 10 \\
KN & 5 & 5 & 5 & 5 & 0 & 10 & 10 & 10 & 10 \\
WO & 6 & 4 & 6 & 6 & 0 & 8 & 1 & 10 & 8 \\
JS & 9 & 10 & 5 & 5 & 5 & 9 & 10 & 9 & 9 \\
DS & 8 & 4 & 5 & 0 & 1 & 10 & 7 & 10 & 9 \\
JT & 4 & 3 & 6 & $\frac{5}{7.0}$ & $\frac{7}{4.5}$ & $\frac{8}{7.6}$ & $\frac{2}{6.4}$ & $\frac{10}{8.5}$ & $\frac{9}{8.8}$ \\
MEAN & 6.7 & 5.3 & $\frac{5.4}{3.0}$ &
\end{tabular}

Table 24

METFESSEL ALLOCATION WEIGHTS, MARYLAND SCREENING II

\begin{tabular}{|c|c|c|c|c|c|c|c|c|c|}
\hline \multirow{2}{*}{ Participant } & \multicolumn{9}{|c|}{ MAGI Variable \# } \\
\hline & 9,10 & 23 & 26 & 29 & 33 & 35 & 36 & 40 & 42 \\
\hline $\mathrm{RB}$ & 0 & 5 & 6 & 6 & 15 & 20 & 3 & 25 & 20 \\
\hline $\mathrm{JH}$ & 12 & 9 & 12 & 1 & 5 & 17 & 9 & 17 & 18 \\
\hline RH & 8 & 10 & 10 & 2 & 25 & 5 & 15 & 10 & 15 \\
\hline WH & 12 & 17 & 12 & 3 & 6 & 6 & 17 & 10 & 17 \\
\hline $\mathrm{BH}$ & 16 & 1 & 14 & 4 & 12 & 15 & 18 & 12 & 8 \\
\hline TH & 20 & $1 \overline{6}$ & 0 & 1 & 12 & 3 & 24 & 4 & 20 \\
\hline RK & 10 & 15 & 5 & 5 & 6 & 10 & 15 & 17 & 17 \\
\hline SL & 5 & 10 & 5 & 5 & 25 & 15 & 5 & 15 & 15 \\
\hline HM & 10 & 6 & 15 & 5 & 5 & 17 & 8 & 17 & 17 \\
\hline KN & 10 & 10 & 10 & 10 & 4 & 14 & 14 & 14 & 14 \\
\hline wo & 10 & & 10 & 10 & 7 & 15 & 7 & 20 & 15 \\
\hline JS & 15.3 & 15.3 & 6.1 & 5.1 & 6.1 & 12.3 & 15.3 & 12.3 & 12.2 \\
\hline DS & 12 & 8 & 8 & 4 & 6 & 18 & 10 & 18 & 16 \\
\hline JT & 5 & 3 & 4 & 5 & 20 & 20 & 3 & 20 & 20 \\
\hline MEAN & $\overline{10.4}$ & 9.4 & 8.4 & 4.7 & $\overline{11.0}$ & $\overline{13.4}$ & $\overline{11.7}$ & $\overline{15.1}$ & $\overline{16.0}$ \\
\hline
\end{tabular}


Analysis of Weights

Table 25 shows correlations between weights chosen by different methods for each person; Table 26 shows correlations among the 14 Rating weight sets. These are measures of the influence of choice of person on weights. The correlation between Messrs. Halpern's and Mueller's Rating weights 10.903 ) is used as an indicator of the effect of mood and uncertainty.

Correlations between persons (not shown) were also calculated for both the Categorization and Metfessel weight sets. Using a nonparametric pairedobservations test 10 with $\alpha=0.05$, Rating between-persons correlations (Table 26) do not differ significantly from Categorization or Metfessel Allocation between-persons correlations.

By the modified White's nonparametric two-sample test described above, each of the three groups of between-methods correlations (Table 25) is significantly greater $(p<0.001)$ than the Rating between-persons correlations (Table 26). This means that choice of person (from within the Advisory Panel) makes much more of a difference in weights than choice of method (among Categorization, Rating, or Metfessel Allocation). Carryover from one weighting method to the next makes between-method correlations higher than they would otherwise be. There is no carryover between persons; therefore, between-methods correlations may be higher than between-persons correlations only for that reason.

The indicator of influence of mood and uncertainty $\left(r_{\text {Halpern-Mueller }}=\right.$ 0.903 ! falls in the middle of each set of between-methods correlations (Table 25). Thus, it cannot be said that mood and uncertainty have a greater effect on weights than choice of weighting method.

As explained above, we compare the three sets of between-methods correlations (Table 25) using a nonparametric paired observations test. The results are:

1. there is no significant difference between the $r_{C-R}$ and $r_{R-M}$ samples or between the $r_{C-R}$ and $r_{C-M}$ samples; and

2. the $r_{C-M}$ sample is significantly $(p<0.01)$ smaller than the $r_{R-M}$ sample,

where $C, R$, and $M$ stand for the Categorization, Rating, and Metfessel Allocation weighting methods, respectively. Thus, it makes more difference if one chooses Categorization instead of Metfessel Allocation than if he chooses Rating rather than Metfessel Allocation. 
The last analysis of weights is a comparison of the spread of Rating and Metfessel weights versus that of Categorization weights. We hypothesize above that Categorization tends to underestimate ratios of importance of attributes, and that this should be reflected in lower coefficients of variation (CV) for Categorization weights than for weights chosen by the other two methods. The nonparametric paired observations test supports this. The mean Categorization $\mathrm{CV}$ is 0.390 , while those for Rating and Metfessel Allocation are 0.619 and 0.546 , respectively. Therefore, the $14 \mathrm{CV}$ 's for Rating, and those for Metfessel Allocation, are significantly larger $(p<0.01)$ than those for Categorization.

Correlations among mean weights (Table 25) are higher than between-methods correlations for most participants. This indicates that, as is expected, there is less variability among group mean weights than among weights for one individual. The central tendency of means obscures differences of opinions among participants.

Candidate Area Definition

Exclusionary Screening. Exclusionary Screening candidate areas were generated for each set of exclusionary criteria listed in Table 21 . Table 27 gives the number of cells and fraction of study area that passes each set. Between $0 \%$ and $20 \%$ of the study area passes all criteria for only 2 persons and the group median (Figures 10 to 12). Three others are so strict that no cells pass for them. The remaining sets allow more than $20 \%$ of the cells to pass. In an actual siting study, if initial criteria are too lenient (or stringent), then a second stricter (or looser) set of criteria would be defined and another set of candidate areas generated.

For six persons, about $22 \%$ of the study area passes. Their exclusionary criteria are similar but not identical. Nearly the same areas passed all criteria for each person (not shown). Hence, the data base is robust with respect to exclusionary criteria; different criteria produce similar areas. This is confimed by Figure 13 which shows cells picked by all eleven persons who had non-empty candidate area sets. The $6.61 \%$ of the study area included is nearly identical to the $6.82 \%$ shown in Figure 11 . This shows that ten other persons agreed with that screening, indicating that choice of person may be relatively unimportant. Were panel members with lenient criteria to tighten them, however, important differences in candidate areas might still arise. 


\section{Table 25}

BETWEEN-METHODS CORRELATIONS, MARYLAND SCREENING II

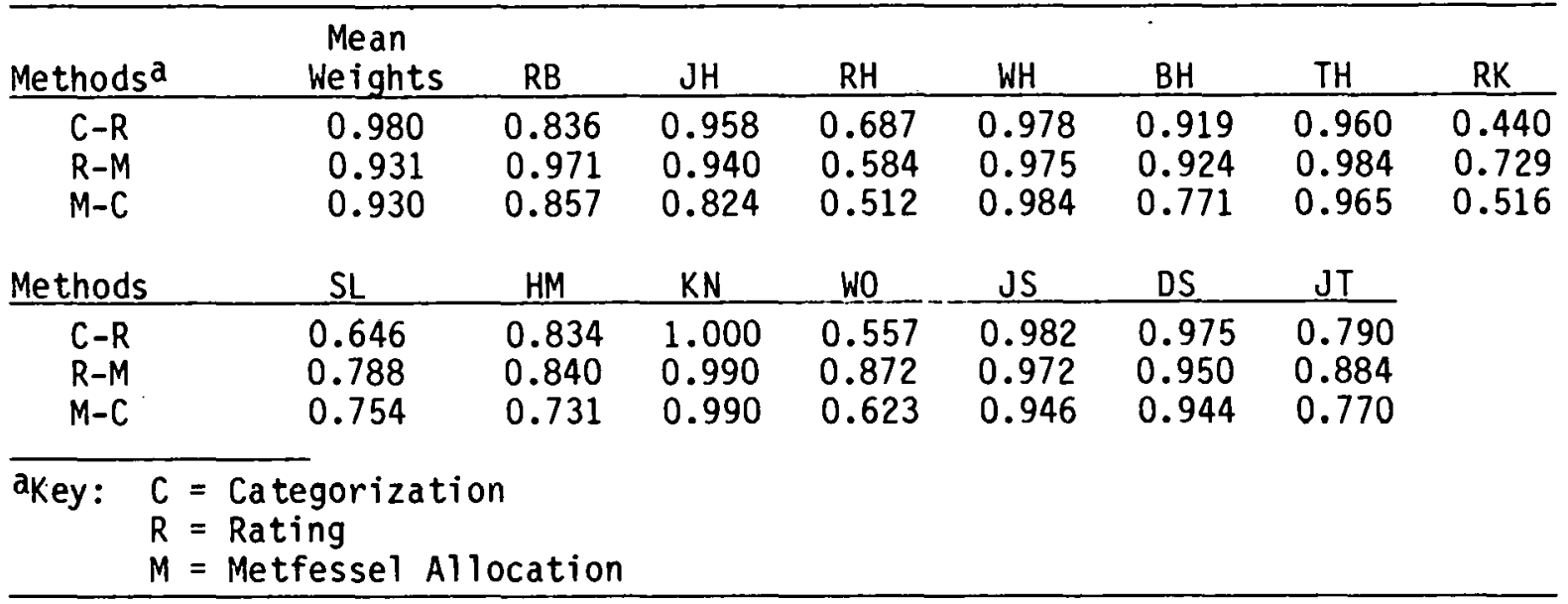

\section{Table 26}

CORRELATIONS BETWEEN RATING WEIGHT SETS, MARYLAND SCREENING II

\begin{tabular}{|c|c|c|c|c|c|c|c|c|c|c|c|c|c|}
\hline ipant & $\mathrm{JH}$ & RH & WH & BH & $T H$ & PK & $S L$ & HM & $\mathrm{KN}$ & WO & US & DS & $\mathrm{JT}$ \\
\hline RB & 0.466 & 0.773 & -0.157 & -0.284 & -0.162 & 0.587 & 0.554 & 0.213 & 0.306 & 0.351 & 0.134 & 0.373 & 0.841 \\
\hline $\mathrm{JH}$ & & 0.563 & 0.215 & 0.067 & -0.245 & 0.564 & -0.185 & 0.903 & 0.610 & 0.833 & 0.348 & 0.858 & 0.678 \\
\hline RH & & & 0.290 & 0.297 & 0.199 & 0.584 & 0.504 & 0.276 & 0.374 & 0.180 & 0.266 & 0.604 & 0.680 \\
\hline WH & & & & 0.242 & 0.554 & 0.243 & 0.123 & 0.241 & 0.309 & -0.037 & 0.602 & 0.429 & -0.251 \\
\hline BH & & & & & 0.337 & -0.132 & -0.064 & -0.036 & 0.000 & -0.344 & -0.010 & 0.260 & -0.184 \\
\hline TH & & & & & & 0.362 & 0.508 & -0.201 & -0.015 & -0.522 & 0.535 & 0.114 & -0.442 \\
\hline RK & & & & & & & 0.449 & 0.522 & 0.431 & 0.445 & 0.667 & 0.672 & 0.473 \\
\hline$S L$ & & & & & & & & -0.410 & -0.181 & -0.442 & 0.295 & 0.000 & 0.105 \\
\hline HM & & & & & & & & & 0.766 & 0.887 & 0.499 & 0.849 & 0.432 \\
\hline KN & & & & & & & & & & 0.574 & 0.668 & 0.803 & 0.258 \\
\hline wo & & & & & & & & & & & 0.197 & 0.600 & 0.640 \\
\hline JS & & & & & & & & & & & & 0.112 & -0.145 \\
\hline DS & & & & & & & & & & & & & 0.390 \\
\hline
\end{tabular}


Table 27

NUMBER OF CELLS PASSING ALL EXCLUSIONARY CRITERIA, MARYLAND SCREENING II Number of Cells

Participant Passing All Screens

Percentage

\begin{tabular}{crc} 
Participant & Passing All Screens & of Study Area \\
\hline RB & 0 & 0 \\
JH & 4129 & 22.67 \\
RH & 1335 & 7.33 \\
WH & 4180 & 22.95 \\
BH & 4103 & 22.52 \\
TH & 9436 & 50.90 \\
RK & 4165 & 22.86 \\
SL & 1243 & 6.82 \\
HM & 5138 & 27.71 \\
KN & 0 & 0 \\
WO & 5302 & 28.60 \\
JS & 4030 & 22.12 \\
DS & 4128 & 22.66 \\
JT & 0 & 0 \\
MEDIAN CRITERIA & 3533 & 19.39 \\
\hline
\end{tabular}

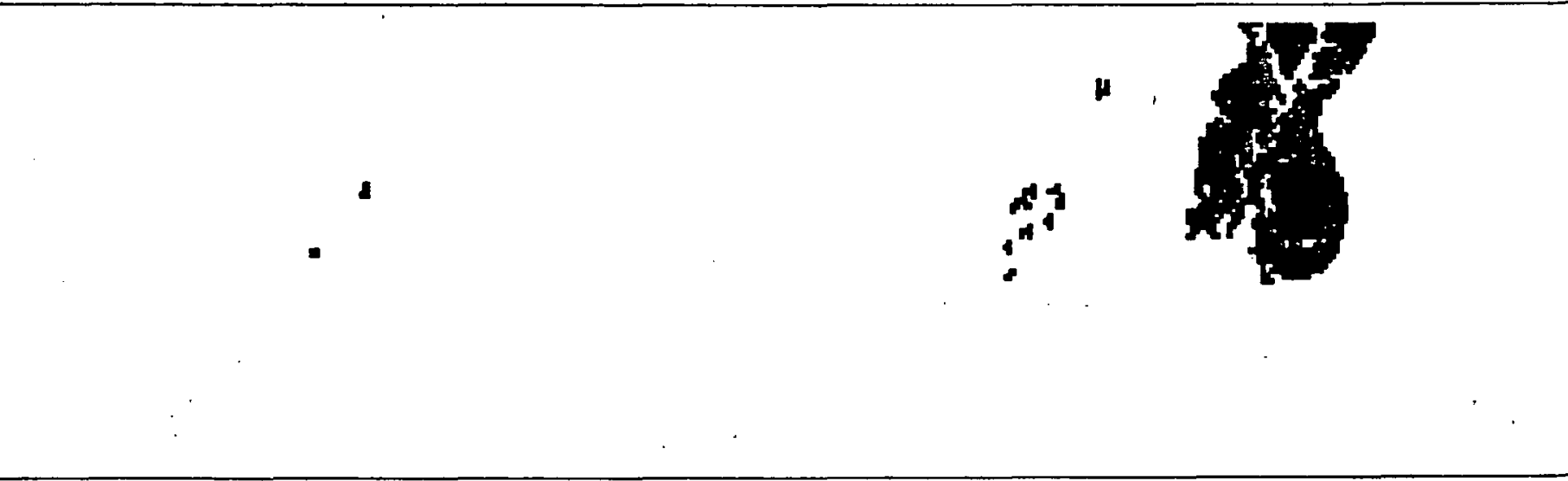

Figure 10. Exclusionary Screening Candidate Areas, Advisory Panel (MH), Maryland Screening II. 


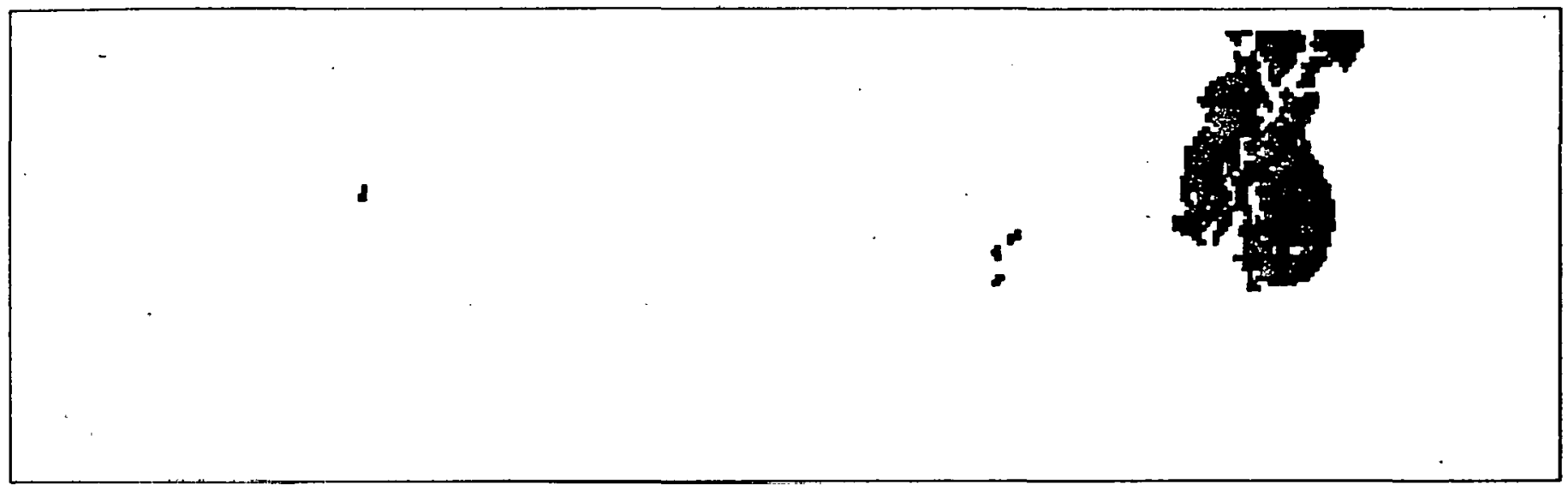

Figure 11. Exclusionary Screening Candidate Areas, Advisory Panel (SL), Maryland Screening II.

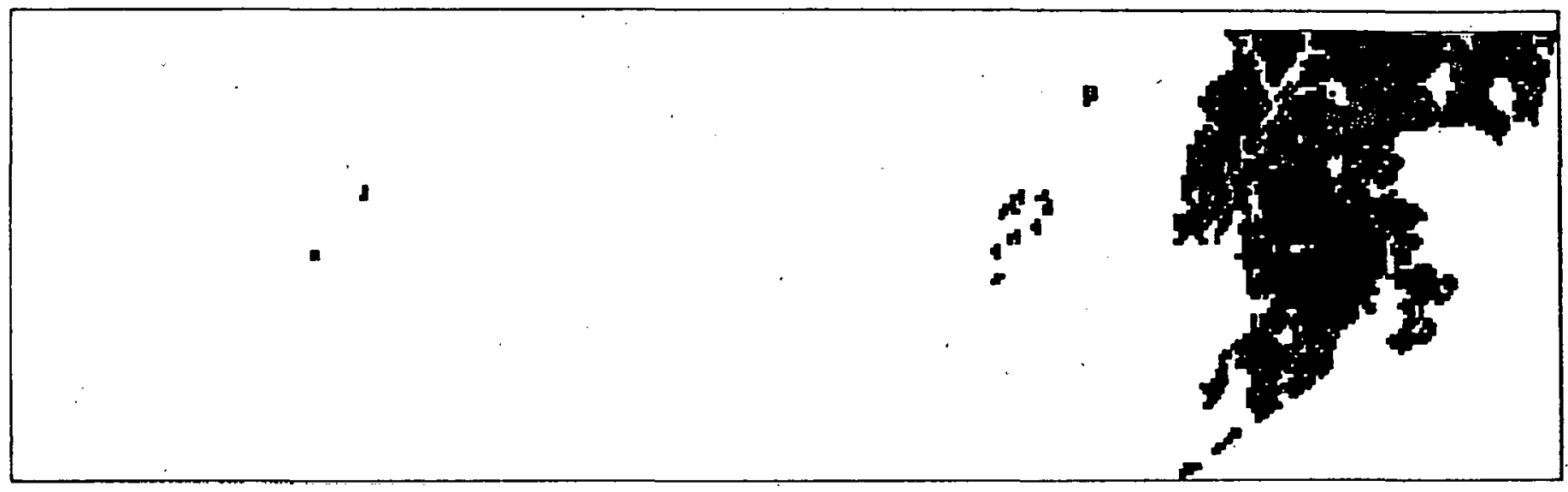

Figure 12. Exclusionary Screening Candidate Areas, Advisory Panel Group Median Criteria, Maryland Screening II. 


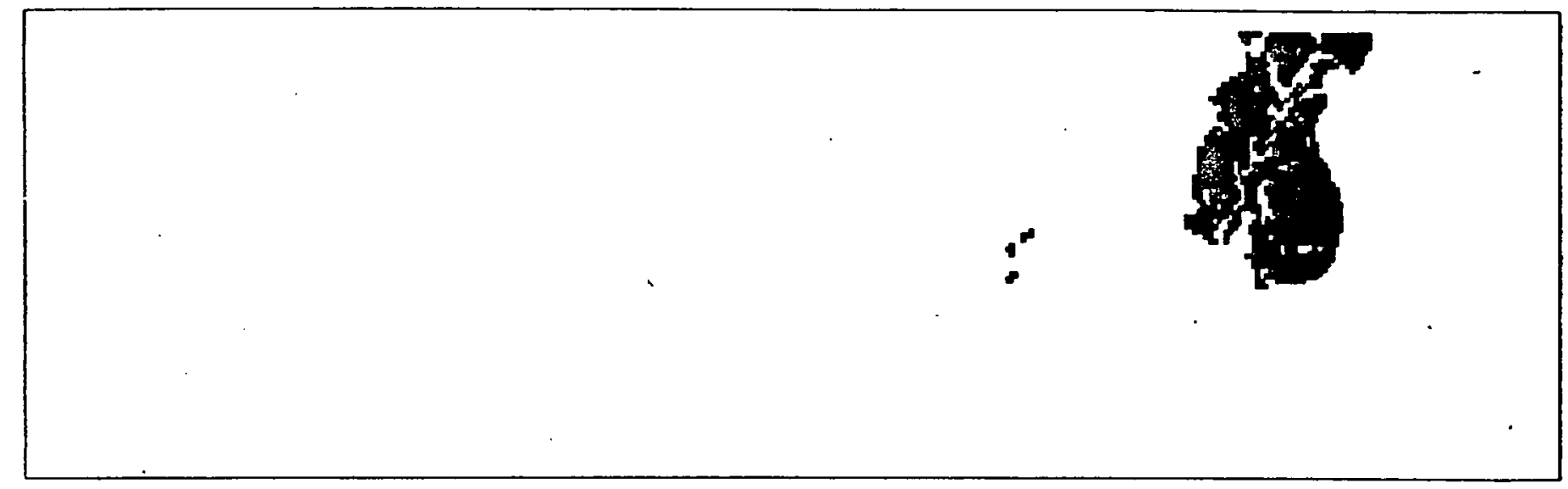

Figure 13. Cells Passing Exclusionary Criteria of 11 Persons Having Non-Empty Candidate Area Sets, Maryland Screening II.

Weighting Summation. The smaller number of attributes used in this study (9) produces less discrimination among cells than the 17 used in Chapter 2. That three of the attributes are measures of population exacerbates this problem. Large numbers of cells have identical attribute values and, therefore, the same suitability scores. This makes it difficult to establish precise $2 \%$ and $8 \%$ cutoffs. So many cells have the same suitability that there may not be natural breaks at the percentages required. As in Chapter 2, this proved to be such a problem that no attempt was made to separate the top $2 \%$ cells. The " $8 \% "$ areas actually contain from less than $7 \%$ to over $17 \%$ of the study area. This makes interpretation of fraction of overlap of areas more difficult.

One person's Categorization, Rating, and Metfessel Allocation areas are shown in Figures 14 through 16. Another person's Metfessel Allocation areas are shown in Figure 17. The differences between Figures 16 and 17 are typical of those between pairs of persons. In comparison, most differences among weighting methods are smal1. 


\section{Analysis of Cell Suitability Scores and Candidate Areas}

Exclusionary Screening vs Weighting Summation. Table 28 presents proportions of overlap of three sets of Exclusionary Areas with corresponding Categorization, Rating, and Metfessel Allocation areas. Weighting summation areas are defined in Table 28 so that they include about the same number of cells as the screening areas. Differences between the two decision rules are small for the areas shown in Figures 10 and 17 and nonexistent for the areas shown in Figure 11. They are large for the group consensus exclusionary criteria and weights, whose area sets disagree more than they agree (Figures 12 and 18). The more pronounced differences may be attributable to a larger proportion of the study area in the group consensus areas than in either of the others. The differences might decrease were stricter criteria chosen. Nevertheless, these exclusionary criteria make tradeoffs among attributes of which the group consensus does not annrnive

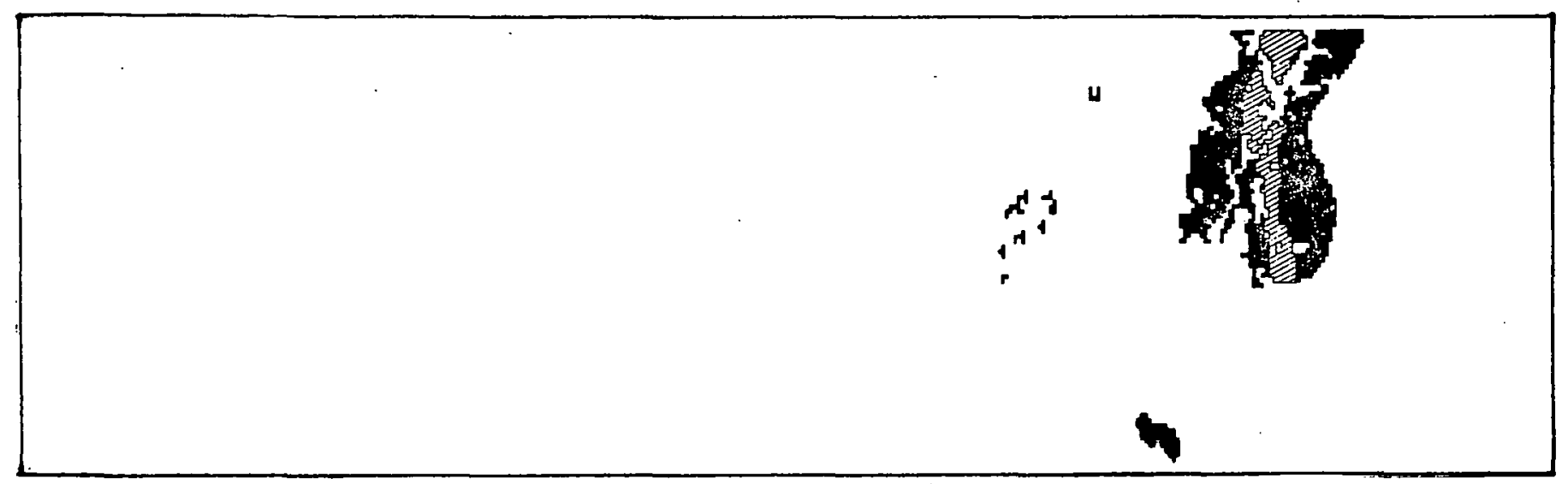

Figure 14. Categorization Candidate Areas, Advisory Panel (HM), Maryland Screening II. 


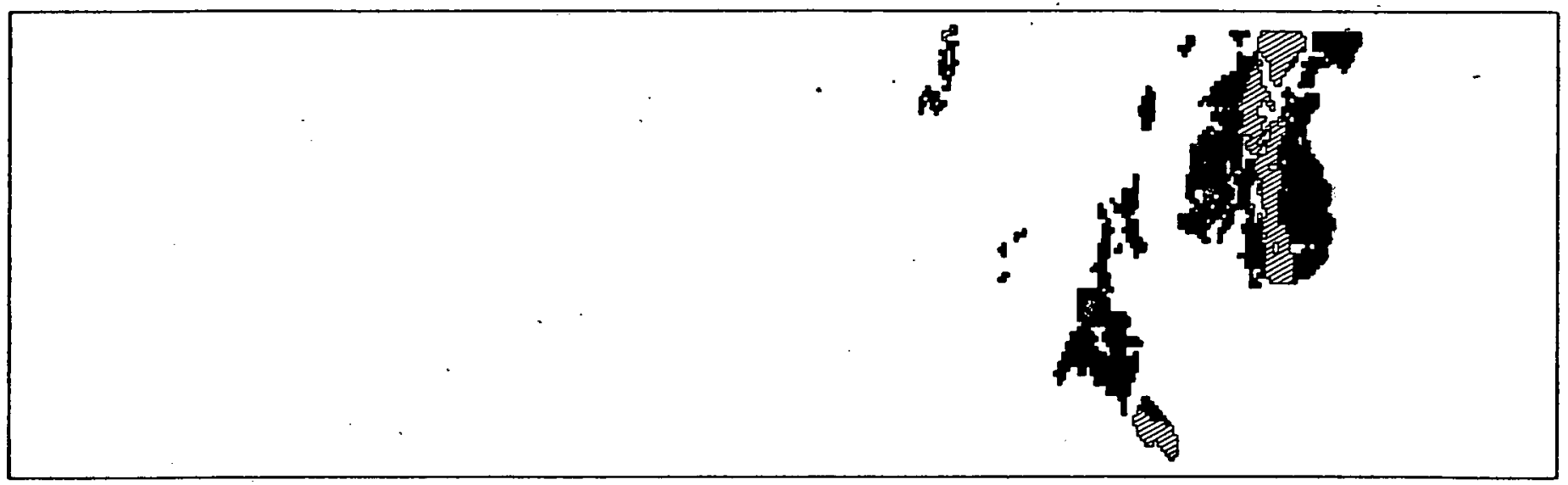

Figure 15. Rating Candidate Areas, Advisory Panel (HM), Maryl and Screening II.

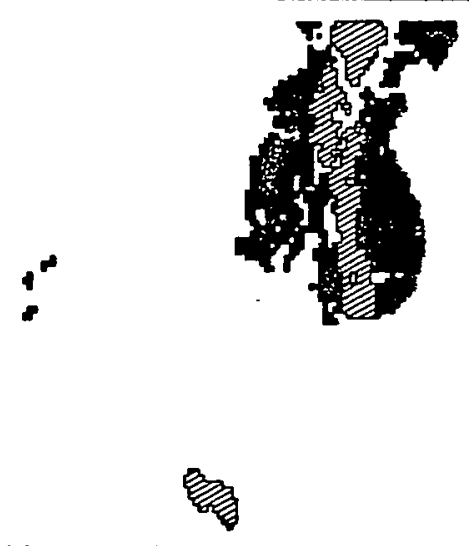

Figure 16. Metfessel Allocation Candidate Areas, Advisory Panel (HM), Maryland Screening II. 


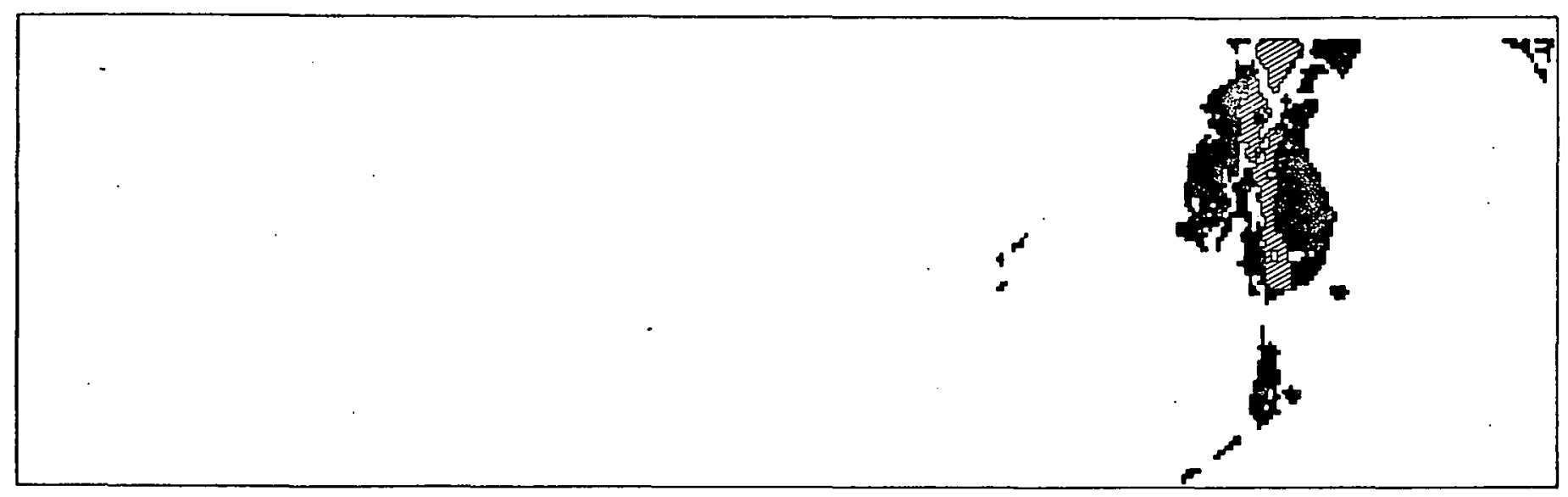

Figure 17. Metfessel Allocation Candidate Areas, Advisory Panel (MH), Maryland Screening II.

Table 28

EXCLUSIONARY SCREENING AND WEIGHTING SUMMATION PROPORTIONS OF OVERLAP OF CANDIDATE AREAS, ADVISORY PANEL, MARYLAND SCREENING II

\begin{tabular}{|c|c|c|c|c|}
\hline Participant & $\begin{array}{l}\text { Weighting } \\
\text { Method }\end{array}$ & $\begin{array}{l}\text { Proportion of } \\
\text { Study Area in } \\
\text { Exclusionary } \\
\text { Screening } \\
\text { Area Only }\end{array}$ & $\begin{array}{l}\text { Proportion of Study } \\
\text { Area in Both Ex- } \\
\text { clusionary Screen- } \\
\text { ing and Weighting } \\
\text { Summation }\end{array}$ & $\begin{array}{l}\text { Proportion of } \\
\text { Study Area in } \\
\text { Weighting } \\
\text { Summation } \\
\text { Area Only }\end{array}$ \\
\hline \multirow[t]{2}{*}{$\mathrm{RH}$} & \multirow{2}{*}{$\begin{array}{l}\text { Categorization } \\
\text { Rating } \\
\text { Metfessel } \\
\text { Allocation }\end{array}$} & $\begin{array}{l}0.001 \\
0.019\end{array}$ & $\begin{array}{l}0.072 \\
0.055\end{array}$ & $\begin{array}{l}0.000 \\
0.012\end{array}$ \\
\hline & & 0.006 & 0.067 & 0.011 \\
\hline \multirow[t]{2}{*}{$S L$} & \multirow{2}{*}{$\begin{array}{l}\text { Categorization } \\
\text { Rating } \\
\text { Metfessel } \\
\text { Allocation }\end{array}$} & $\begin{array}{l}0.001 \\
0.001\end{array}$ & $\begin{array}{l}0.067 \\
0.067\end{array}$ & $\begin{array}{l}0.000 \\
0.000\end{array}$ \\
\hline & & 0.001 & 0.067 & 0.000 \\
\hline \multirow[t]{2}{*}{ Group } & \multirow{2}{*}{$\begin{array}{l}\text { Categorization } \\
\text { Rating } \\
\text { Metfessel } \\
\text { Allocation }\end{array}$} & $\begin{array}{l}0.021 \\
0.110\end{array}$ & $\begin{array}{l}0.173 \\
0.084\end{array}$ & $\begin{array}{l}0.029 \\
0.184\end{array}$ \\
\hline & & 0.122 & 0.072 & 0.158 \\
\hline
\end{tabular}




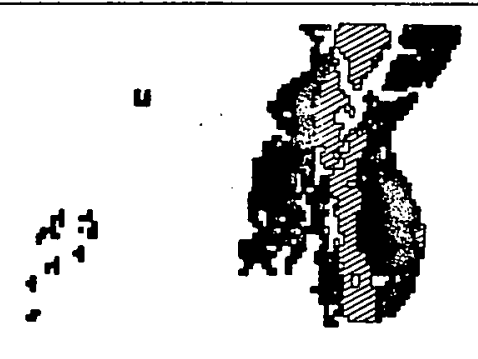

Figure 18. Metfessel Allocation Candidate Areas, Advisory Panel Group Mean, Maryland Screening II.

Comparison of Weighting Methods. Between-persons (Table 29) and between - weighting method (Table 30) correlations were calculated among different sets of suitability scores, just as they were among weight sets.

Comparison of correlations between weights (Tables 25 and 26) with those between suitabilities shows that the latter are much higher. This is expected because there is a natural ordering among cells in that some are better in all attributes than others. This agrees with the results of chapter 2.

Each of the three groups of between-method correlations of Table 29 is significantly greater $(p<0.001)$ than the between-persons correlations for Metfessel Allocation (Table 30). Hence, choice of person (from within the Advisory Panel) makes more of a difference in suitability scores than choice of weighting method (from among the three considered). This was also a conclusion from the analysis of the weights themselves, above. Since betweenmethods correlations are biased upward by carryover, these results could be misleading.

As in the analysis of weights, the indication of influence of mood and

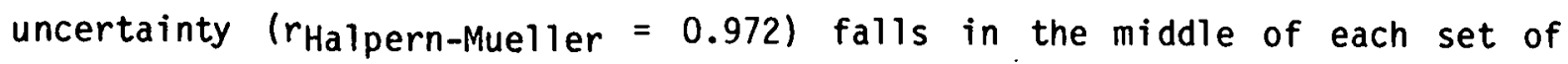




\section{Table 29}

BETWEEN-METHODS CORRELATIONS OF SUITABILITY SCORES, MARYLAND SCREENING II

\begin{tabular}{llllllllllllllll}
\hline Methods & RB & JH & RH & WH & BH & TH & RK & SL & HM & KN & WO & JS & DS & JT & Mean \\
Weights
\end{tabular}

between-methods correlations. The data again fail to show that mood and uncertainty have a greater effect on suitabilities than choice of weighting method (from among the three considered).

The three sets of between-methods correlations (Table 29) do not differ significantly among themselves. This is in contrast to the correlations of weight sets (Table 25), in which Categorization-Metfessel Allocation correlations are significantly smaller than Rating-Metfessel Allocation correlations. Therefore, choosing between Categorization and Metfessel Allocation makes no more difference in suitabilities than choosing between Rating and Metfessel Allocation.

\section{Table 30}

BETWEEN-PERSONS CORRELATIONS OF METFESSEL ALLOCATION SUITABILITY SCORES, MARYLAND SCREENING II

\begin{tabular}{|c|c|c|c|c|c|c|c|c|c|c|c|c|c|}
\hline $\begin{array}{l}\text { Partic- } \\
\text { ipant }\end{array}$ & $\mathrm{JH}$ & RH & WH & $\mathrm{BH}$ & TH & RK & SL & HM & KN & WO & JS & DS & JT \\
\hline $\begin{array}{l}\text { RB } \\
\text { JH } \\
\text { RH } \\
\text { WH } \\
\text { BH } \\
\text { TH } \\
\text { RK } \\
\text { SL } \\
\text { HM } \\
\text { KN } \\
\text { WO } \\
\text { JS } \\
\text { DS }\end{array}$ & .756 & $\begin{array}{l}.717 \\
.865\end{array}$ & $\begin{array}{l}.618 \\
.913 \\
.917\end{array}$ & $\begin{array}{l}.463 \\
.85 \\
.76 \\
.789\end{array}$ & $\begin{array}{l}.356 \\
.803 \\
.823 \\
.901 \\
.825\end{array}$ & $\begin{array}{l}.741 \\
.927 \\
.905 \\
.972 \\
.763 \\
.858\end{array}$ & $\begin{array}{l}.885 \\
.855 \\
.937 \\
.838 \\
.669 \\
.686 \\
.898\end{array}$ & $\begin{array}{l}.793 \\
.972 \\
.852 \\
.887 \\
.874 \\
.739 \\
.913 \\
.860\end{array}$ & $\begin{array}{l}.694 \\
.884 \\
.840 \\
.915 \\
.855 \\
.805 \\
.943 \\
.837 \\
.942\end{array}$ & $\begin{array}{l}.752 \\
.892 \\
.832 \\
.868 \\
.869 \\
.756 \\
.918 \\
.852 \\
.959 \\
.984\end{array}$ & $\begin{array}{l}.549 \\
.901 \\
.863 \\
.963 \\
.872 \\
.947 \\
.953 \\
.797 \\
.883 \\
.937 \\
.889\end{array}$ & $\begin{array}{l}.753 \\
.984 \\
.863 \\
.911 \\
.889 \\
.828 \\
.944 \\
.868 \\
.979 \\
.938 \\
.947 \\
.935\end{array}$ & $\begin{array}{l}.949 \\
.860 \\
.821 \\
.712 \\
.681 \\
.559 \\
.815 \\
.938 \\
.883 \\
.788 \\
.851 \\
.698 \\
.873\end{array}$ \\
\hline
\end{tabular}


Proportions of overlap between weighting methods and between persons are presented in Tables 31 and 32, respectively. There is generally more overlap. among candidate areas from different methods (same person) than there is among different persons. Of the 45 between-methods overlap calculations, in only 8 do both sets contain 0.05 or more of the area not al so included in the other.

The largest between-methods differences are among the areas shown in Figures 19 through 21. These Categorization and Metfessel Allocation areas share only $2.21 \%$ of the study area, while Categorization chooses $7.45 \%$ of the study area not included for Metfessel Allocation, and Metfessel Allocation includes $15.42 \%$ of the study area not included for Categorization. This difference is large compared to other between-methods overlaps. Surprisingly, the associated between-methods correlations (Tables 25 and 29) are about average. A reason for this might be that a large proportion (over 17\%) of the total study area is included in the Rating and Metfessel Allocation areas. In an even greater number of overlaps (33 of 91) (Table 32), both area sets contain $0.5 \%$ or more of the study area not included in the other set. Twenty five of the 33 involve two persons whose Metfessel Allocation areas contain 17\% of the study area instead of $8 \%$. This may have influenced the results.

The overlaps of Tables 31 and 32 fail to show that choice of weighting method makes more of a difference than person.

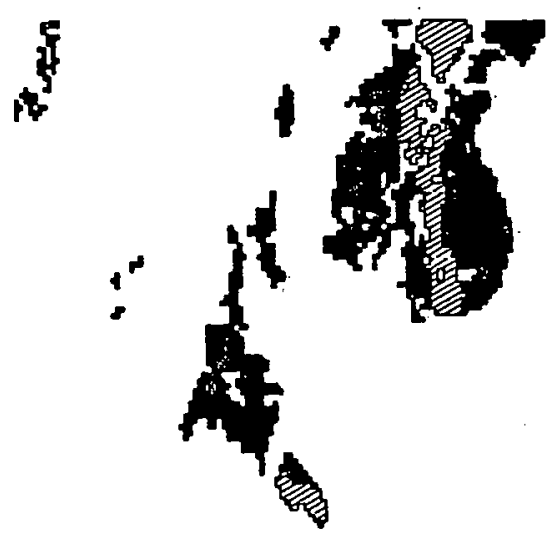

Figure 19. Categorization Candidate Areas, Advisory Panel (JH), Maryl and Screening II. 

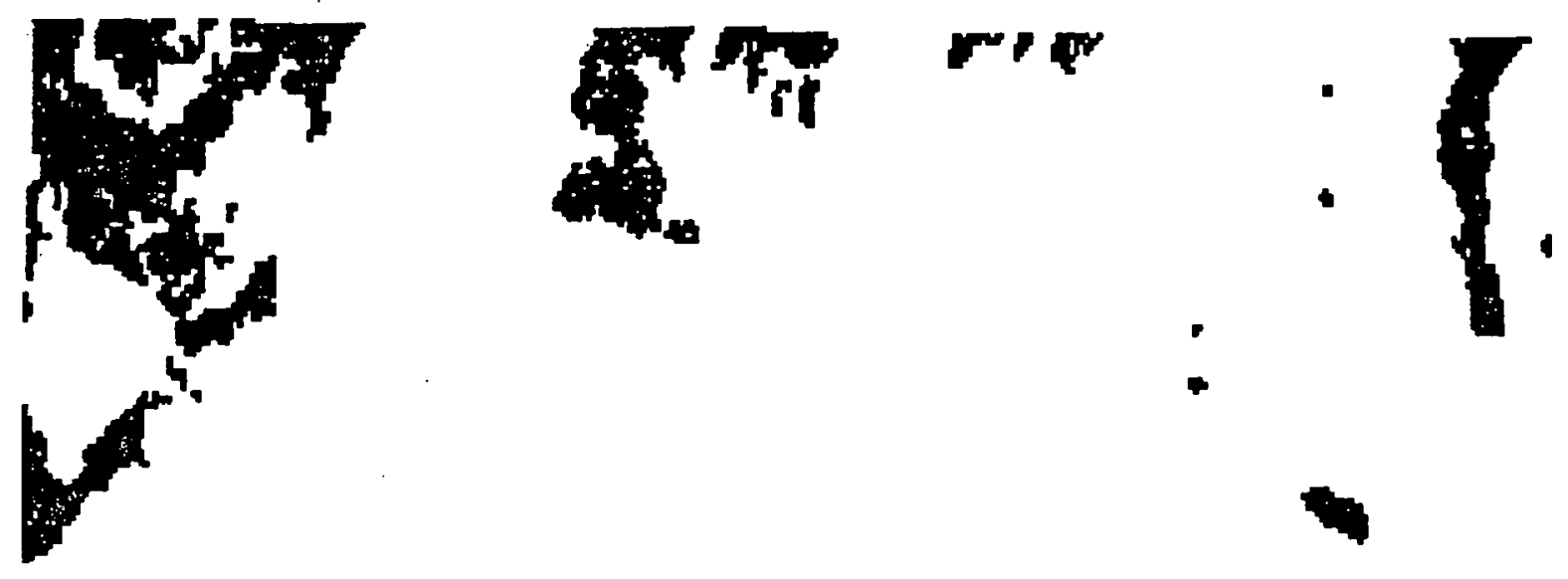

Figure 20. Rating Candidate Areas, Advisory Panel (JH), Maryl and Screening II
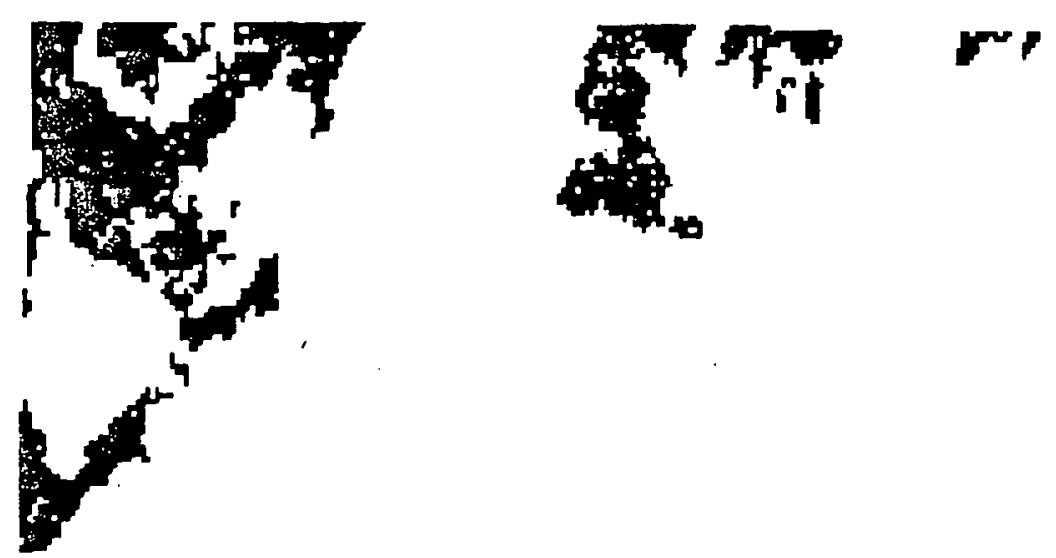

Figure 21. Metfessel Allocation Candidate Areas, Advisory Panel (JH), Maryland Screening II 
Table 31

BETWEEN - WEIGHTING METHODS PROPORTIONS OF OVERLAP OF CANDIDATE AREAS, MARYLAND SCREENING II

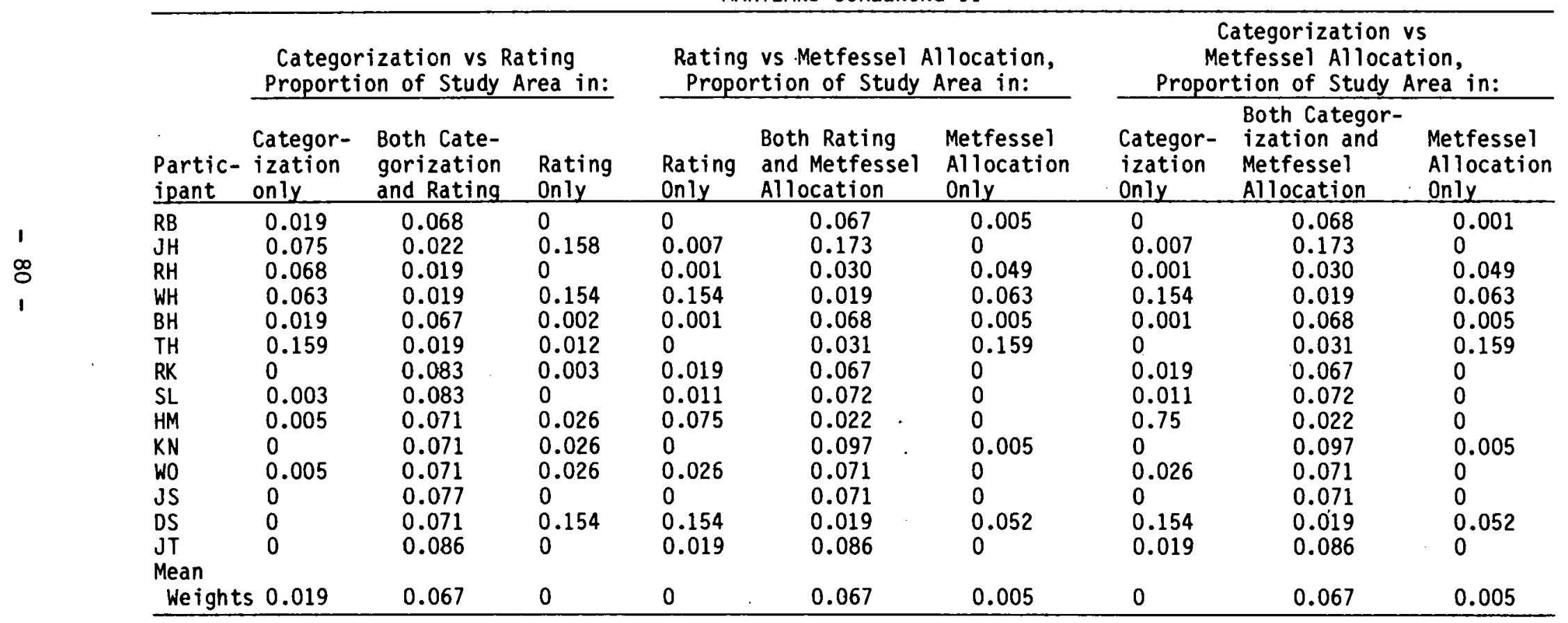


Table 32

BEIWEBH-PGPSONS PROPCRTIONS OF OVERLAP OF METFESSE ALLOCATION CANDIDATE AFEAS, ADVISCFY PANE, MARYLAND SOREENING II

\begin{tabular}{|c|c|c|c|c|c|c|c|c|c|c|c|c|c|c|c|c|c|c|c|c|c|c|}
\hline \multicolumn{23}{|c|}{ Person 2: } \\
\hline Person 1 & L onl & shared & 2 only & 1 only & shared & $2 \mathrm{coly}$ & 1 I onle & shared & 2 only & 1 only & share & 2 eally & 1 only & shared & 2 ond $x$ & $1 \mathrm{only}$ & shared & $2 \mathrm{coly}$ & 1 only & shared & 2 only & Barsen 1 \\
\hline$P B$ & 0.054 & 0.019 & 0.154 & 0.005 & 0.067 & 0.011 & 0.005 & 0.067 & 0.014 & 0.001 & 0.072 & 0 & 0.054 & 0.019 & 0.159 & 0.005 & 0.67 & 0 & 0.001 & 0.072 & 0 & $\boldsymbol{B}$ \\
\hline JH & & & & 0.154 & 0.019 & 0.060 & Q. 154 & 0.019 & 0.063 & a. 154 & 0.019 & 0.054 & Q.154 & 6.019 & 0.005 & 0.154 & 0.019 & 0.049 & a. 154 & 0.019 & 0.053 & $\mathrm{JH}$ \\
\hline$P H$ & & & & & & & 0 & 0.078 & 0.003 & 0.011 & 0.067 & 0.005 & 0.060 & 0.019 & 0.199 & 0.011 & $0.06 ?$ & 0 & 0.011 & 0.067 & 0.005 & RH \\
\hline WH & & & & & & & & & & 0.014 & 0.067 & 0.005 & 0.053 & 0.019 & 0159 & 0.014 & 0.067 & 0 & 0.014 & 0.067 & 0.005 & WH \\
\hline EH & & & & & & & & & & & & & 0.054 & 0.019 & 0.159 & 0.005 & $0.06 ?$ & 0 & 0 & 0.72 & 0 & BH \\
\hline$T H$ & & & & & & & & & & & & & & & & 0.159 & 0.019 & 0.049 & a.159 & 0.019 & 0.053 & $T H$ \\
\hline$P R$ & & & & & & & & & & & & & . & & & & & & 0 & 0.067 & 0.005 & $P F$ \\
\hline
\end{tabular}

Person 2

\begin{tabular}{|c|c|c|c|c|c|c|c|c|c|c|c|c|c|c|c|c|c|c|c|}
\hline \multirow[b]{2}{*}{ Persen 1} & \multicolumn{3}{|c|}{$M$} & \multicolumn{3}{|c|}{ N } & \multicolumn{3}{|c|}{ wo } & \multicolumn{3}{|c|}{ JS } & \multicolumn{3}{|c|}{ DS } & \multicolumn{3}{|c|}{ JT } & \multirow[b]{2}{*}{ Ferson 1} \\
\hline & $10 x y$ & Lsharad & $2 \cos x$ & 1 Indx & stares & 2 only & $1 \mathrm{mlx}$ & shared & $2 \mathrm{coly}$ & 1 only & shared & 2 only & 1 only & shared & 2 only & $1 \mathrm{only}$ & shared & $2 \mathrm{mly}$ & \\
\hline RB & 0,005 & 0.067 & 0,003 & 0,001 & 0,072 & 0.029 & 0,005 & 0,067 & 0.003 & 0.005 & Q 067 & 0.003 & 0.005 & Q.067 & 0.003 & 0.005 & Q.067 & 0 & $P B$ \\
\hline $\mathrm{JH}$ & 0.154 & 0.013 & 0.052 & 0.154 & 0.019 & 0.083 & 0.154 & 0.019 & 0.052 & 0.154 & 0.019 & 0.052 & 0.154 & 0.019 & 0.052 & 0.154 & 0.019 & 0.049 & JH \\
\hline PH & 0.011 & 0.060 & 0.003 & 0.011 & 0.067 & Q. 034 & 0.011 & 0,067 & 0,003 & 0.011 & 6,067 & 0.003 & 0.011 & 0.067 & 0.003 & 0.011 & 0.067 & 0 & PH \\
\hline$W H$ & 0.011 & $0.0 \pi$ & 0 & 0.011 & 0.071 & 0.031 & 0.011 & 0.071 & 0 & 0.011 & 0.071 & 0 & 0.011 & 0.07 & 0 & 0.014 & 0.067 & 0 & HH \\
\hline BH & 0,0015 & 0,060 & 0.003 & 0 & 0.072 & 0.029 & 0.005 & 0.067 & 0.003 & 0.005 & C.067 & 0.003 & 0.005 & 0.067 & 0.003 & 0.005 & 0,667 & 0 & EH \\
\hline$T H$ & 0.159 & 0.017 & 0.052 & 0.159 & 0.019 & 0.083 & C. 159 & 0.019 & 0.052 & 0.159 & 0.019 & 0.052 & 0.199 & 0.019 & 0.052 & 0.159 & 0.019 & 0.049 & TH \\
\hline RK & 0 & 0.067 & 0.003 & 0 & 0.067 & 0.034 & 0 & 0.067 & 0,003 & 0 & Q.067 & 0.003 & 0 & 0.067 & 0,003 & 0 & 0.067 & 0 & RK \\
\hline SL & 0.065 & 0.067 & 0.003 & 0 & 0.072 & 0.020 & 0.005 & 0.067 & 0.003 & 0.005 & 0.067 & 0.003 & 0.005 & 0.067 & 0.003 & 0.005 & 0.067 & 0 & SL \\
\hline M & & & & 0 & 0.071 & 0.031 & 0 & 0.071 & 0 & 0 & 0.071 & 0 & 0 & 0.071 & 0 & 0.003 & 0.067 & 0 & mM \\
\hline $\mathrm{KN}$ & & - & & & & & 0.031 & 0.071 & 0 & 0.031 & 0.071 & 0 & 0.031 & $0.0 \pi$ & 0 & 0.034 & 0.067 & 0 & IN \\
\hline wo & & . & & & & & & & & 0 & 0.071 & 0 & 0 & 0.071 & 0 & 0.003 & 0.067 & 0 & wo \\
\hline JS & & & & & & & & & & & & & 0 & 0.07 & 0 & 0.003 & 0.067 & 0 & JS \\
\hline DS & & & & & & & & & & & & & & & & 0.003 & 0,067 & 0 & DS \\
\hline
\end{tabular}


CONCLUSIONS

The results reported in this chapter can not be directly compared with those reported in Chapter 2. A different level of knowledge of both the specifics of the siting problem and the details of siting methodologies is represented in the two groups of decision makers. More significantly, the number of attributes included in the analysis is less than half that used in Chapter 2. In addition, the unavoidable carryover of results from one weighting method to another reduces potential differences attributable to method.' Nevertheless, there is information to be inferred from these differences as well as the differences tested in the experimental procedure.

1. Unlike the results reported in Chapter 2, correlations both between persons and between methods are relatively high. Correlations between methods are attributable to carryover, and correlations between persons are probably attributable to the smaller number of attributes involved. The few that were included were considered important by $50 \%$ or more of the advisory panel, so there was relatively little disagreement about their relative significance. With a larger number of attributes there is more opportunity for disagreement.

2. The smaller number of attributes appears to produce a greater robustness of results to differences in exclusion criteria and weights. This is attributable to the coarser scale of the assessment and, therefore, reduced opportunity for small-scale disagreements between individuals. This is particularly apparent in the broad distribution over the region of candidate areas in the first study compared to the single large group of candidate areas in the second.

3. Exclusionary Screening produces different areas from Weighting Summation screening although not so great a difference as in Chapter 2 . The greatest difference is between Exclusionary Screening and Weighting Summation candidate areas based on combined group criteria and weights.

4. Categorization Weights tend to underestimate importance ratios and are more different from Metfessel Allocation weights than are Rating Weights. This difference does not carry over to suitabilities due to the robustness of the solutions.

5. As reported for the Maryland Screening of Chapter 2, choice of person is more important to results than choice of method.

6.- Differences between person and methods are obscured by use of group concensus Exclusion Criteria and Weights. 


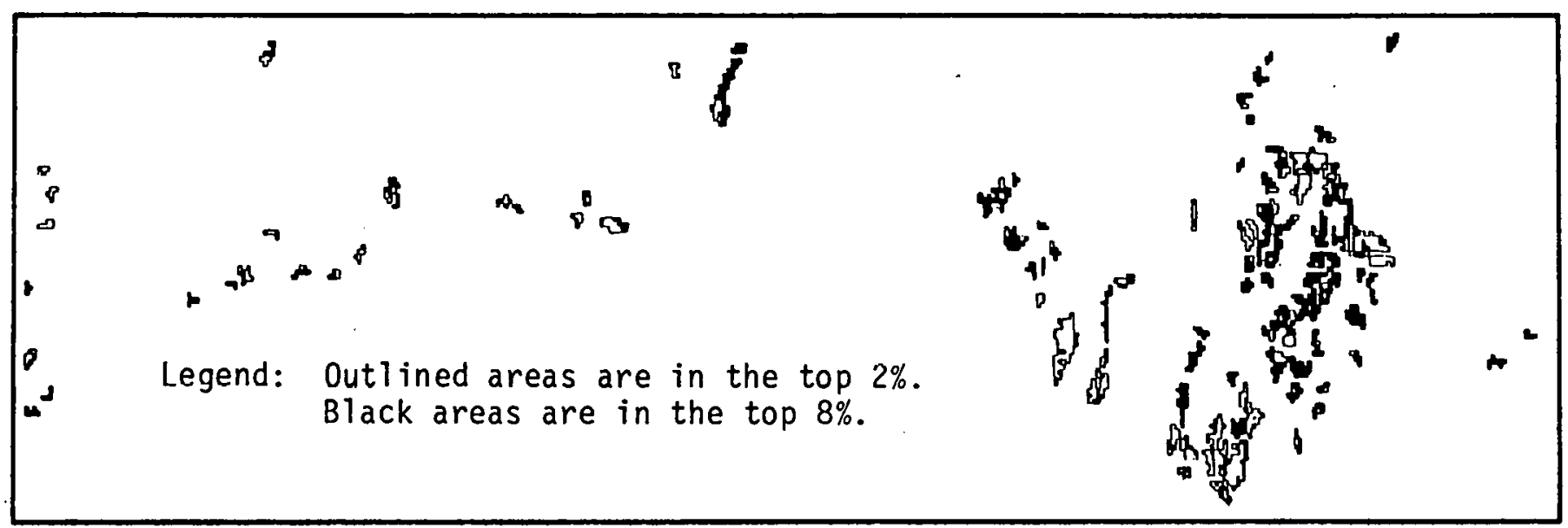

a. Rating Weighting Method

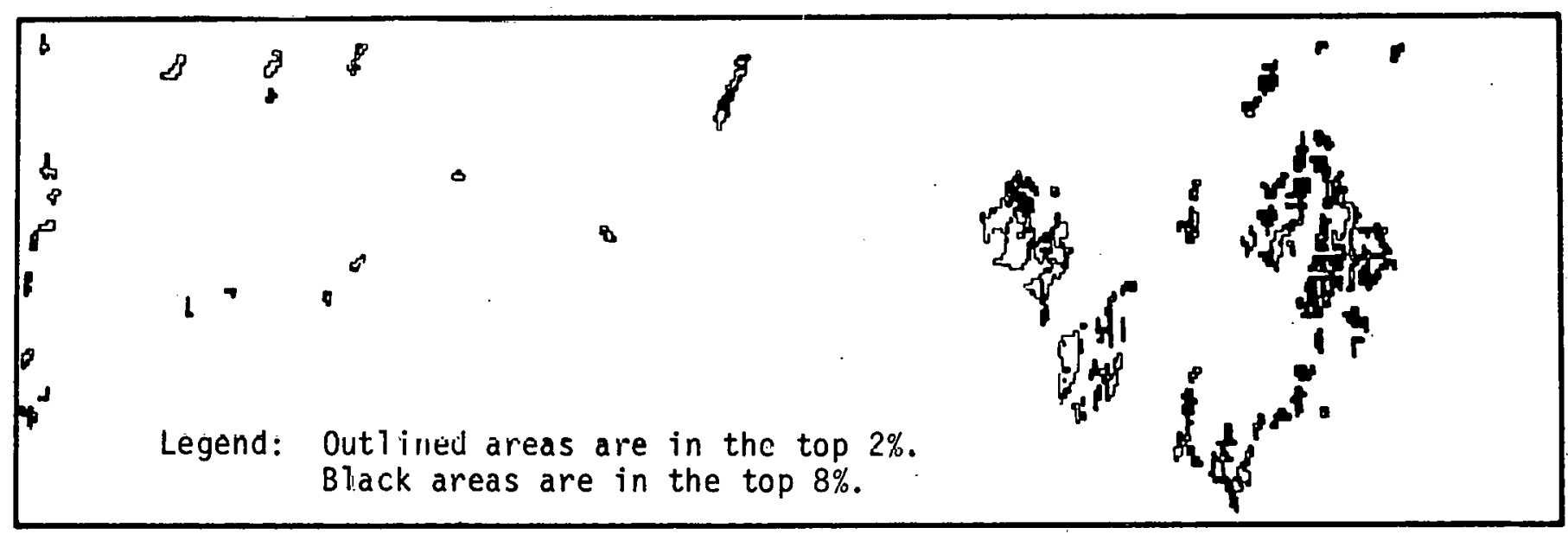

b. Indifference Tradeoff Weighting Method

Figure 4. Weighting Summation Candidate Areas, Mr. Mueller, Maryland Screening 1. 
1. B. F. Hobbs, Description of Variables within the Maryland Automated Geographic Information System (MAGI), Informal Report, Maryland Power Plant Siting Program, Annapolis, Maryland, Aug. 5, 1977.

2. B. F. Hobbs, Power Plant Siting and the Weighting Sumation Method of Decision Making, M.S. Thesis, State University of New York, College of Enviromental Science and Forestry, Syracuse, New York, 1978.

3. P. M. Meier and D. Morell, Issues in Clustered Nuclear Siting: A Comparison of a Hypothetical Nuclear Energy Center in New Jersey with Dispersed Nuclear Siting, BNL 50561, Figures 5-2 and 5-3, Sept. 1977.

4. U.S. Nuclear Regulatory Commission, Nuclear Energy Site Survey--1975, Part V: Resource Availability and Site Screening, NECSS-75, NUREG-0001, Washington, D.C., Jan. 1976.

5. J. S. Jalbert and J. E. Dobson, A Cell Based Load Use Screening Procedure for Regional Siting Analysis, ORNL/NUREG/TM-80, Oak Ridge National Laboratory, 1977.

6. Rogers and Golden and Allan Mallach/Associates, Eastern Shore Power Plant Siting Study, Maryland Major Facilities Study, Vol. 2, PPSA-4, prepared for the Maryland Power Plant Siting Program, Annapolis, Maryland, 1977.

7. C. White, The use of ranks in a test of significance for comparing two treatments, Biometric Bul1. 8, 33-41 (1952).

8. G. W. Snedecor, Statistical Methods Applied to Experiments in Agriculture and Biology, Section 5.8, Iowa State University Press, Ames, Iowa, 1956.

9. S. S. Stevens, On the theory of scales of measurement, Science 103(2684), $677-680(1946)$.

10. G. W. Snedecor, op. cit., Section 5.8 . 
Chapter 4

WESTERN UNITED STATES ANALYSES

The analyses of this chapter are almost identical to those of chapter 3. The same 14-member panel applied the same three weighting methods, and the resulting weights and candidate areas are compared as in Chapter 3. Again, no theoretically valid weighting method was applied. A different study area is used in this chapter, and cooling technology is not limited to evaporative cooling towers; instead, a mix of dry and evaporative cooling is optimized for each cell.1

STUDY AREA AND DATA BASE

Figure 22 shows the study area which encompasses eleven western states. It is extremely diverse, and includes rain forests, high mountain ranges, cold and hot deserts, the Great Plains, a long coastline, a number of major cities, and the most sparsely populated areas in the continental U.S. It was chosen because a cell-based information system exists for the region, created for a hypothetical Nuclear Energy Center siting study. 2 Also, Sandia Laboratories used a portion of the study area (Central Utah) and the same data base for another comparison of regional screening methods ${ }^{3}$ which enables us to compare their results with ours. Cell size is 10 miles square, considerably larger then the Maryland cells; there are 11942 of them.

ATTRIBUTES AND VALUE FUNCTIONS

Since the Nuclear Energy Center siting study sought candidate areas for 6 GW(e). of nuclear power, their attributes and value functions were slightly inappropriate for $2 \mathrm{GW}(e)$ of power. A few changes were made, most notably dropping some attributes which are inappropriate to this scale of power generation and recalculating magnitudes of others (Table 33). Complete documentation, as distributed to Advisory Panel Members, is presented el sewhere. 4

PARTICIPANTS

The same fourteen siting experts who chose weights and exclusion criteria in Chapter 3 participated in this study.

PROCEDURES FOR ANALYSIS

The data gathering and analysis procedures applied here are almost identical to those used in Chapter 3; refer there for descriptions. One change is 


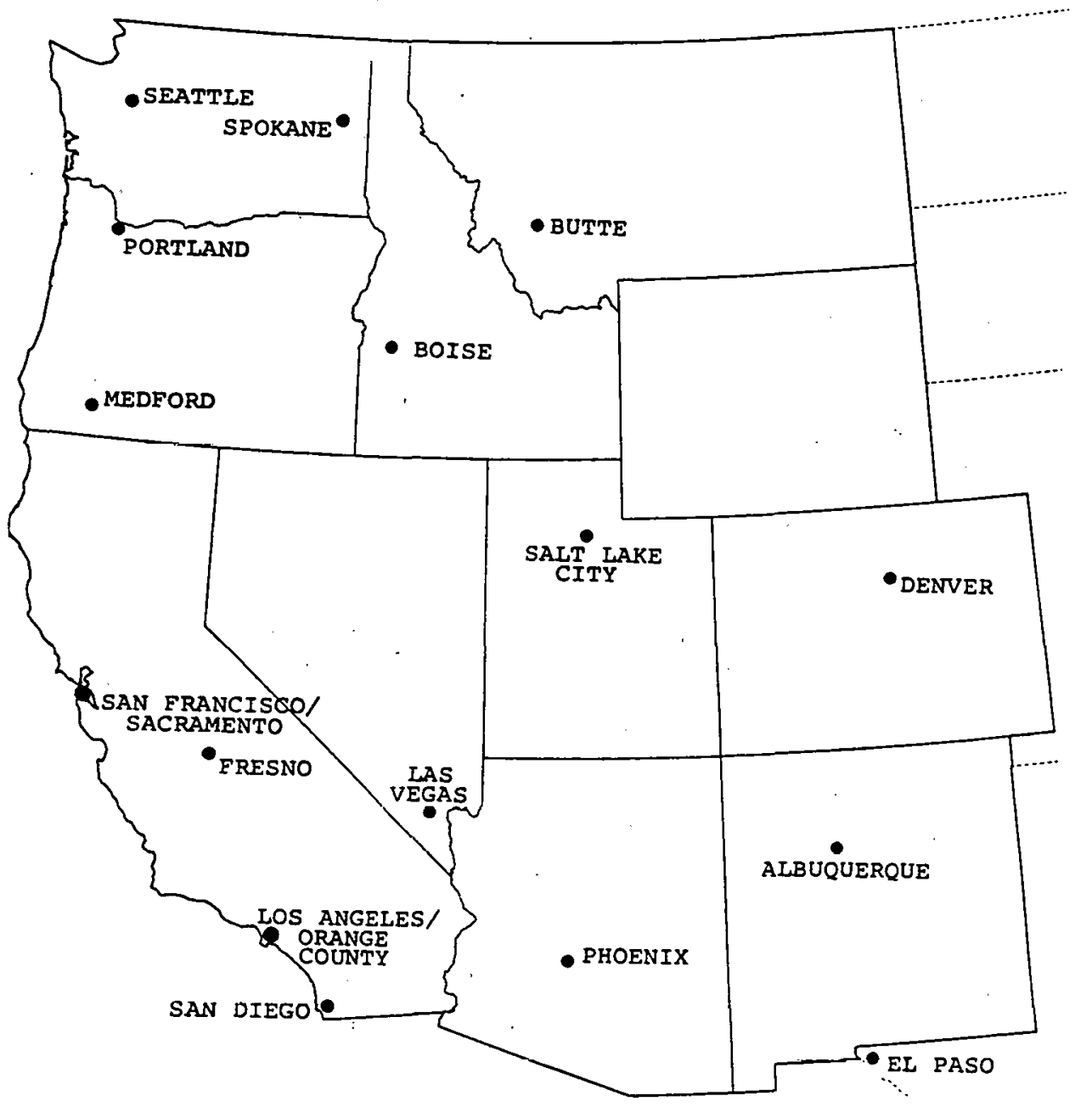

Figure 22. Western United States Study Area Showing Major Cities.

Source: Gottlieb, Robinson and Smith, Note 1 
Table 33

VARIABLES AND VALUE FUNCTIONS, WESTERN U.S.

Key: 10 = Best Possible Level or Category

0 - Worst Possible Level or Category

\section{Attribute}

Category

Value

1. Protected and

National Parks, Forests, Historic

Restricted Lands

Monuments or Wilderness Areas

Other

2. 30 Mile Site

Population

Factor

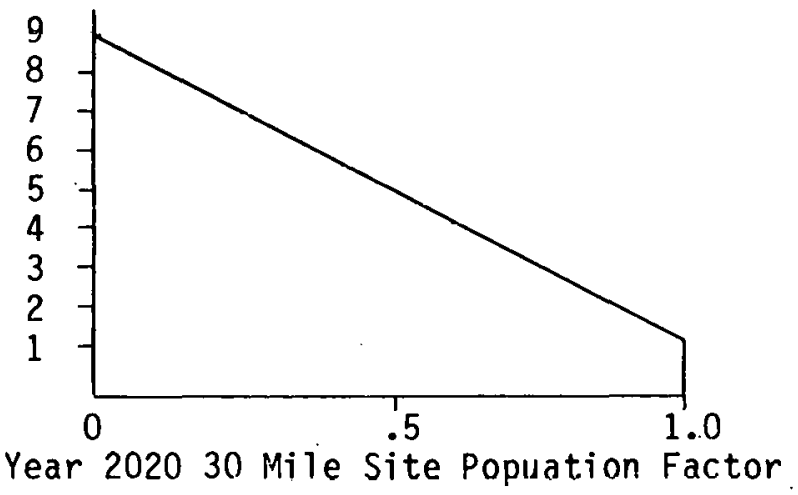

3. Airports and Air Corridors

Airport

Busy Air Corridors

Other

4. Seismic Design Costa

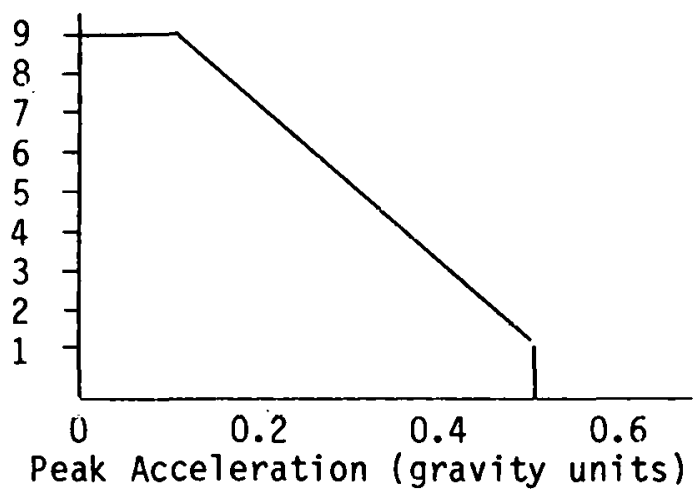

5. Power Transmission Costb

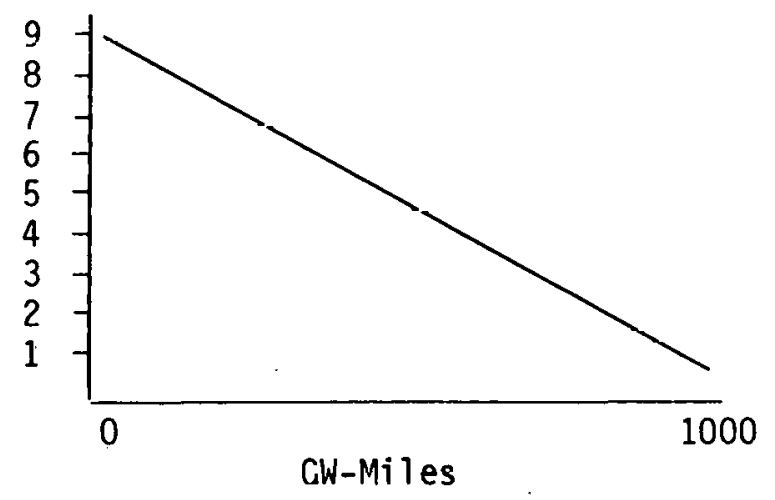


6. Cooling Costs $c$

7. Land Form

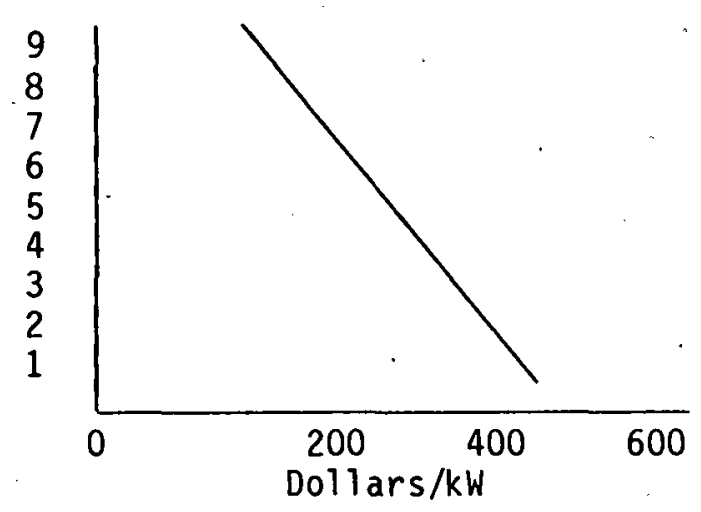

$$
\begin{aligned}
& \text { over } 80 \% \text { Gentle Slope } \\
& 50 \%-80 \% \text { Gentle Slope } \\
& 20 \%-50 \% \text { Gentle Slope } \\
& \text { less than } 20 \% \text { Gentle Slope }
\end{aligned}
$$

Source: Adapted from Gottlieb, Robinson, and Smith, Note 1.

aEach $0.1 \mathrm{~g}$ increment imposes a cost of about $\$ 25 / \mathrm{kW}(\mathrm{e})$.

bA GW-mile costs about $\$ 400,000$ (1985 dollars).

CThe cost of the optimal wet/dry cooling combination for each cell.

that there is no indicator of the influence of mood and uncertainty defined in this chapter because no two persons on this panel, have worked together on a siting project with this data base.

RESULTS

Exclusion Levels

Table 34 presents exclusion criteria for seven variables. Cells having values equal to or less than any exclusion level are dropped.

Weights

Tables 35, 36, and 37 display Categorization, Rating, and Metfessel Allocation weights, respectively, selected by the 14 participants. 


\section{Table 34}

EXCLUSION LEVELS, WESTERN U.S. SCREENING

\begin{tabular}{clllllll}
\hline & \multicolumn{7}{c}{ Attribute } \\
\cline { 2 - 8 } Participant & 1 & 2 & 3 & 4 & 5 & 6 & 7 \\
\hline RB & 0 & 7 & 5 & 5 & 2 & 3 & 1 \\
JH & 0 & 4 & 0 & 0 & 5 & 7 & 2 \\
RH & 0 & 6 & 5 & 6 & 6 & 3 & 2 \\
WH & 0 & 5 & 0 & 1 & 0 & 0 & 2 \\
BH & 0 & 7 & 0 & 1 & 0 & 4 & 2 \\
TH & 0 & 5 & 5 & 5 & 0 & 0 & 1 \\
RK & 0 & 3.5 & 0 & 2 & 1 & 0 & 5 \\
SL & 0 & 8 & 5 & 1 & 3 & 5 & 5 \\
HM & 0 & 5 & 0 & 0 & 0 & 0 & 0 \\
KN & 0 & 4.5 & 0 & 0 & 0 & 0 & 1 \\
WO & 0 & 5 & 0 & 0 & 0 & 0 & 2 \\
JS & 0 & 5 & 5 & 0 & 0 & 0 & 1 \\
DS & 0 & 5 & 5 & 1 & 1 & 1 & 1 \\
JT & 0 & 5 & 5 & 6 & 8 & 6 & 5 \\
\hline MEDIAN & 0 & 5.357 & 5 & $\frac{1}{2}$ & 1.857 & 2.071 & $\frac{5}{2}$ \\
Or MEAND & & & & & & &
\end{tabular}

aCells having a rating (Table 1) equal to or less than the indicated levels are dropped.

bedians are used for variables with discrete categories; means are used for continuous variables.

Table 35

CATEGORIZATION WEIGHTS, WESTERN U.S. SCREENING

\begin{tabular}{cccccccc}
\hline & \multicolumn{7}{c}{ Attribute } \\
\cline { 2 - 7 } Participant & 1 & 2 & 3 & 1 & 5 & 6 & 7 \\
\hline RB & 2 & 4 & 3 & 2 & 1 & 2 & 1 \\
JH & 4 & 4 & 2 & 2 & 2 & 2 & 1 \\
RH & 4 & 4 & 3 & 3 & 2 & 1 & 1 \\
WH & 4 & 4 & 3 & 2 & 2 & 2 & 1 \\
BH & 4 & 4 & 2 & 2 & 1 & 4 & 2 \\
TH & 4 & 4 & 2 & 2 & 1 & 1 & 1 \\
RK & 4 & 4.5 & 2 & 4 & 1 & 4 & 3 \\
SL & 4 & 4 & 3 & 4 & 2 & 2 & 2 \\
HM & 3 & 3 & 2 & 1 & 4 & 4 & 2 \\
KN & 4 & 4.5 & 3 & 2 & 1 & 1 & 1 \\
WO & 4 & 4 & 4 & 3 & 2 & 2 & 2 \\
JS & 0 & 4 & 4 & 1 & 1 & 1 & 1 \\
DS & 4 & 4 & 3 & 2 & 1 & 1 & 1 \\
JT & 4 & 4 & 2 & 4 & 2 & 2 & 3 \\
MEAN & 3.714 & 3.929 & 2.914 & 2.429 & 1.643 & 2.143 & 1.571 \\
\hline
\end{tabular}


Table 36

RATING WEIGHTS, WESTERN U.S. SCREENING

\begin{tabular}{cccccccc}
\hline & \multicolumn{7}{c}{ Attribute } \\
\cline { 2 - 8 } Participant & 1 & 2 & 3 & 4 & 5 & 6 & 7 \\
\hline RB & 4 & 10 & 7 & 4 & 1 & 3 & 0 \\
JH & 7 & 10 & 5 & 6 & 2 & 4 & 0 \\
RH & 9 & 10 & 8 & 7 & 4 & 2 & 0 \\
WH & 10 & 9 & 7 & 4 & 4 & 4 & 0 \\
BH & 10 & 10 & 5 & 3.2 & 1.6 & 8 & 0 \\
TH & 10 & 8 & 5 & 7 & 1 & 0 & 2 \\
RK & 9 & 10 & 6 & 9.8 & 3 & 9.6 & 4 \\
SL & 7 & 9 & 7 & 10 & 1 & 6 & 5 \\
HM & 7.5 & 7.5 & 5 & 0 & 9.5 & 10 & 2 \\
KN & 10 & 10 & 6 & 4 & 2 & 0 & 2 \\
WO & 10 & 7 & 7 & 5 & 0 & 3 & 3 \\
JS & 10 & 9 & 10 & 4 & 4 & 4 & 3 \\
DS & 9 & 10 & 6 & 5 & 1 & 0 & 2 \\
JT & 8 & 10 & 6 & 9 & 0 & 5 & 2 \\
MEAN & 8.607 & 9.25 & 6.429 & 5.571 & 2.579 & 4.186 & 1.786 \\
\hline
\end{tabular}

Table 37

METFESSEL ALLOCATION WEIGHTS, WESTERN U.S. SCREENING

\begin{tabular}{cccccrrr}
\hline & \multicolumn{7}{c}{ Attribute } \\
\cline { 2 - 8 } Participant & 1 & 2 & 3 & 4 & 5 & 6 & 7 \\
\hline RB & 10 & 50 & 20 & 10 & 3 & 7 & 0 \\
JH & 25 & 21 & 15 & 15 & 10 & 10 & 4 \\
RH & 25 & 40 & 15 & 10 & 5 & 3 & 2 \\
WH & 25 & 22 & 18 & 10 & 10 & 10 & 5 \\
BH & 28 & 28 & 11 & 7 & 3 & 22 & 1 \\
TH & 30 & 25 & 15 & 20 & 3 & 2 & 5 \\
RK & 18 & 20 & 10 & 19 & 10 & 19 & 4 \\
SL & 10 & 25 & 12 & 30 & 5 & 8 & 10 \\
HM & 15 & 15 & 10 & 5 & 25 & 20 & 10 \\
KN & 25 & 35 & 20 & 10 & 5 & 3 & 2 \\
WO & 18 & 18 & 18 & 15 & 5 & 13 & 13 \\
JS & 22 & 18 & 22 & 10 & 10 & 10 & 8 \\
DS & 24 & 30 & 16 & 12 & 6 & 4 & 8 \\
JT & 20 & 25 & 10 & 25 & 5 & 5 & 10 \\
MEAN & 21.07 & 26.57 & 15.14 & 14.14 & 7.5 & 9.71 & 5.86 \\
\hline
\end{tabular}


Analysis of Weights

Table 38 displays correlations between weight sets chosen by each person using different methods. Table 39 displays correlations between persons for the Rating method. These are indicators of the influence of choice of person on weights.

Correlations (not shown) between persons were also calculated for both the Categorization and Metfessel weight sets. A nonparametric paired observations test 5 shows that Rating correlations are significantly greater $(p<0.01)$ than both Categorization and Metfessel correlations. Chapter 3, in contrast, finds no significant differences. This test is invalid in this case however, because each set of 91 between-persons correlations has only 13, not 90 degrees of freedom (14 independent weight sets). A more valid test might show that the differences are insignificant.

By a modification of White's nonparametric two-sample test (see Chapter 3 ), each of the three groups of between-methods correlations (Table 38) is significantly greater $(p<0.001)$ than the Rating between-persons correlations (Table 39). This means that choice of person (from within the Advisory panel) makes a much greater difference in weights than choice of method (among Categorization, Rating, or Metfessel Allocation), just as in Chapter 3.

Also as in Chapter 3 , the three sets of between-methods correlations (Table 38) are compared using the nonparametric paired observations test. Unlike Chapter 3 , where one pair of sets was significantly different, none of the sets is significantly different from any of the others at the 0.1 level of confidence.

The làst test compares the "spread" of weight sets from different methods. We hypothesize that Categorization should understate ratios of importance of attributes, resulting in lower coefficients of variation (CV). The nonparametric paired observations test described above supports this. The mean $\mathrm{CV}$ is 0.474 for Categorization, while it is 0.679 for Rating and 0.663 for Metfessel Allocation. Each of the 14 Rating and Metfessel Allocation weight sets have significantly higher $(p<0.01) \mathrm{CV}$ 's than the 14 Categorization sets. This agrees with the results in Chapter 3.

The three correlations between mean weights (Table 38) are higher than most of the participants' between-methods correlations, and the CV's of the mean Categorization (0.334), Rating (0.480), and Metfessel Allocation weights (0.484) are much lower than the mean CV for each method. Therefore, as in 
Table 38

BETWEEN-METHODS CORRELATIONS, WESTERN U.S. SCREENINGa

Mean

$\begin{array}{lllllllllllllll}\text { Methods } & \text { RB } & \text { JH } & \text { RH } & \text { WH } & \text { BH } & \text { TH } & \text { RK } & \text { SL } & H M & \text { KN } & \text { WO } & \text { JS } & \text { DS } & \text { JT Weights }\end{array}$

$\begin{array}{llllllllllllllll}\text { C-R } & .992 & .869 & .977 & .990 & .971 & .891 & .881 & .951 & .965 & .981 & .905 & .988 & .977 & .924 & 0.988\end{array}$

$\begin{array}{lllllllllllllllll}\text { R-M } & .942 & .886 & .857 & .983 & .993 & .996 & .922 & .907 & .916 & .956 & .913 & .994 & .981 & .960 & 0.979\end{array}$

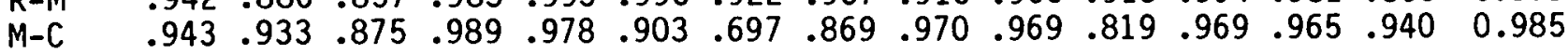

akey: $C=$ Categorization

$\mathrm{R}=$ Rating

$M=$ Metfessel Allocation

Chapter 3, group mean weights vary less among themselves than individual's weights, and differences of opinion among members are obscured by mean weights. Use of mean weights also lessens the effect of choice of method.

Candidate Area Definition

Exclusionary Screening. A set of Exclusionary Screening candidate areas was generated for each set of exclusionary criteria in Table 34 . Candidate areas consist of all cells with attribute value levels higher than all exclusionary criteria. Table 40 gives the number of cells and fraction of study area that passes each set of exclusionary criteria. Only one person excluded all cells; that person also excluded all cells in the Maryland Screening (Chapter 3). Another person, who also excluded all cells in western Maryland, here accepts more cells (64\%) than anyone else but one. Only four persons allowed between $0 \%$ and $20 \%$ of the study area. Two of those persons' areas are

\section{Table 39}

BETWEEN-PERSONS CORRELATIONS OF RATING WEIGHT SETS, WESTERN U.S. SCREENING

\begin{tabular}{|c|c|c|c|c|c|c|c|c|c|c|c|c|c|}
\hline $\begin{array}{l}\text { Partic- } \\
\text { ipant }\end{array}$ & $\mathrm{JH}$ & RH & WH & $\mathrm{BH}$ & TH & RK & SL & $H M$ & $\mathrm{KN}$ & WO & JS & DS & UT \\
\hline $\begin{array}{l}\text { RB } \\
\text { JH } \\
\text { RH } \\
\text { WH } \\
\text { BH } \\
\text { TH } \\
\text { RK } \\
\text { SL } \\
H M \\
\text { KN } \\
W O \\
\text { JS } \\
\text { DS }\end{array}$ & .887 & $\begin{array}{l}.826 \\
.896\end{array}$ & $\begin{array}{l}.752 \\
.857 \\
.905\end{array}$ & $\begin{array}{l}.682 \\
.827 \\
.644 \\
.848\end{array}$ & $\begin{array}{l}.601 \\
.780 \\
.861 \\
.756 \\
.550\end{array}$ & $\begin{array}{l}.590 \\
.796 \\
.523 \\
.529 \\
.772 \\
.549\end{array}$ & $\begin{array}{l}.683 \\
.766 \\
.641 \\
.423 \\
.454 \\
.709 \\
.821\end{array}$ & $\begin{array}{r}.097 \\
.133 \\
.039 \\
.385 \\
.504 \\
-.256 \\
.004 \\
-.471\end{array}$ & $\begin{array}{l}.721 \\
.801 \\
.886 \\
.866 \\
.648 \\
.919 \\
.418 \\
.526 \\
.016\end{array}$ & $\begin{array}{r}.628 \\
.718 \\
.759 \\
.785 \\
.697 \\
.882 \\
.590 \\
.637 \\
-.120 \\
.859\end{array}$ & $\begin{array}{l}.754 \\
.702 \\
.836 \\
.906 \\
.692 \\
.717 \\
.325 \\
.363 \\
.216 \\
.868 \\
.848\end{array}$ & $\begin{array}{r}.774 \\
.840 \\
.899 \\
.826 \\
.629 \\
.944 \\
.499 \\
.657 \\
-.109 \\
.985 \\
.875 \\
.835\end{array}$ & $\begin{array}{r}.780 \\
.904 \\
.772 \\
.666 \\
.704 \\
.811 \\
.892 \\
.947 \\
-.217 \\
.702 \\
.791 \\
.574 \\
.793\end{array}$ \\
\hline
\end{tabular}


shown in Figures 23 and 24. In an actual siting study, screening criteria would be 100 sened or tightened if too few or too many cells passed.

Figure 25 shows the number of persons accepting each cell. There is a large degree of consensus. This is to be expected, as Tables 34 and 40 show that participants who choose fewer cells generally have stricter criteria on every attribute than particpants who accept more cells.

Weighting Summation. As in Chapter 3, the small number of attributes used resulted in less discrimination among cells than in Chapter 2, where 17 attributes were used. Hence, the $8 \%$ cutoff was rarely exactly achieved; cutoffs range from $7 \%$ to $10 \%$. This is a narrower range than in chapter 3 , however.

One participant's Categorization, Rating, and Metfessel Allocation areas are shown in Figures 26 through 28. Differences among them are among the largest that appear between methods for a single person. Figures 29 and 30 display representative Metfessel Allocation candidate areas. Differences among Figures 28 through 30 are representative of differences between Metfessel Allocation areas chosen by different persons. Figure 31 presents the number of persons for which each cell falls in the top $8 \%$ of Metfessel Allocation suitabilities.

Table 40

NUMBER OF CELLS PASSING EXCLUSIONARY SCREENING CRITERIA, WESTERN U.S. SCREENING

\begin{tabular}{|c|c|c|c|c|c|c|c|c|c|}
\hline & \multicolumn{8}{|c|}{ Number of Criteria Passed } & \multirow{2}{*}{$\begin{array}{l}\text { Percent of Study } \\
\text { Area Passing } \\
\text { A11 Screens }\end{array}$} \\
\hline & 0 & 1 & 2 & 3 & 4 & 5 & 6 & 7 & \\
\hline $\mathrm{RB}$ & 0 & 0 & 12 & 252 & 1300 & 2810 & 4495 & 3055 & 25.62 \\
\hline $\mathrm{JH}$ & 0 & 0 & 0 & 355 & 1832 & 3714 & 4680 & 1343 & 11.26 \\
\hline RH & 0 & 7 & 181 & 1111 & 2529 & 4090 & 3509 & 497 & 4.17 \\
\hline WH & 0 & 0 & 0 & 25 & 274 & 2557 & 3259 & 5809 & 48.72 \\
\hline $\mathrm{BH}$ & 0 & 0 & 0 & 25 & 321 & 2604 & 3456 & 5488 & 46.02 \\
\hline TH & 0 & 0 & 12 & 250 & 1278 & 2731 & 3276 & 3277 & 27.48 \\
\hline RK & 0 & 0 & 0 & 40 & 878 & 3710 & 6907 & 389 & 3.26 \\
\hline SL & 0 & 8 & 61 & 275 & 1626 & 5136 & 4501 & 317 & 2.66 \\
\hline HM & 0 & 0 & 0 & 0 & 0 & 93 & 3508 & 8323 & 69.80 \\
\hline KN & 0 & 0 & 0 & 0 & 10 & 1564 & 2691 & 7659 & 64.23 \\
\hline WO & 0 & 0 & 0 & 0 & 39 & 2465 & 3278 & 6142 & 51.51 \\
\hline $\mathrm{JS}$ & 0 & 0 & 0 & 13 & 389 & 2000 & 4175 & 5347 & 44.48 \\
\hline DS & 0 & 0 & 18 & 122 & 826 & 2798 & 4096 & 4064 & 34.68 \\
\hline $\begin{array}{l}\mathrm{JT} \\
\text { Grou }\end{array}$ & 5 & 96 & 1059 & 3323 & 4640 & 2735 & 66 & 0 & 0.00 \\
\hline $\begin{array}{l}\text { Group } \\
\text { Consensus }\end{array}$ & 0 & 0 & 0 & 37 & 662 & 2490 & 3464 & 5271 & 44.20 \\
\hline
\end{tabular}




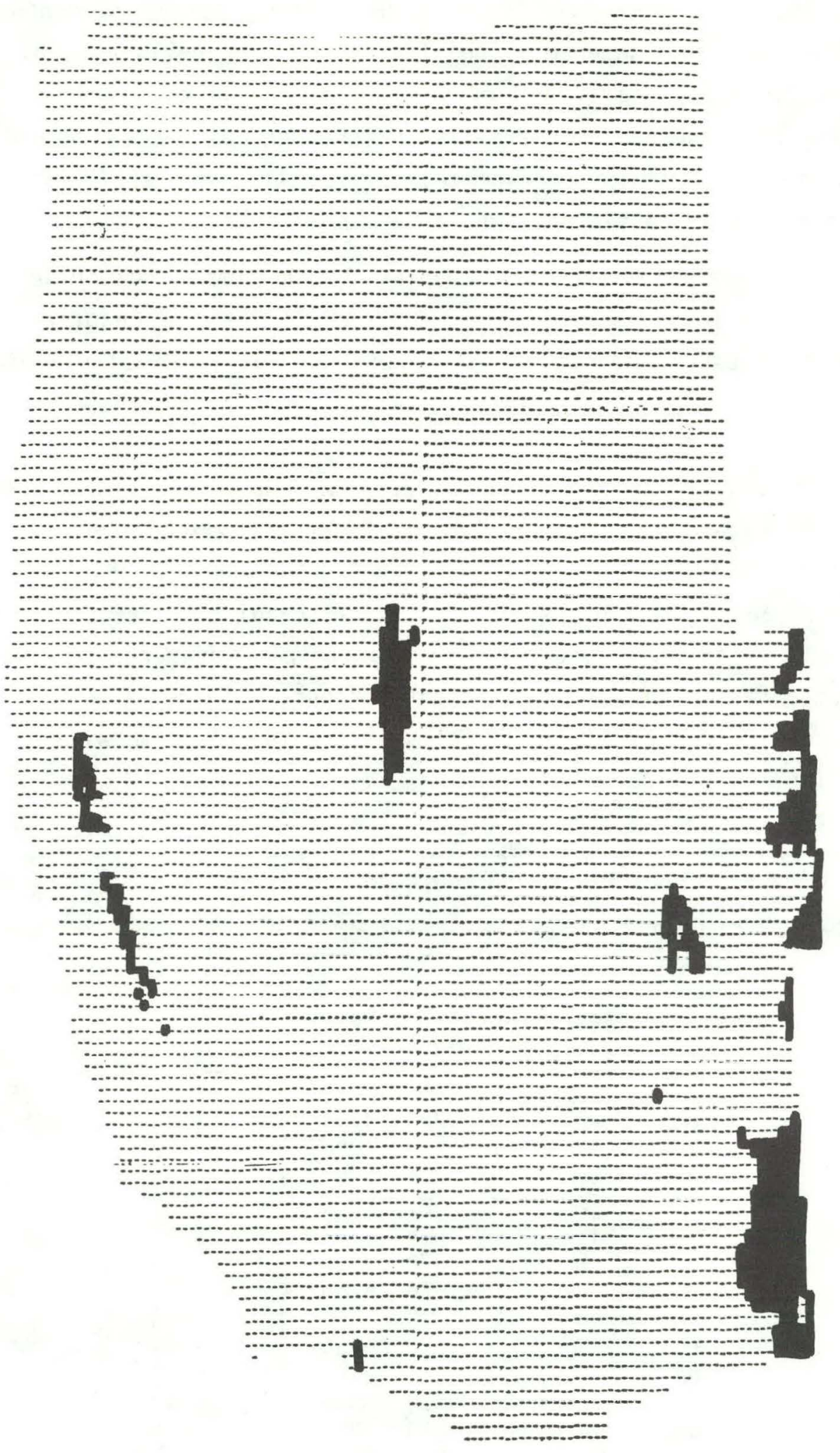

Figure 23. Exclusionary Screening Candidate Areas, Advisory Panel (RK), Western U.S. Screening. 


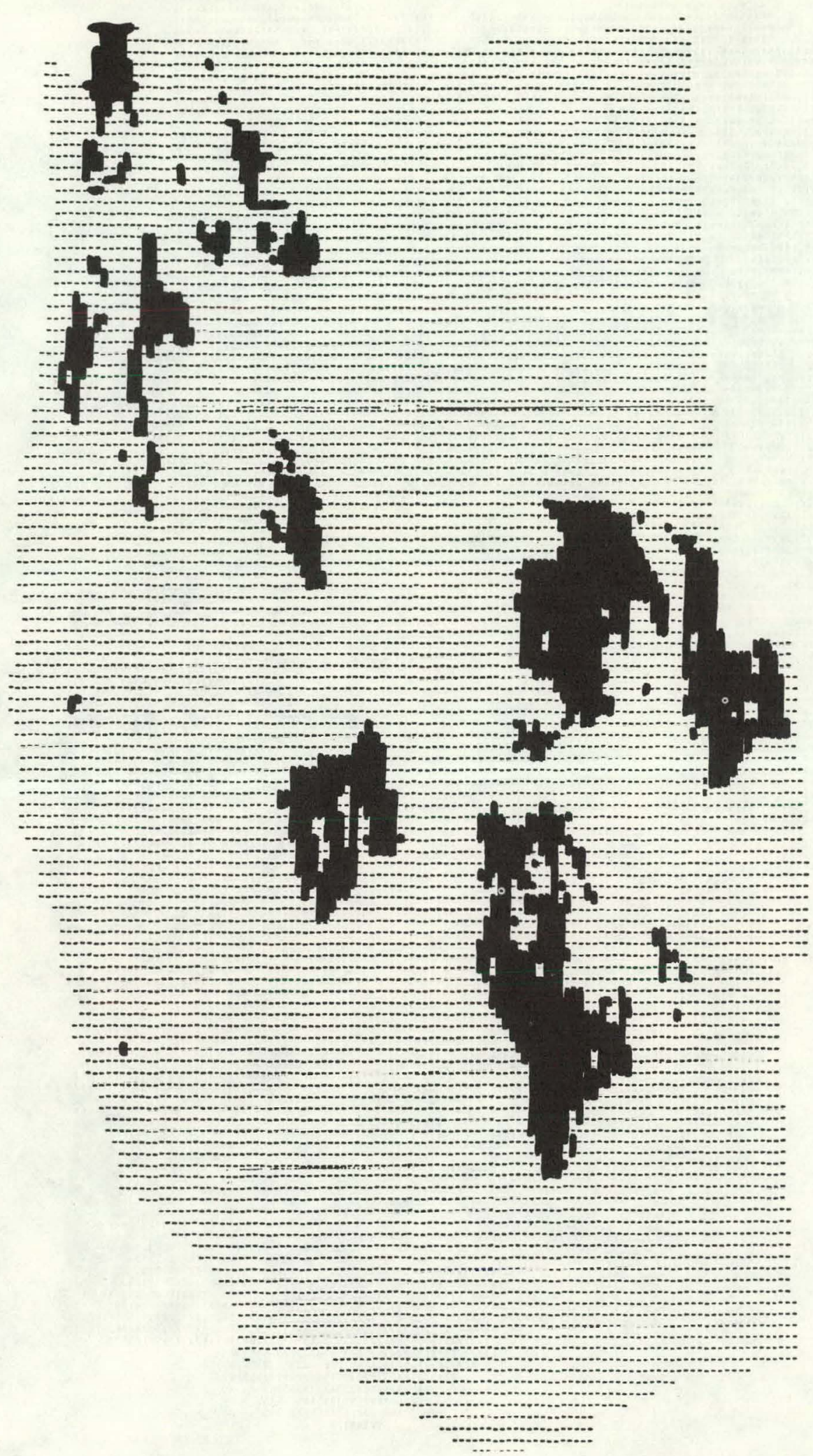

Figure 24. Exclusionary Screening Candidate Areas, Advisory Panel (JH), Western U.S. Screening. 


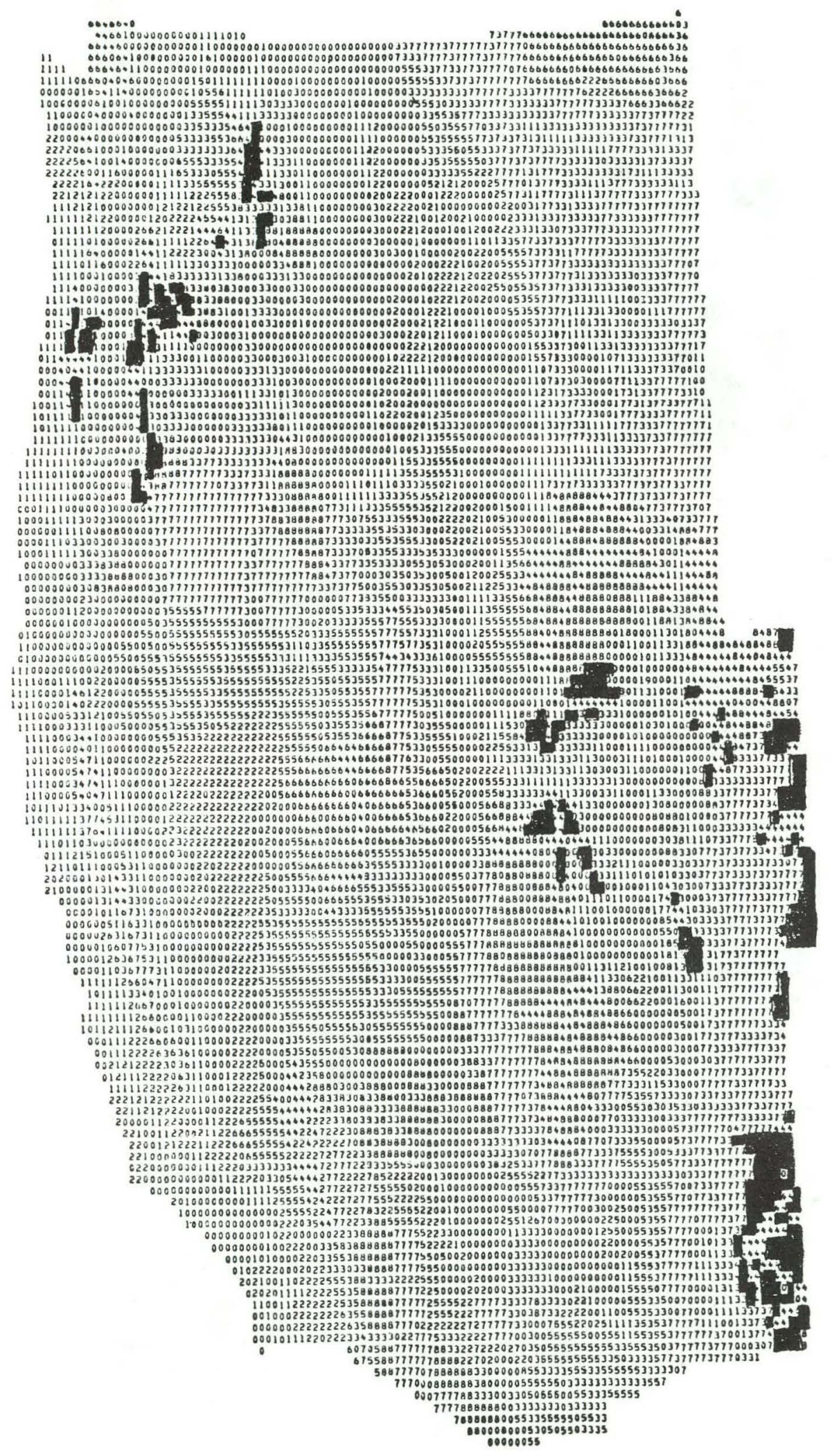

Figure 25. Number of Persons for Which Each Cell Passed A1l Exclusionary Criteria, Advisory Panel, Western U.S. Screening. Darkened areas were passed by more than 10 persons. 


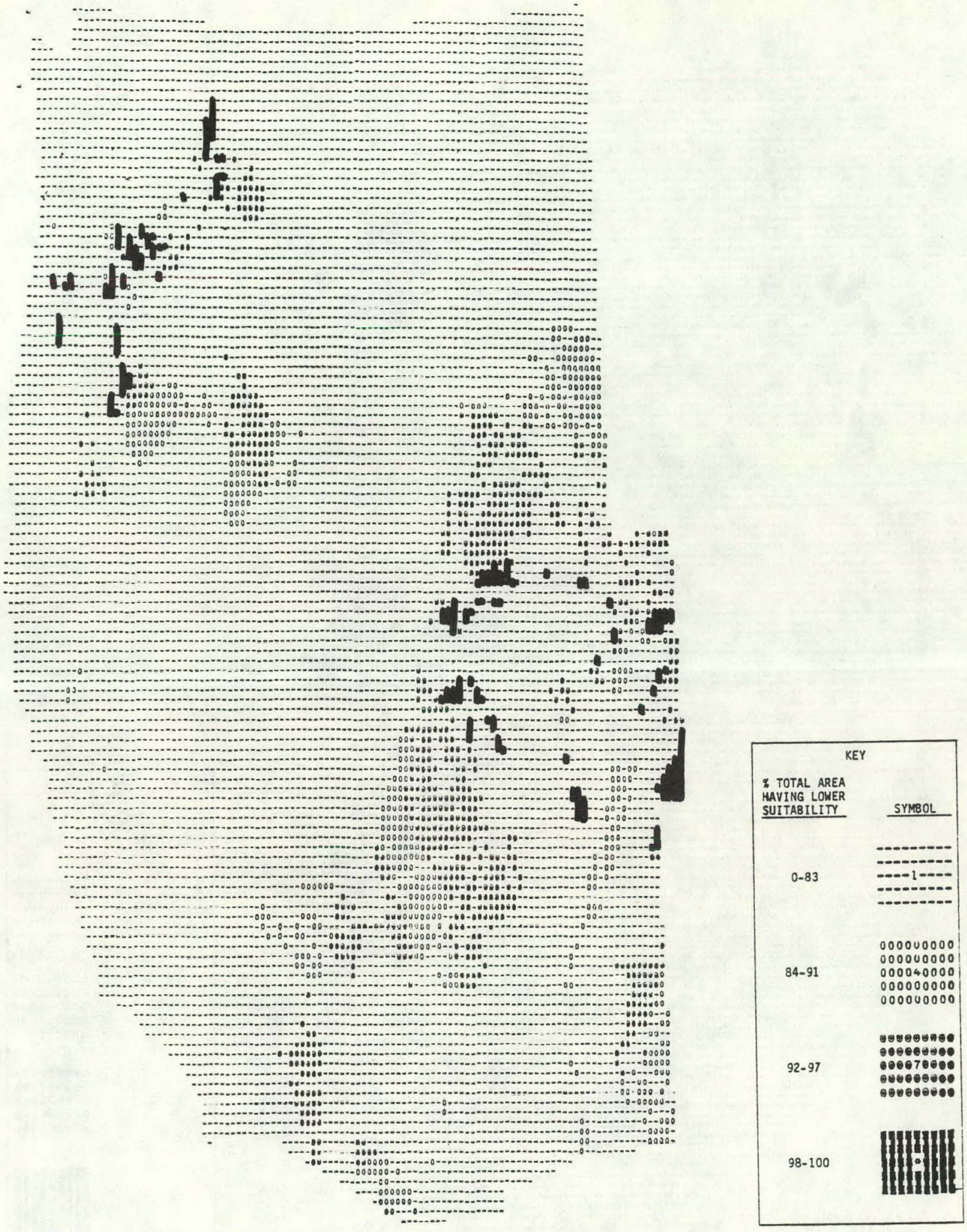

Figure 26. Categorization Candidate Areas, Advisory Panel (KN), Western U.S. Screening. 


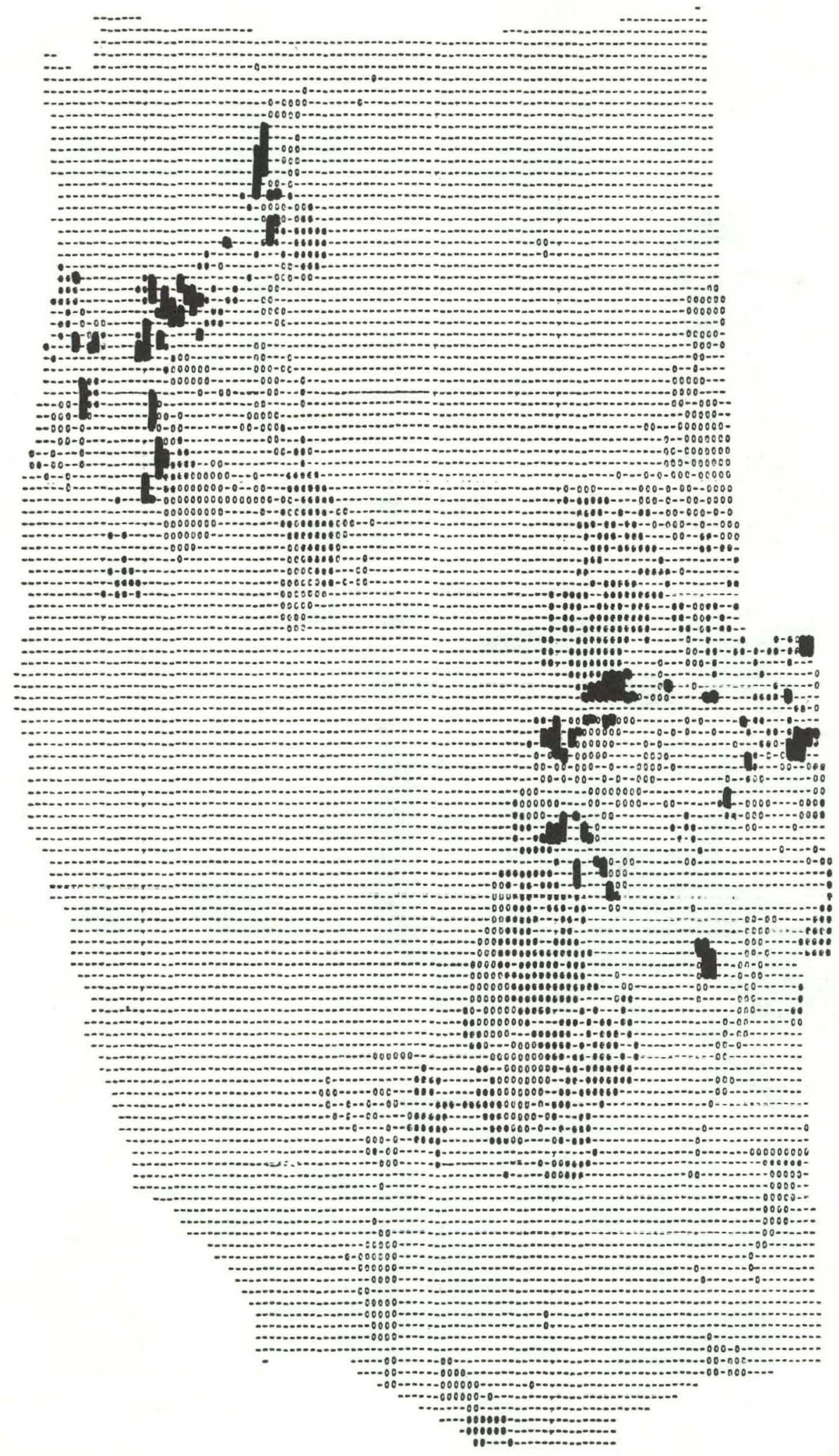

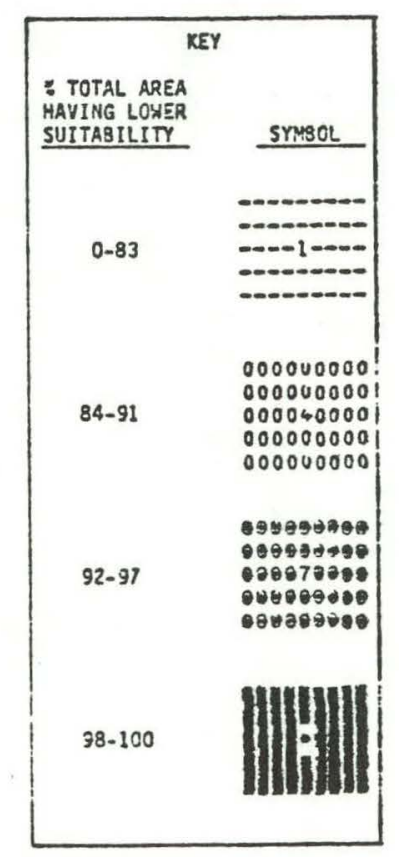

Figure 27. Rating Candidate Areas, Advisory Panel (KN), Western U.S. Screening. 




Figure 28. Metfessel Allocation Candidiate Areas, Advisory Panel (KN), Western U.S. Screening. 

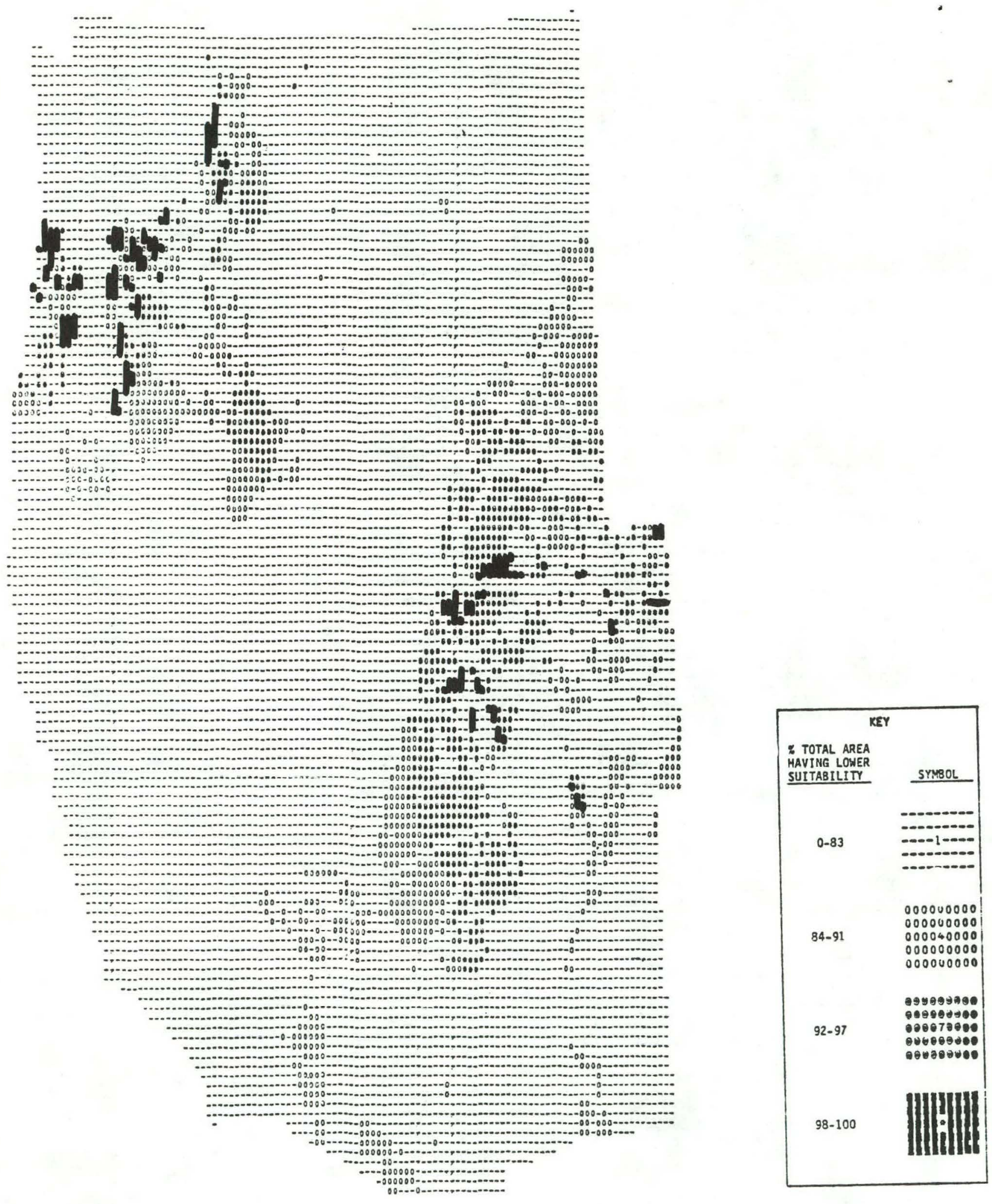

Figure 29. Metfessel Allocation Candidate Areas, Advisory Panel (RK), Western U.S. Screening. 

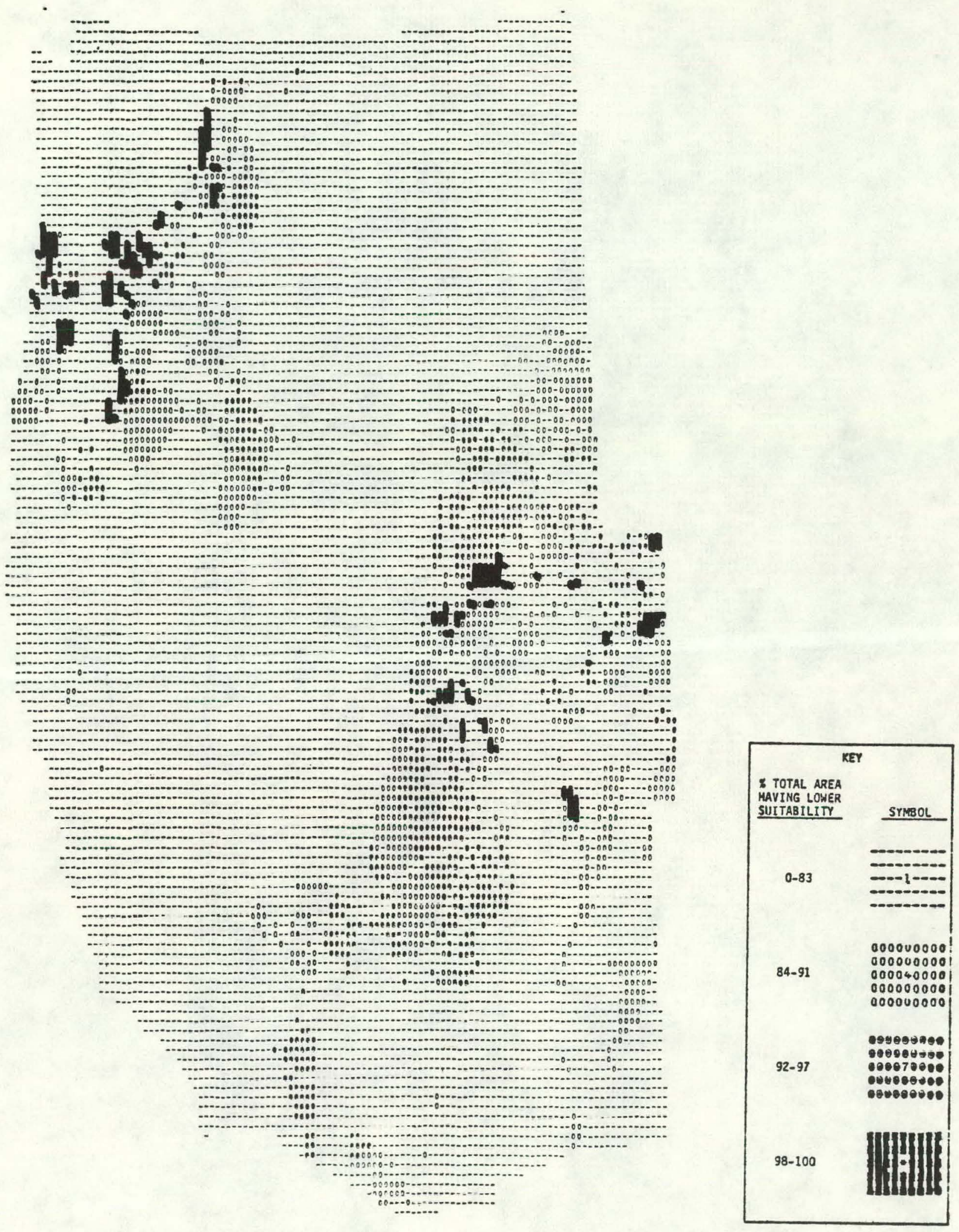

Figure 30. Metfessel Allocation Candidate Areas, Advisory Panel (JH), Western U.S. Screening. 


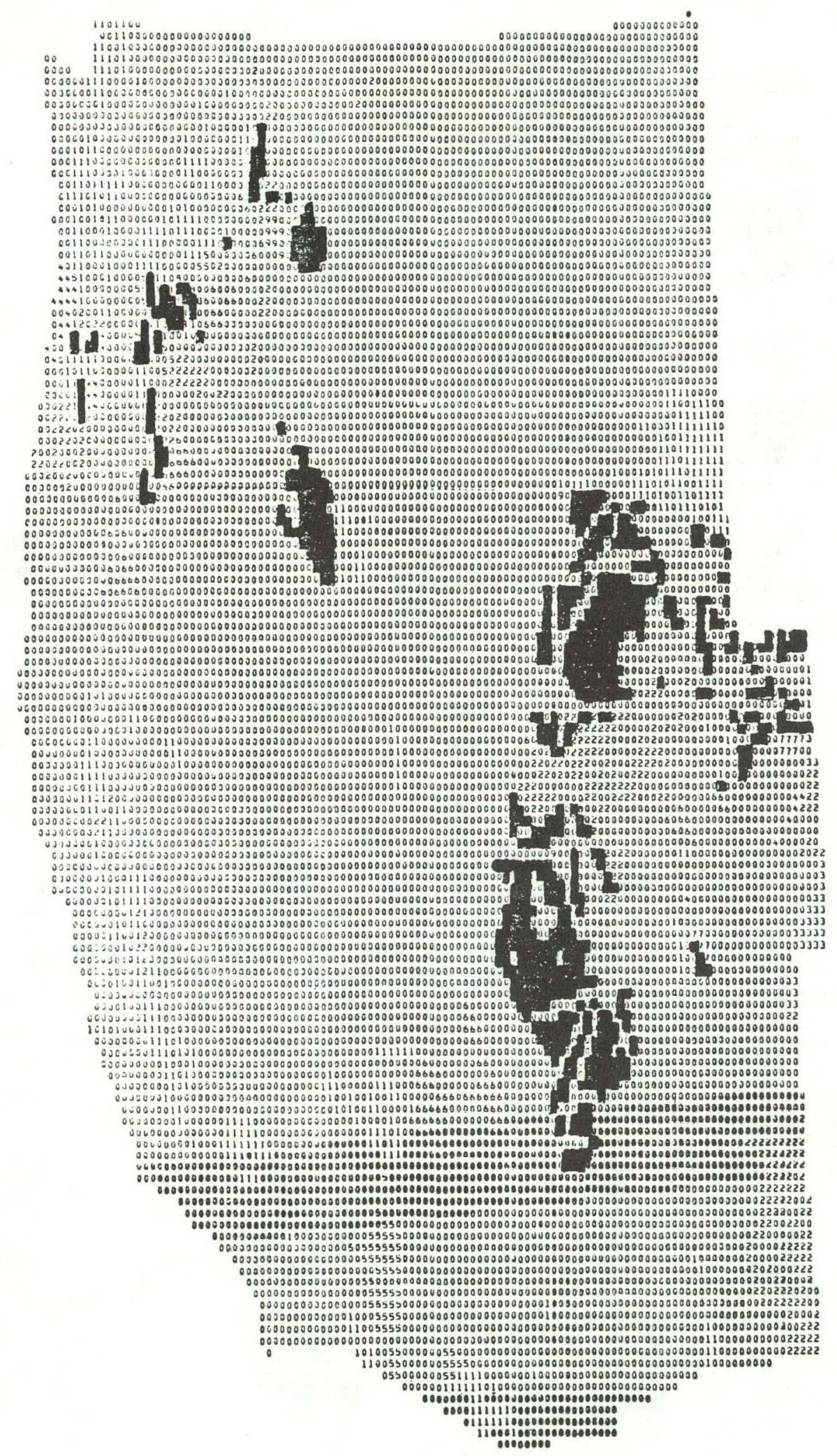

Figure 31. Number of persons for which each cell passed was in the top $8 \%$ of Metfessel Allocation Screening Areas. Darkened areas were passed by more than 10 persons. 
Analysis of Cell Suitability Scores and Candidate Areas

Exclusionary Screening vs Weighting Summation. Table 41 presents proportions of overlap of seven sets of Exclusionary Screening areas with their corresponding Categorization, Rating, and Metfessel Allocation areas. Weighting Summation areas are defined in Table 41 so that they include about the same number of cells as the screening areas. For 3 of the 6 persons represented in Table 41, there is more disagreement than agreement between the two decision rules. Exclusionary Screening areas in Figure 23 for example, have almost no overlap with the top $1.3 \%$ of Metfessel Allocation areas for the same person in Figure 29. There are also large differences between another person's Exclusionary Screening and Weighting Summation areas (Figures 24 and 30). This is also the case in the Sandia Laboratories study which uses a modified version of the same data base. 6 other participants and group consensus results agree more than they disagree.

Comparison of Weighting Methods. Table 42 shows between-methods proportions of overlap and Table 43 shows between-persons (Metfessel Allocation) overlaps. There are greater differences between methods here than in the Maryland study (Chapter 3), even though fewer attributes are weighted. Mean between-methods overlap is about $87.5 \%$. Mean between-persons overlap for Metfessel Allocation areas is about $83.3 \%$, slightly less than mean between-methods overlap.

Although differences due to choice of method are generally small, they are large in a few cases. Figures 26 through 29 show one person's Categorization and Metfessel Allocation areas which overlap only about $75 \%$ with his Rating areas. This is still greater, however, than the bctween-methuds overlaps in the Maryland study of Chapter 2.

\section{CONCLUSIONS}

The conditions of this study were nearly identical to those of the study reported in Chapter 3 , and the results are correspondingly similar.

1. Correlations between persons and between methods is high, apparently because of carryover between methods and the small number of attributes all preselected as important by the Advisory Panel which produces robust results.

2. Agreement between Exclusionary Screening and Weighting Summation Candidate Areas is smal1. Unlike the results of Chapter 3, there was more agree- 
Table 41

EXCLUSIONARY SCREENING AND WEIGHTING SUMMATION PROPORTIONS OF OVERLAP OF CANDIDATE AREAS, WESTERN U.S. SCREENING

\begin{tabular}{|c|c|c|c|c|}
\hline Participant & $\begin{array}{l}\text { Weighting } \\
\text { Methoda }\end{array}$ & $\begin{array}{l}\text { Proportion of } \\
\text { Study Area in } \\
\text { Exclusionary } \\
\text { Screening } \\
\text { Area Only }\end{array}$ & $\begin{array}{l}\text { Proportion of } \\
\text { Study Area in } \\
\text { Both Exclusion- } \\
\text { ary Screening } \\
\text { and Weighting } \\
\text { Summation Areas }\end{array}$ & $\begin{array}{l}\text { Proportion of } \\
\text { Study Area in } \\
\text { Weighting } \\
\text { Summation } \\
\text { Area Only }\end{array}$ \\
\hline $\mathrm{RB}$ & $\begin{array}{l}C \\
R \\
M\end{array}$ & $\begin{array}{l}0.043 \\
0.020 \\
0.028\end{array}$ & $\begin{array}{l}0.213 \\
0.236 \\
0.228\end{array}$ & $\begin{array}{l}0.022 \\
0.024 \\
0.022\end{array}$ \\
\hline $\mathrm{JH}$ & $\begin{array}{l}C \\
R \\
M\end{array}$ & $\begin{array}{l}0.057 \\
0.058 \\
0.059\end{array}$ & $\begin{array}{l}0.055 \\
0.055 \\
0.054\end{array}$ & $\begin{array}{l}0.078 \\
0.077 \\
0.051\end{array}$ \\
\hline $\mathrm{RH}$ & $\begin{array}{l}C \\
R \\
M\end{array}$ & $\begin{array}{l}0.026 \\
0.016 \\
0.016\end{array}$ & $\begin{array}{l}0.016 \\
0.025 \\
0.025\end{array}$ & $\begin{array}{l}0.002 \\
0.015 \\
0.015\end{array}$ \\
\hline TH & $\begin{array}{l}\mathrm{C} \\
\mathrm{R} \\
\mathrm{M}\end{array}$ & $\begin{array}{l}0.046 \\
0.022 \\
0.013\end{array}$ & $\begin{array}{l}0.229 \\
0.253 \\
0.261\end{array}$ & $\begin{array}{l}0.045 \\
0.015 \\
0.016\end{array}$ \\
\hline RK & $\begin{array}{l}\mathrm{C} \\
\mathrm{R} \\
\mathrm{M}\end{array}$ & $\begin{array}{l}0.027 \\
0.032 \\
0.031\end{array}$ & $\begin{array}{l}0.006 \\
0.001 \\
0.002\end{array}$ & $\begin{array}{l}0.011 \\
0.014 \\
0.011\end{array}$ \\
\hline SL & $\begin{array}{l}\mathrm{C} \\
\mathrm{R} \\
\mathrm{M}\end{array}$ & $\begin{array}{l}0.022 \\
0.012 \\
0.022\end{array}$ & $\begin{array}{l}0.004 \\
0.015 \\
0.005\end{array}$ & $\begin{array}{l}0.011 \\
0.011 \\
0.011\end{array}$ \\
\hline $\begin{array}{l}\text { Consensus } \\
\text { Consensus } \\
\text { Consensus }\end{array}$ & $\begin{array}{l}C \\
R \\
M\end{array}$ & $\begin{array}{l}0.106 \\
0.098 \\
0.109\end{array}$ & $\begin{array}{l}0.336 \\
0.344 \\
0.333\end{array}$ & $\begin{array}{l}0.099 \\
0.097 \\
0.103\end{array}$ \\
\hline
\end{tabular}

ment between results from group concensus exclusion criteria and weights than there was for individuals.

3. As in results from chapters 2 and 3 , Categorization tends to understate ratios of importance compared to other methods.

4. As reported in Chapter 3, choice of person is more important to results than choice of method, and use of group concensus exclusion criteria and weights obscures differences between persons and methods. 
Table 42

BETWEEN-WEIGHTING METHODS PROPORTIONS OF OVERLAP OF CANDIDATE AREAS, WESTERN U.S. SCREENINGa

\begin{tabular}{|c|c|c|c|c|c|c|c|c|c|}
\hline \multirow[b]{2}{*}{$\begin{array}{l}\text { Partic- } \\
\text { ipant }\end{array}$} & \multicolumn{3}{|c|}{ Catecorization vs Rating } & \multicolumn{3}{|c|}{ - Rating vs Metfessel Allocation } & \multicolumn{3}{|c|}{$\begin{array}{l}\text { Categorization vs } \\
\text { Metfessel Allocation }\end{array}$} \\
\hline & $\begin{array}{l}\text { Propor- } \\
\text { tion in } \\
\text { Categor- } \\
\text { ization } \\
\text { only }\end{array}$ & $\begin{array}{c}\text { Proportion } \\
\text { in } \\
\text { Both Cate- } \\
\text { gorization } \\
\text { and Rating }\end{array}$ & $\begin{array}{l}\text { Propor- } \\
\text { tion in } \\
\text { Pating } \\
\text { Conly }\end{array}$ & $\begin{array}{l}\text { Propor- } \\
\text { tion in } \\
\text { Rating } \\
\text { Only }\end{array}$ & $\begin{array}{l}\text { Proportion in } \\
\text { Both Rating } \\
\text { and Metfessel } \\
\text { Allocation }\end{array}$ & $\begin{array}{l}\text { Propor- } \\
\text { tion in } \\
\text { Metfessel } \\
\text { Allocation } \\
\text { Only }\end{array}$ & $\begin{array}{l}\text { Propor- } \\
\text { tion in } \\
\text { Categor- } \\
\text { ization } \\
\text { Only }\end{array}$ & $\begin{array}{l}\text { Proportion in } \\
\text { Both Categor- } \\
\text { ization and } \\
\text { Metfessel } \\
\text { Allocation }\end{array}$ & $\begin{array}{l}\text { Propor- } \\
\text { tion in } \\
\text { Metfessel } \\
\text { Allocation } \\
\text { Only }\end{array}$ \\
\hline $\begin{array}{l}\text { RB } \\
\text { JH } \\
\text { RH } \\
\text { WH } \\
\text { BH } \\
\text { TH } \\
\text { RK } \\
\text { SL } \\
\text { HM } \\
\text { KN } \\
\text { WO } \\
\text { JS } \\
\text { DS } \\
\text { JT }\end{array}$ & $\begin{array}{l}0.010 \\
0.015 \\
0.004 \\
0 \\
0.001 \\
0.002 \\
0.011 \\
0.010 \\
0.021 \\
0 \\
0.016 \\
0.015 \\
0 \\
0.026 \\
\end{array}$ & $\begin{array}{l}0.070 \\
0.059 \\
0.085 \\
0.074 \\
0.066 \\
0.083 \\
0.069 \\
0.059 \\
0.071 \\
0.078 \\
0.064 \\
0.074 \\
0.078 \\
0.058 \\
\end{array}$ & $\begin{array}{l}0 \\
0.010 \\
0.015 \\
0.015 \\
0.012 \\
0 \\
0.005 \\
0.005 \\
0.027 \\
0.017 \\
0.016 \\
0.001 \\
0.005 \\
0.019 \\
\end{array}$ & $\begin{array}{l}0.014 \\
0.010 \\
0.027 \\
0.015 \\
0.011 \\
0 \\
0.017 \\
0 \\
0.022 \\
0.024 \\
0 \\
0 \\
0 \\
0.019 \\
\end{array}$ & $\begin{array}{l}0.056 \\
0.059 \\
0.073 \\
0.074 \\
0.068 \\
0.083 \\
0.057 \\
0.064 \\
0.076 \\
0.071 \\
0.079 \\
0.076 \\
0.083 \\
0.058 \\
\end{array}$ & $\begin{array}{l}0.017 \\
0.015 \\
0.001 \\
0 \\
0.005 \\
0.006 \\
0.017 \\
0.014 \\
0.024 \\
0.003 \\
0 \\
0 \\
0.007 \\
0.025 \\
\end{array}$ & $\begin{array}{l}0.024 \\
0 \\
0.015 \\
0 \\
0.012 \\
0.003 \\
0.024 \\
0 \\
0 \\
0.007 \\
0.016 \\
0.006 \\
0 \\
0.003 \\
\end{array}$ & $\begin{array}{l}0.056 \\
0.074 \\
0.074 \\
0.074 \\
0.056 \\
0.083 \\
0.056 \\
0.068 \\
0.092 \\
0.071 \\
0.064 \\
0.074 \\
0.078 \\
0.083 \\
\end{array}$ & $\begin{array}{l}0.017 \\
0 \\
0 \\
0 \\
0.017 \\
0.006 \\
0.019 \\
0.010 \\
0.008 \\
0.003 \\
0.016 \\
0.002 \\
0.012 \\
0 \\
\end{array}$ \\
\hline $\begin{array}{l}\overline{\text { Mean }} \\
\text { Overlaps }\end{array}$ & s 0.009 & 0.071 & 0.011 & 0.011 & 0.070 & 0.009 & 0.008 & 0.072 & 0.008 \\
\hline $\begin{array}{l}\text { Mean } \\
\text { Weights }\end{array}$ & 0.011 & 0.068 & 0.003 & 0.002 & 0.069 & 0.006 & 0.006 & 0.073 & 0.001 \\
\hline
\end{tabular}


Table 43

BETWEEN-PERSONS FROPCRTIONS $\propto$ OV OVPLAP of METFESSEL ALLOCATION CANIDATE AREAS, ADVISORY PANEL, WESTEPN U.S. SCREBNIMG

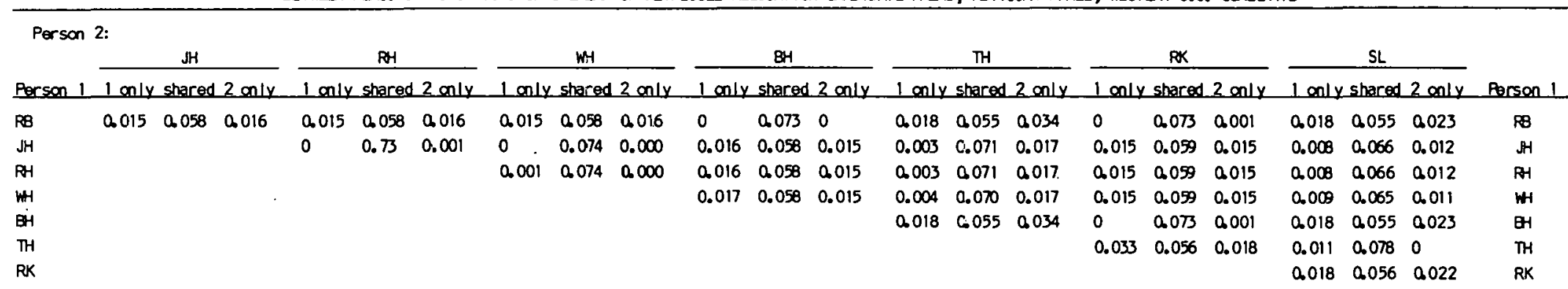

1
Person 2$$
\text { KN }
$$

Parson 17 only shared 2 only 1 only shared 2 only $\begin{array}{lll}0.015 & 0.058 \quad 0.042\end{array}$

$0.025 \quad 0.058 \quad 0.015$

0

$0.073 \quad 0.001$

0.0740

$\begin{array}{lll}0.001 & 0.073 \quad 0.027\end{array}$

$\begin{array}{llll}0 & 0.074 & 0.036\end{array}$

$\begin{array}{llll}0.001 & 0.073 & 0.001\end{array}$

$0.015 \quad 0.058 \quad 0.016$

$\begin{array}{llll}0.018 & 0.071 & 0.003\end{array}$

$\begin{array}{lll}0.015 & 0.059 & 0.015\end{array}$

$\begin{array}{llll}0.012 & 0.066 & 0.008\end{array}$

$\begin{array}{llll}0.027 & 0.073 & 0.001\end{array}$

$0.015 \quad 0.059 \quad 0.041$

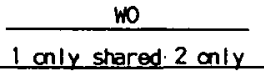

JS $0.018 \quad 0.055 \quad 0.025$ $\begin{array}{llll}0.018 & 0.056 & 0.024\end{array}$ $\begin{array}{llll}0.018 & 0.056 & 0.024\end{array}$ $\begin{array}{llll}0.018 & 0.056 & 0.024\end{array}$ $\begin{array}{llll}0.018 & 0.055 & 0.025\end{array}$ $\begin{array}{llll}0.020 & 0.069 & 0.011\end{array}$ $0.018 \quad 0.056 \quad 0.024$ $\begin{array}{llll}0.010 & 0.068 & 0.012\end{array}$ $0.044 \quad 0.056 \quad 0.024$ $\begin{array}{lll}0.008 & 0.056 & 0.024\end{array}$

\begin{tabular}{|c|c|c|c|c|c|c|c|c|c|}
\hline 0.017 & 0055 & 0.020 & 0.018 & 0.055 & 0,025 & 0.018 & 0,055 & 0,028 & $F B$ \\
\hline 0.002 & 0.072 & 0.004 & 0.003 & 0.071 & 0.019 & 0.003 & 0.071 & 0.012 & $\boldsymbol{H}$ \\
\hline 0.002 & 0.072 & 0.004 & 0.003 & 0.071 & 0.019 & 0,003 & 0.071 & 0.012 & FH \\
\hline 0.002 & 0.072 & 0.004 & 0.003 & 0.071 & 0.019 & 0.004 & 0.071 & 0.012 & $W H$ \\
\hline 0.017 & 0.056 & 0,020 & 0.018 & 0.055 & 0,035 & 0.018 & 0,055 & 0,029 & 早 \\
\hline 0.016 & 0.073 & 0.003 & 0 & 0.089 & 0.001 & 0.006 & 0.083 & 0 & $\mathrm{TH}$ \\
\hline 0.018 & 0.056 & 0,020 & 0.017 & 0.057 & 0.033 & 0.018 & 0.056 & 0.027 & RK \\
\hline 0.016 & 0.062 & 0.014 & 0 & 0.078 & 0.012 & 0 & 0,078 & 0.005 & SL \\
\hline 0,027 & 0.073 & 0.003 & 0.029 & 0.071 & 0.019 & 0,030 & 0.070 & 0013 & $\mathrm{HM}$ \\
\hline 0.008 & 0.072 & 0.004 & 0.003 & 0.071 & 0.019 & 0.003 & 0.071 & 0.012 & WN \\
\hline \multirow[t]{3}{*}{0.021} & 0.059 & 0.017 & 0.011 & 0,069 & 0.021 & 0.011 & 0.069 & 0.014 & wo \\
\hline & & & 0.002 & 0.074 & 0.016 & 0.003 & 0.073 & 0.010 & JS \\
\hline & & & & & & 0.007 & 0,083 & 0 & $\infty$ \\
\hline
\end{tabular}

Data are expressed as proportion of study area. 
Notes

Chapter 4

1. The method used to determine optimum wet/dry cooling combinations is given in P. Gottlieb, J. H. Robinson, and D. R. Smith, Preliminary Assessment of Nuclear Energy Centers and Energy Systems Complexes in the Western United States, ORNL/Sub-17272/1, Appendix A, Dames and Moore, Los Angeles, California, prepared for Western Interstate Energy Board/WINB, Denver, Colorado, 1977.

2. Ibid.

3. R. L. Keeney, C. W. Kirkwood, C. Ford, J. H. Robinson, and P. Gottlieb, An Evaluation and Comparison of Nuclear Power Plant Siting Methodologies, NUREG/CR-0407, SAND 78-1284, Sandia Laboratories, prepared for U.S. Nuclear Regulatory Commission, March 1979.

4. P. Gottlieb, J. H. Robinson, and D. R. Smith, op. cit.

5. G. W. Snedecor, Statistical Methods Applied to Experiments in Agriculture and Biology, Section 5.8, Iowa State University Press, Ames, Iowa, 1956.

6. R. L. Keeney et al., op. cit. 
APPENDIX 1

METHODS FOR REGIONAL SCREENING

Regional screening attempts to narrow a large study area loften many thousands of square miles) to a few candidate areas having high probability of containing suitable sites. Screening usually relies on published secondary and tertiary information, such as U.S.G.S. maps and stream flow data and Bureau of Census population counts. At this stage data are rarely gathered in the field. Once all information is in hand, a decision rule is used to choose candidate areas. Decision rules used for regional screening are discussed in this Appendix, along with methods for choosing weights necessary for some rules. For more detailed explanation and critique of these methods, see the companion volume to this report by Hobbs. 1

\section{EXCLUSIONARY SCREENING}

This method defines candidate areas by finding locations that are satisfactory in every attribute. The range of each attribute is divided into two categories: "unacceptable" and "acceptable." Failure in one attribute is as bad as failure in all. There are natural dividing points for some attributes, usually because of legal restrictions. Examples include population density, ${ }^{2}$ proximity to active faults, 3 presence of endangered species, ${ }^{4}$ and thermal pollution. 5 High levels of any or all of the other attributes cannot compensate for unsatisfactory levels in these attributes; tradeoffs are irrelevant.

In practice, however, discretionary attributes which are not exclusionary by nature are frequently treated as though they are. Examples include:

1. Distance to water supply6;

2. Costs related to access 7 ;

3. Wildlife habitats and unique vegetation areas 8 ;

4. Transmission distance ${ }^{9}$; and

5. Distance to railroad. 10

There are no natural cutorfs for such attributes - one cannot say that 4.9 miles to a railroad is acceptable and 5.0 miles is not. An area might, fail one such criterion by a small amount, but be so good in others that it would be found best in a later stage. In such a case Exclusionary Screening makes tradeoffs that decision makers would not accept if they could consider them explicitly. 
This notion of implied tradeoffs is an important one. Consider Figure A1. The axes of the graph represent levels of two different attributes. Better sites are up and to the right; shaded sites are excluded. Thus, sites $A$ and B are "better" than the rest because only they are acceptable in both attributes. Tradeoffs are inferred by these cutoffs; $C$ and $D$ are each better in one attribute than $A$ or $B$. Attribute weights can be inferred from these tradeoffs, by noting the slope of line segments connecting acceptable and unacceptable sites. First, the cutoff for Attribute 1 implies that $A$ is preferred to $C$, so $W_{1}$ must be greater than $W_{2}$. Second, the cutoff for Attribute 2 implies that $B$ is preferred to $D$, so $W_{1}$ must be less than $4 W_{2}$. Were we to use Weighting Summation with weights outside of those ranges, either $C$ or $D$ will be found to be more suitable than $A$ and $B$.

Contrary to the asse:tion of some researchers, attributes are not "weighted" equally in exclusionary screening. A change in the cutoffs can change the implied weights.

If no areas are excluded which are better in at least one attribute than acceptable areas then no tradeoffs are made. In this case, results of Exclusionary Screening, Weighting Summation, and most other decision rules will be similar.

There are several variations on the general theme of Exclusionary Screening. One is to accept areas that pass all but $m$ cutoffs, where $m$ is a number greater than 1. A poor performance in one attribute can then be compensated by good levels in others. Another approach, Lexicographic Screening, first screens out areas using the most important attribute, followed by the next most important one, and so on, until a satisfactorily small number of areas remain. Alternatively, one can first use a restrictive set of cutoffs, and if too few areas pass, then relax the criteria.

WEIGHTING SUMMATION

This decision rule chooses areas maximizing:

$$
\text { Suitability }=\sum_{i=1}^{n} w_{j} v_{i}\left(x_{i}\right) \text {, }
$$

where $W_{j}$ is the weight of attribute $X_{j}$, and $V_{j}()$ is its value or suitability function. Normally, a specified percentage of the highest scoring areas are chosen. 


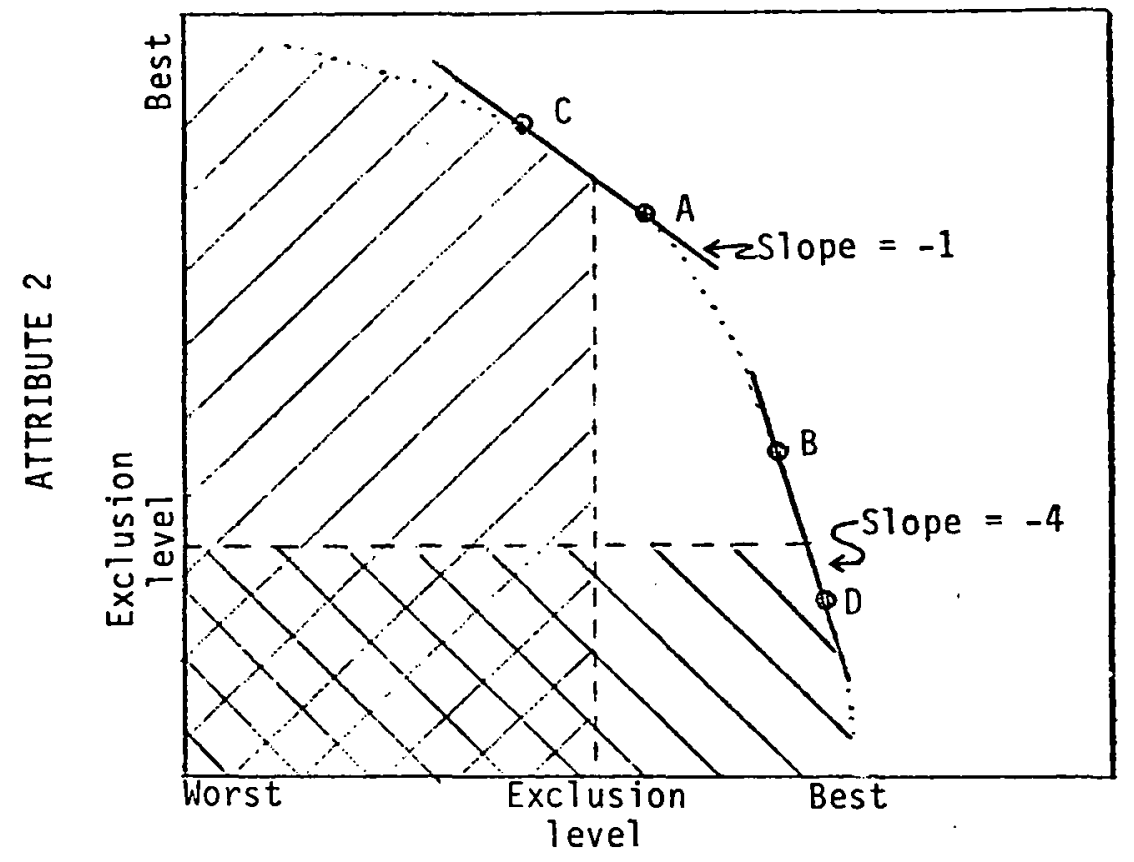

ATTRIBUTE 1

Figure Al. Ratios of Weights Implied by Exclusion Levels. 
Attribute value functions can be created by any of several available techniques surveyed elsewhere.11 A large number of weighting methods is also. available. Several are explained later in this subsection.

This deceptively simple decision rule has been used in many siting studies12 with little discussion of important underlying assumptions. These assumptions may or may not hold in any particular application; if they do not, areas that decision makers prefer on the basis of tradeoffs they are willing to make may be prematurely discarded. These assumptions are detailed below.

Difference independence is the first facet of the assumption of additive independence. It requires that each attribute value function be invariate over all levels of other attributes. Preference independence, the second facet, requires that tradeoffs decision makers are willing to make among attribute value functions not depend on levels of any of the attributes. That is, if one is willing to give up one unit of $v_{1}\left(x_{1}\right)$ to gain 2 units of $v_{2}\left(x_{2}\right)$, his willingness to do so should not depend on the levels of $x_{1}, x_{2}$, or any other attribute.

The third facet of additive independence concerns risk and is more complex. For the purpose of this report, suffice it to say that Weighting Summation is invalid if attribute levels are uncertain, and if preferences for lotteries depend not only on marginal distributions of attributes but also on their joint distributions. If so, and if difference and preference independence hold for all attributes, then the multiplicative form of Decision Analysis (discussed later in this section) should be used instead of Weighting Summation. For further discussion of this assumption refer elsewhere.13

Use of Weighting Summation presumes that attribute value functions are on an interval level of measurement. Differences between numbers are meaningful in interval scales, but the zero point is aribitrary. For instance, on the interval Farenheit temperature scale, it makes sense to say that $10^{\circ}$ is halfway between $0^{\circ}$ and $20^{\circ}$--but it is nonsense to state that $20^{\circ}$ is twice as warm as $10^{\circ}$. A number of methods can be used to create interval-scaled value functions.14 Scaling techniques that do not assure an interval level of measurement are widely applied in siting, however, in violation of measurement theory. The empirical research reported on in Chapters 2, 3, and 4 does not test the effect of different scaling techniques on the results of regional screening. Nonetheless, readers should avoid inferring that choice of scaling method does not matter; the question has not been properly investigated. 
Weights must be ratio scaled. If attribute $X_{1}$ is twice as "important" as $x_{2}, w_{1}$ should be twice as large as $w_{2}$. Furthemore, weights should represent the importance of unit changes in their attribute value functions. If decision makers are indifferent between a change in $v_{1}\left(x_{1}\right)$ of 1 and a change in $v_{2}\left(x_{2}\right)$ of $1 / 3$, then $w_{1}=1 / 3 W_{2}$. Only this type of importance should be used. An attribute's weight is thus inextricably linked to its value function. One cannot meaningfully choose a weight unless the value function has been defined, otherwise, tradeoffs may be made which do not reflect decision makers preferences. One might assert, a priori, that "farmland" should receive half the weight of "cost." Depending on the actual ranges of the attributes and their value functions, however, this could imply that each acre of farmland is worth $\$ 200$-- or $\$ 2,000,000$. Several regional site screenings make the mistake of setting weights without defining or presenting attributes and their value functions.15 The resulting Weighting Summation models are, at best, misleading representations of preferences, as there is no way to detemine what tradeoffs the weight setters have made.

Some methods for choosing weights are specifically designed to produce ratio scales representing the correct type of importance. Others are not. The former group of methods generally ask decision makers to tradeoff attribute value functions, so that weights are consistent with tradeoffs they are willing to make. Methods that do not assure valid weights usually ask for judgmental assessment of an attribute's importance, where "importance" is ambiguously defined. Those methods make no effort to determine if weights are consistent with tradeoffs decision makers would make.

The six weighting methods applied in Chapters 2,3 , and 4 are described below. They include: Categorization, Rating, Metfessel Allocation, The Churchman-Ackoff Procedure, Indifference Tradeoff, and Decision Analysis. The last three in theory assure ratio scaled weights representing the correct type of importance. Furthemore, Decision Analysis chooses weights that reflect attitudes towards risk. Metfessel Allocation assures a ratio scale, but not the appropriate kind of importance. Categorization and Rating assures neither characteristic.

Other weighting methods are available, and are explained elsewhere. 16 One is Ranking, which assigns 1 to the least important attribute, 2 to the next most important, etc. Ratio Questioning is similar to Metfessel Allocation; it asks for ratios of importances of two attributes at a time. Saaty's 
Eigenvector Prioritization Method is a way to resolve inconsistencies that arise among such ratio questions. Finally, "observer-derived" weights can be obtained from overall judgments of suitability of a number of sites by either multiple regression or linear programming.

\section{Categorization}

This method assigns attributes to categories such as "very important," "important," and "least important" with weights 3, 2, and 1, respectively. Ratios between more and less important attributes are fixed by the scale, and are arbitrary; they probably bear no relationship to actual importance ratios, and a ratio scale is not achieved. There are several examples of use of this method in siting. 17

Rating

This technique asks decision makers to rate the importance of each attribute on a scale of, say, 0 to 10 . There are no questions to check ratios. This is the most commonly applied weighting method 18 ; it does not assure valid weights.

Metfessel Allocation

In this method, decision makers allocate 100 points among the attributes in proportion to their importance. One siting study recommends its use.19

The Churchman-Ackoff Procedure

This approach is also called the Successive Comparison Technique. The method has three stages. The first stage is Rating. In the second stage, decision makers follow a step-wise procedure, in which they repeatedly choose between two hypothetical sites with different attribute values. Each decision is a check on the weights assigned in the first stage. Weights are adjusted so that they are consistent with the choices. The third stage is Ratio Questioning in which decision makers are required to accept or adjust the ratios among weights.

Churchman and Ackoff outline two alternative but similar approaches for accomplishing the second stage. 20 The first is used when there are few attributes. In following the sequence of steps, a decision maker selects between two hypothetical sites with various combinations of attribute levels. For each site, individual attributes have either the best possible or worst possible score. To simplify explanation, only attributes at their best levels are listed. Thus, $s\left(x_{1}, x_{3}\right)$ specifies a site in which attributes $x_{1}$ and $x_{3}$ are at their best value and all the other attributes are at their worst value. It is assumed that each attribute value function in on a scale of 0.0 to 1.0 ,

$$
-114 \text { - }
$$


representing the worst and best values, respectively, of each attribute. Attributes are ranked, so that $x_{1}$ is most important, $x_{2}$ the next most important, and so forth, for a total of $n$ attributes. A decision maker follows the procedure below, choosing between two combinations of attribute values at a time. Each step is a logical test to which the Rating weights selected in the first stage must conform. If the weights are not consistent with the choice made he must alter the weights and/or the choice. The decision maker than continues to the next step, as specified in the procedure.

A. Choose between $s\left(x_{1}\right)$ and $s\left(x_{2}, x_{3}, \ldots, x_{n}\right)$.

1. If $S\left(X_{1}\right)$ is preferred, adjust weights so that

$w_{1}>w_{2}+w_{3}+\ldots+w_{n}$.

Proceed to $C$.

2. If no preference exists, adjust weights so that

$w_{1}=w_{2}+w_{3}+\ldots+w_{n}$.

proceed to $C$.

3. If $s\left(X_{1}\right)$ is least preferred, adjust weights so that

$w_{1}<w_{2}+w_{3}+\ldots+w_{n}$.

Proceed to $B$.

B. Choose between $s\left(x_{1}\right)$ and $s\left(x_{2}, x_{3}, \ldots, x_{n-1}\right)$. Note that $x_{n}$ now

has its poorest value in both sites.

1. If $S\left(X_{1}\right)$ is preferred, adjust weights so that

$w_{1}>w_{2}+w_{3}+\ldots+w_{n-1}$.

Proceed to $C$.

2. If no preference exists, adjust weights so that

$w_{1}=w_{2}+w_{3}+\ldots+w_{n-1}$.

Proceed to $C$.

3. If $s\left(X_{1}\right)$ is least preferred, adjust weights so that

$w_{1}<w_{2}+w_{3}+\ldots+w_{n-1}$.

Repeat the $B$ cycle, reducing the number of attributes at their best value one at a time until an exit to $C$ occurs or a choice is made between $S\left(x_{1}\right)$ and $S\left(x_{2}, x_{3}\right)$. Proceed to $C$ after this choice.

C. Move to the next highest ranked attribute $\left(x_{2}\right)$, and compare it to the remaining attributes below it: Proceed as in $A$ and $B$ until the choice between $S\left(x_{n-2}\right)$ and $S\left(x_{n-1}, x_{n}\right)$ is made. 
The result of this series of steps is approximately ratio-scaled weights, with approximately the correct type of importance. They are approximate because. there can be more than one set of weights that is consistent with the logical checks of the procedure. Decision makers are constrained in adjusting the weights, but still have some leeway. An example of this version of Stage 2 is given below.

The Rating weights assigned in Stage 1 are:

$$
\begin{aligned}
& W_{1}=1.0 \\
& W_{2}=0.8 \\
& W_{3}=0.3 \\
& W_{4}=0.1
\end{aligned}
$$

A. Between $S\left(X_{1}\right)$ and $S\left(X_{2}, x_{3}, x_{4}\right)$, the decision maker decides $S\left(X_{2}, X_{3}, X_{4}\right)$ is better. The consistency check:

Is $1.0<0.8+0.3+0.1$ ? It is, so he proceeds to step $B$.

B. Between $S\left(x_{1}\right)$ and $S\left(x_{2}, x_{3}\right)$, the decision maker selects $S\left(x_{1}\right)$. The inequality $1.0>0.8+0.3$ is not true, and the choice and/or weights must be altered. He/she changes $W_{2}$ to 0.6 , and now the choice and weights are consistent. Proceed to $\mathrm{C}$.

C. Between $S\left(x_{2}\right)$ and $S\left(x_{3}, x_{4}\right)$, the decision maker chooses $S\left(x_{3}, x_{4}\right)$. The inequality $0.6<0.3+0.1$ does not hold, however. Therefore, the choice and/or the weights must be altered so that they are consistent. The decision maker decides to make $W_{3}=0.35$ and $W_{4}$ $=0.3$. This choice (and previous choices) and weights are now consistent. As the choice between $s\left(x_{n-2}\right)$ and $s\left(x_{n-1}, x_{n}\right)$ has been made, Stage 2 is completed.

The alternative method for the second stage is used when there are more than eight or so attributes. Attributes are broken down into groups of 4-6 each, and the above procedure is applied within each group. The groups must have at least one attribute in common, so that one overall set of weights results. This keeps the complexity of the second stage down to a managable level; decision makers may otherwise find questions involving 6 or more attributes difficult to handle.

The third stage, Ratio Questioning, has been used in a public health planning problem.21 It checks the results of the other two stages.

This method was used to rank land use plans in rural virginia. 22 
Indifference Tradeoff

Suppose that two equally suitable sites ( $A$ and $B$ ) differ only in two attributes, $x_{1}$ and $x_{2}$. This implies that:

$$
\sum_{i=1}^{n} w_{i} v_{i}\left(x_{i} A\right)=\sum_{i=1}^{n} w_{i} v_{i}\left(x_{i} B\right),
$$

or

$$
w_{1} v_{1}\left(x_{1} A\right)+w_{2} v_{2}\left(x_{2} A\right)=w_{1} v_{1}\left(x_{1} B\right)+w_{2} v_{2}\left(x_{2} B\right)
$$

or

$$
\frac{v_{1}\left(x_{1}\right)}{v_{2}\left(x_{2}\right)}=\frac{-w_{2}}{w_{1}}
$$

This suggests a simple method for assessing weights. Decision makers can be asked "For what level $V_{2}\left(X_{2}^{\prime}\right)$ would you be indifferent between:

1. A site with values $(1,0)$ for $V_{1}\left(x_{1}\right)$ and $\dot{V}_{2}\left(x_{2}\right)$, respectively; and

2. A site with values $\left(0, v_{2}\left(x_{2}{ }^{\prime}\right)\right)$."

The ratio of the weights would be:

$$
\frac{v_{1}\left(x_{1}\right)}{v_{2}\left(x_{2}\right)}=\frac{1-0}{0-v_{2}\left(x_{2}^{\prime}\right)}=\frac{1}{-v_{2}\left(x_{2}^{\prime}\right)}=\frac{-w_{2}}{w_{1}} \text {. }
$$

If enough of these questions are asked, so that each attribute is considered at least once, and a scaling constant is introduced (so that, say, $\left.\sum_{i=1}^{n} w_{i}=1.0\right)$, a unique set of weights is defined. When more than $(n-1)$ questions are asked, they act as consistency checks. The weight setter should resolve any inconsistencies.

An equivalent and perhaps simpler form for the questions is "What is the maximum amount $V_{1}\left(X_{1}\right)$ of $V_{1}\left(X_{1}\right)$ that you would give up to obtain (say) 0.5 more of $v_{2}\left(x_{2}\right)$ for a site?" 
This method is often used as part of Decision Analysis weighting. Published applications include nuclear power plant location in the state of Washington 23 and pumped storage siting in New Mexico. 24

Decision Analysis

Decision Analysis refers to a general approach to problem solving, not just selection of weights. It chooses weights that reflect decision makers' attitudes towards risk. To do this, at least one "lottery" question must be answered, which fixes the expected utility of a multiattributed site. From this and other information, one or more Decision Analysis weights can be calculated.

A common variant of the method starts by offering a decision maker two alternative hypothetical sites. He is required to give the probability $p$ at which he is indifferent between:

1. A site with:

a. The attribute whose weight is being assessed at its best value, and

b. all other attributes at their worst level, and

2. a lottery with:

a. chance $p$ of all attributes at their best level, and

b. chance $(1-p)$ of all attributes at their worst level.

If all attribute value functions are scaled from 0 (worst) to 1 (best), then the weight being assessed is precisely equal to $p$. This can be shown by equating the expected utilities of the alternatives 1 and 2 , above, using the Decision Analysis multiplicative utility function (given later in this Appendix). Each attribute weight can be assessed in this manner. In practice, however, a set of Indifference Tradeoff weights is determined first, and then multiplied by the ratio of one attribute's Decision Analysis and Indifference Tradeoff weights. This approach is adopted by two Decision Analysis siting studies. 25 In theory, weights chosen by the two methods are proportional. Chapter 2 tests this.

ALTERNATIVE DECISION RULES

Exclusionary Screening and Weighting Summation are not the only possible decision rules for regional screening. Two others are examined here: the 
Power Law and the Decision Analysis Multiplicative form.

The Power Law takes the following form:

$$
\text { Suitability }=\prod_{i=1}^{n} v_{i}\left(x_{i}\right)^{W_{i}} \text {, }
$$

where $w_{j}$ is the weight of attribute $x_{i}$ and $v_{j}()$ its value function. If the sum of the weights equals 1 , then the percentage change in suitability is a weighted average of percentage changes in attribute value functions. Site ranks are still preserved if weights sum to any other number. value independence is assumed, as is preference independence among logarithms of attribute value functions. 26 Furthermore, attribute value functions must be on a ratio level of measurement, not merely interval scaled. This follows from the fact that suitability falls to zero when just one $v_{j}\left(X_{j}\right)$ is zero.

The method also presumes that decision makers perceive value or importance in a logarithic fashion, rather than linearly. A decision maker might choose attribute weights 1,2 , and 3 when he actually means $\mathrm{e}^{1}$, $\mathrm{e}^{2}$, and $\mathrm{e}^{3}$. Researchers in "psychophysics" believe that physical phenomena are often preceived in this manner, 27 and some management scientists believe that this is also true for value. 28

The Power Law has been used in final site evaluation in two studies, 29 and for water resources planning. 30

The Decision Analysis multiplicative form is one of many possible utility functions used by Decision Analysis. It is commonly applied, as most other forms are more difficult to assess. It has the following form:

$$
\text { Utility }=\left\{\left[\prod_{i=1}^{n}\left[1+k k_{j} v_{j}\left(x_{i}\right)\right]\right]-1\right\} / k
$$

where

$$
\begin{aligned}
v_{j}()= & \text { Decision Analysis utility function } \\
& \text { for attribute } x_{i} \text {, reflecting atti- } \\
& \text { tudes towards risk. Attribute val- } \\
& \text { ue functions not reflecting risk } \\
& \text { attitudes should not be used. } v_{j}() \\
& \text { is scaled from } 0 \text { to } 1 . \\
k_{j}= & \text { Decision Analysis weight for } x_{j} . \\
k= & \text { Scaling constant, so that utility } \\
& \text { ranges from } 0 \text { to } 1 .
\end{aligned}
$$


As with Weighting Summation, all attributes should be difference lor, more precisely, utility) and preference independent. If risk exists and is. quantified, and if decision makers care not only about attributes' marginal probability distributions but also about their joint distributions, then the multiplicative form is more valid than Weighting Summation. Consult Keeney and Raiffa31 for a detailed exposition of the theory of multiattribute Decision Analysis.

Probability distributions are rarely specified in final site selection, however, and never in regional screening. The Decision Analysis multiplicative form has only two published applications to siting problems. 32 
NOTES

APPENDIX 1

1. B. F. Hobbs, Analytical Multiobjective Decision Methods for Power Plant Siting: A Review of Theory and Applications, BNL-NUREG-51204, Brookhaven National Laboratory, 1979.

2. 10 CFR 100 .

3. Ibid.

4. Endangered Species Act of 1973, P.L. 93-205.

5. Federal Water Pollution Control Act Amendments of 1972, P.L. 92-500.

6. Gilbert Associates, Energy Park Development Site Identification Study, Vol. I, Reading, Pennsylvania, 1974.

7. Rogers and Golden and Allan Mallach/Associates, Eastern Shore Power Plant Siting Study, Maryland Major Facilities Study, Vol. 2, PPSA-4, prepared for the Maryland Power Plant Siting Program, Annapolis, Maryland, 1977.

8. P. Womeldorff and D. Sengstaken, Dependable power plant siting state-of-the-art methodology, Proc. Am. Power Conf. 37, 605-618 (1975).

9. Houston Light and Power Company, Enviromental Report, South Texas 1 and 2, Construction Permit Review, U.S. Nuclear Regulatory Commission Docket \#50-498/499, July 1974.

10. Ohio Edison Company, Enviromental Report, Erie Nuclear Plants, Units 1 and 2, Construction Permit Review, U.S. - Nuclear Regulatory Commission Docket \#50-581/582, March 1977.

11. B. F. Hobbs, op. cit; B. F. Hobbs and A. H. Voelker, Analytical Multiobjective Decision-Siting: A Survey and Critique, ORNL-5288, Feb. 1978; P. C. Fishburn, Methods of estimating additive utilities, Management Sci. 13(7), 435-453 (1967).

12. See those listed in J. Calvert, W. Heilman, and H. Smith, Nuclear Power Plant Siting: A Generalized Process, Commonwealth Associates, Jackson, Michigan, prepared for Atomic Industrial Forum, New York, 1974; B. F. Hobbs, op. cit.; B. F. Hobbs and A. H. Voelker, op. cit.; or B. Pierce and M. Rowe, Quantitative Nuclear Power Plant Siting Methods: A Review of Current Practice, BNL-NUREG 28115, Brookhaven National Laboratory, 1979.

13. B. F. Hobbs, op. cit.; R. L. Keeney and H. Raiffa, Decisions with Multiple Objectives: Preferences and Value Tradeoffs, Wiley, New York, T976.

14. See Note 11. 
15. For instance, one regional screening study gives equal weights, a priori, to Economic and Noneconomic Considerations (Detroit Edison Company, Enviromental Report, Greenwood Energy Center, Units 2 and 3, Construc-: tion Permit Stage, Vol. 3, U.S. Nuclear Regulatory Commission Docket \#50-452/453, Jan. 1974, summarized in G. Leal, C. Heidel, and W. McCarthy, Detroit Edison Company, A rational environmental approach to power plant siting, Am. Soc. Mech. Eng. 1972 Annu. Winter Mtng., New York (Nov. 27, 1972. Weights were chosen by a Nominal Group in another study with no reference to specific attributes or value functions ( $A$. $H$. Voelker, Facility Siting: An Application of the Nominal Group Process, ORNL/NUREG/TM-81, Oak Ridge National Laboratory, 1977. Those weights were subsequently used in two hypothetical regional screens with entirely different sets of attributes and value functions ( $J$. E. Dobson, The Maryland Power Plant Siting Project: An Application of the ORNL Land Use Screening Procedure, ORNL/NUREG/TM-79, Oak Ridge National Laboratory, 1977; and Argonne National Laboratory, et al., An Assessment of National Consequences of Increased Coal Utilization, Executive Summary, VoT. 2, prepared for U.S. Department of Energy, Office of the Assistant Secretary of the Environment and Office of Technology Impacts, Washington, DC, Feb. 1979).

16. B. F. Hobbs and A. H. Voelker, op. cit.; B. F. Hobbs, op. cit.

17a. Gilbert/Commonwealth Associates, Maryland Nuclear Alternative Site Comparison Study, Reading, Pennsylvania, and Jackson, Michigan, prepared for Baltimore Gas and Electric Company, 1976.

b. D. Jopling, The FPL Power Plant Siting Evaluation Instrument (PPSEI), Florida Power and Light Company, Miami, Florida, 1973.

c. S. L. Yaffee and C. A. Miller, Toward A Regional Power Plant Siting Method: Maryland Regional Siting Factors Study, FY 1974 Progress Report, ORNL-TM-4944, Oak Ridge NationaT Laboratory, 1974.

18. Some examples:

1

a. Commonwealth Associates, Enviromental Analysis System, Jackson, Michigan, prepared for Northern States Power Company, Minneapolis, Minnesota, Sept. 1972.

b. Florida Power Corporation, The Site Selection Methodology, St. Petersburg, Florida, 1973.

c. J. A. Halpern, D. M. O'Regan, and W. R. Miller, Dames ad Moore, Cranford, New Jersey, Computerized Methods in Power Plant Siting Studies, Second Annu. Univ. of Missouri-Missouri Energy Council Conf. on Energy, Rolla, Missouri, Oct. 7-9, 1975.

d. G. Leal, C. Heidel, and W. McCarthy, op. cit.

e. A. H. Voelker, op. cit.

f. See also the numerous citations in B. F. Hobbs, op. cit.; and B. Pierce and M. Rowe, op. cit. 
19. J. A. Fischer and R. Ahmed, Dames and Moore, A systematic approach to evaluate sites for nuclear power plants, Am. Nucl. Soc. Biennial Conf. Nucl. Power Plant Siting, Portland, Oregon, Aug. 26-28, 1974.

20. C. W. Churchman and R. Ackoff, An approximate measure of value, Operations Res. 2, 172-191 (1954).

21. D. Stimson, Utility measurement in public health decision making, Management Sci. 16(2), B 17-30 (1969).

22. F. Davidson, Dimensions of utility in a regional planning context, Decision Sci. 5(1), 91-101 (1974).

23. R. L. Keeney and K. Nair, Nuclear siting using decision analysis, Energy Policy 5(3), 223-231 (Sept. 1977).

24. R. L. Keeney, Evaluation of proposed storage sites, Operations Res. 27(1), 48-64 (1979).

25. Ibid.; and R. L. Keeney and K. Nair, op. cit.

26. B. F. Hobbs, op. cit.

27. S. S. Stevens, On the Operation known as Judgment, Am. Sci. 54(4), 385-401 (1966).

28. R. L. Gum, R. G. Roefs, and D. B. Kimball, Quantifying social goals: Development of a weighting methodology, Water Resources Res. 12(4), 617-622 (1976).

29a. Houston Light and Power Company, Enviromental Report, Allens Creek 1 and 2, Construction Permit Review, U.S. Nuclear Regulatory Commission Docket \#50-466/46\%, Dec. 1973.

b. Washington Public Power Supply System, Enviromental Report, Units 3 and 5, Construction Permit Review, U.S. Nuclear Regulatory Commission Docket \#50-508/509, Aug. 1974.

30. R. L. Gum, R. G. Roefs, and D. B. Kimball, op. cit.

31. R. L. Keeney and H. Raiffa, op. cit.

32. R. L. Keeney, op. cit.; and R. L. Keeney and K. Nair, op. cit. 